\title{
Coumarin-bisureas as potent fluorescent transmembrane anion transporters
}

Mohamed Fares, ${ }^{\mathrm{a}, \mathrm{b}, \mathrm{c}}$ Xin Wu, ${ }^{\mathrm{a}}$ Daniel A. McNaughton, ${ }^{\mathrm{a}}$ Alexander M. Gilchrist, ${ }^{\mathrm{a}}$ William Lewis, ${ }^{\mathrm{a}}$ Paul A. Keller, ${ }^{\text {b }}$ Alain Arias-Betancur ${ }^{d, e}$, Ricardo Pérez-Tomás ${ }^{d}$, Philip A. Gale, ${ }^{* a, f}$

\begin{abstract}
A series of fluorescent coumarin bis-ureas have been synthesised and their anion transport properties studied. The compounds function as highly potent $\mathrm{HCl}$ co-transport agents in lipid bilayer membranes.
\end{abstract}

The transport of ions across phospholipid bilayer membranes in biological systems is a crucial process in many biological processes including, cell migration and proliferation, and maintaining cellular $\mathrm{pH}$, membrane potential and cellular secretions.[1] Channelopathies are a group of diseases characterised by ion channel impairment, which include cystic fibrosis, epilepsy and cancer.[2] For example, cystic fibrosis transmembrane conductance regulator (CFTR) is a channel present in epithelial cells that is responsible for facilitating the transport of chloride and bicarbonate through the cell membrane. Dysfunctional CFTR channels with reduced anion transport caused chronic lung infections in cystic fibrosis patients, while impairment of sodium, potassium and T-type calcium channels is linked with epilepsy. ${ }^{[3]}$ Channel replacement therapy has been proposed as a new approach to treating channelopathies in which the function of a faulty channel is replaced by an ionophore that can facilitate the flux of ions through a membrane by forming a lipophilic complex. ${ }^{[4]}$

A number of anionophores and anion exchangers show anticancer activity, including the natural product prodigiosin, squaramide derivatives and o-phenylenediamine-based bisureas. ${ }^{[5]}$ Studies have shown that chloride transporters can trigger apoptosis in cells whilst compounds that can cotransport $\mathrm{H}^{+} / \mathrm{Cl}^{-}$can also interfere with autophagy presumably by deacidifying acidic organelles.[5a, 6] However, our understanding of the action of anionophores within cells is still limited with some studies showing particular classes of

\footnotetext{
a. School of Chemistry, The University of Sydney, NSW 2006, Australia. E-mail: philip.gale@sydney.edu.au

b. School of Chemistry \& Molecular Bioscience, Molecular Horizons, University of Wollongong, and Illawarra Health \& Medical Research Institute Wollongong, NSW 2522, Australia.

c. Department of Pharmaceutical Chemistry, Faculty of Pharmacy, Egyptian

Russian University, Cairo 11829, Egypt

d. Department of Pathology and Experimental Therapeutics, Faculty of Medicine

and Health Sciences, Universitat de Barcelona, 08905 Barcelona, Spain

e. Department of Integral Adult Dentistry, Research Centre for Dental Sciences

(CICO), Universidad de La Frontera, Temuco 4811230, Chile

f. The University of Sydney Nano Institute (SydneyNano), The University of Sydney, NSW 2006, Australia.
}

compounds show toxicity whilst other studies show little toxicity but potent anion transport properties.[2c, 5a, 6-7]

A previous study based on a series of fluorescent (thio)ureabased anionophores was conducted to further understand where anionophores localise in cells using fluorescence imaging techniques. ${ }^{[8]}$ However, these mono-(thio)urea transporters showed modest anion binding and transport activities... ${ }^{[8-9]}$ We have conducted another study using squaramide-based fluorescent anionophores to investigate the anion transport activity in the A549 cancer cell line. ${ }^{[10]}$ However, these compounds ( $c \log P=4.9-5.8$ ) elicited attenuated transport activity compared to the parent squaramide derivatives presumably due to replacing one of the active aniline moiety (containing acidic NH that interacts with the anion) with a bulky naphthalimide fluorophore.

To further improve the anion transport properties and to develop potent fluorescent anion transporters that can be used at lower doses, we designed and synthesized new fluorescent 4-methylcoumarin-bisureas conjugates 1-4 (Fig. 1). We have previously shown that ortho-phenylene diamine based bisureas are highly potent anion transporters. ${ }^{[5 d, 5 e, 11]}$

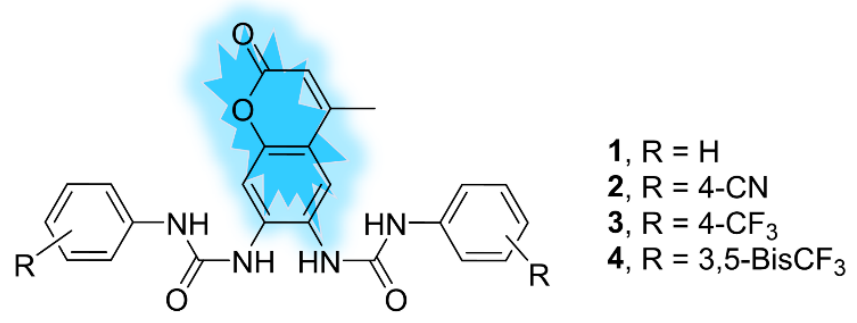

Fig. 1 Structure of designed fluorescent transporters 1-4

The 4-methylcoumarin scaffold is a small molecular weight fluorophore (more anion binding moieties can be added) with extended spectral range, high emission quantum yields and 
confers the advantage of better solubility than 1,8naphthalimide fluorophore. The anion binding and transport activities were evaluated for transporters 1-4. This was followed by investigation of their in vitro cytotoxic effects.

The synthetic strategy started with protection of amino group in $m$-aminophenol using ethyl chloroformate to afford ethyl(3-hydroxyphenyl)carbamate 5 (96\% yield), which was used in the next step without any further purification. ${ }^{[12]} 7-$ Carbethoxyamino-4-methylcoumarin 6 was prepared in 75\% yield by application of von Pechmann condensation of compound 5 and ethyl acetoacetate in 70\% sulfuric acid.[12] Nitration of 6 using aluminium nitrate nonahydrate in acetic anhydride gave two isomers of nitro 7-carbethoxyamino-4methylcoumarin, which were separated by flash column chromatography to afford the desired 6-nitro-7carbethoxyamino-4-methylcoumarin 7 in 36\% yield. Compound 7 was hydrolysed under standard acidic conditions to achieve 6nitro-7-amino-4-methylcoumarin 8 (80\% yield), which was reduced using tin $/ \mathrm{HCl}$ as reported to give the key intermediate 6,7-diamino-4-methylcoumarin 9, in 36\% yield.[13]

Transporters 1, 2 and $\mathbf{4}$ were prepared by nucleophilic addition of the 6,7-diamino-4-methylcoumarin 9 with the corresponding aryl isocyanate in DCM overnight at $45{ }^{\circ} \mathrm{C}$ under an inert atmosphere. Interestingly, attempts to prepare transporter $\mathbf{3}$ using the same procedure failed. Optimization of the reaction involved using different solvents (no solvent, toluene, $\mathrm{DMSO}$ and $\mathrm{CHCl}_{3}$ ), changing the reaction temperature and using a base. The optimal conditions were found by using no solvent and adding excess of the 4-trifluoromethylphenyl isocyanate under inert condition. By applying these conditions, transporter 3 was obtained, however in a low yield (22\%).

The structure of compound $\mathbf{1}$ was confirmed by single crystal Xray diffraction (Figure 2, see SI). Single crystals were obtained by slow evaporation of a DMF/ethanol solution of $\mathbf{1}$ at room temperature. The crystal structure (Fig. 2) showed that coumarin rings are stacked on the top of each other in an antiparallel manner and stabilized by the intermolecular hydrogen bonds (see ESI for more details).

The anion binding abilities of potential transporters 1-4 in solution were investigated using ${ }^{1} \mathrm{H}-\mathrm{NMR}$ titration studies in DMSO- $d_{6} / 0.5 \% \mathrm{H}_{2} \mathrm{O}$ with tetrabutylammonium chloride. The change in chemical shift of the four urea $\mathrm{NHs}$ against the equivalents of anion added was fitted globally to $1: 1$ (for transporter 1) and 1:2 (host: guest, for transporters 2-4) binding modes using BindFit. ${ }^{[14]}$ The results demonstrate moderately $1: 1$ chloride affinity in the range of $50-250 \mathrm{M}^{-1}$ in this highly competitive media similar to the previously reported $O$ phenylenebisureas. (a)

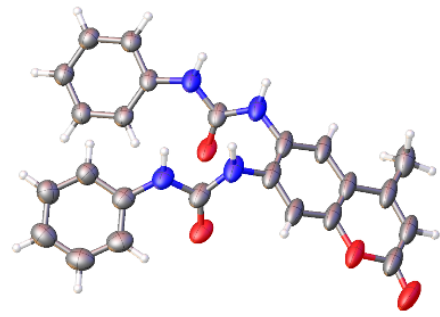

(b)

Fig. 2 X-ray crystal structure of $\mathbf{1}$ (a) ORTEP diagram showing $50 \%$ probability anisotropic displacement ellipsoids at $100 \mathrm{~K}$. bspace-filling models.

Receptors 1-4 were investigated for their chloride transport properties across lipid bilayer via liposome-based techniques using a chloride ion selective electrode (ISE) (Fig. 3a, Table 1). Briefly, unilamellar POPC vesicles with diameter 200 $\mathrm{nm}$ were prepared as reported and loaded with $489 \mathrm{mM} \mathrm{KCl}$, buffered to $\mathrm{pH}=7.2$ and suspended in $489 \mathrm{Mm} \mathrm{KNO}_{3}$ solution which is buffered to $\mathrm{pH}=7.2$. The chloride efflux, as indication of $\mathrm{Cl} / \mathrm{NO}_{3}{ }^{-}$exchange process, was measured using ISE upon addition of DMSO solution of transporters 1-4 to the prepared liposomes. ${ }^{[9]}$

Hill plots were performed by monitoring chloride efflux at different concentrations of tested compounds (expressed as mol\% with respect to lipid concentration) to calculate $\mathrm{EC}_{50}$ (defined as the concentration required to achieve $50 \%$ the chloride efflux at $270 \mathrm{~s}$ ) and Hill coefficient. The $\mathrm{EC}_{50}$ is used as a measure of anion transporter potency, while Hill coefficient has been linked to the stoichiometry of the formed complex during the transport across the lipid bilayer. ${ }^{[15]}$ As illustrated in Table 1 and Fig. 3, the unsubstituted coumarin-bisureas hybrid 1 emerged as the least active transporter with $\mathrm{EC}_{50}=4.3 \times 10^{-1}$ mol\%, followed by transporter $4\left(\mathrm{EC}_{50}=1.5 \times 10^{-2} \mathrm{~mol} \%\right.$ ) (Fig. 3d, Table 1). Transporters 2 and 3, with $p-\mathrm{CN}$ and $p-\mathrm{CF}_{3}$ substituents respectively, emerged as the most active transporters with low $\mathrm{EC}_{50}$ values of $7.0 \times 10^{-3}$ and $7.4 \times 10^{-3}$ mol\% respectively. Transporters 2-4 $\left(\mathrm{EC}_{50}=1.5 \times 10^{-2}-7.0 \times 10^{-}\right.$ 3 mol\%) (Fig. 3d, Table 1) showed superior transport activity across the lipid bilayer than the previously reported fluorescent naphthalimide-(thio)ureas with at least 10 times lower $\mathrm{EC}_{50}$ values. $[8,10]$

By utilizing the cationophore coupled- $\mathrm{KCl}$ assay, ${ }^{[9]}$ valinomycin (Vln) or monensin (Mon) were used to investigate the mechanism of anion transport of the fluorescent transporters 1-4 (Fig. 3b-C, see $\mathrm{SI}$ ). This assay was used to determine whether the anionophore transports only chloride in a uniport process resulting in a net flow of charge across the membrane (an electrogenic transporter) if the anionophore couples to valinomycin, or if the anionophore couples to monesin it shows it is functioning as an $\mathrm{H}^{+} / \mathrm{Cl}^{-}$cotransporter resulting in an electroneutral transport process (no net flow of charge). 
Table 1. Transport and anion binding properties of compounds 1-4.

\begin{tabular}{|c|c|c|c|c|c|}
\hline & & 1 & 2 & 3 & 4 \\
\hline \multirow{6}{*}{ 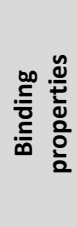 } & ${ }^{\mathrm{c}} \log P$ [a] & 3.67 & - & - & - \\
\hline & $1: 1\left(\mathrm{~K}_{\mathrm{a}}\right), \mathrm{DMSO}-d_{6} / 0.5 \% \mathrm{H}_{2} \mathrm{O}$ & 81 & - & - & - \\
\hline & covfit $^{[b]}$ & $4.6 \times 10^{-4}$ & - & - & - \\
\hline & $1: 2\left(K_{\mathrm{a}}\right), \mathrm{DMSO}-d_{6} / 0.5 \% \mathrm{H}_{2} \mathrm{O}$ & - & $\mathrm{K}_{11}: 186 ; \mathrm{K}_{12}: 2$ & $\mathrm{~K}_{11}: 239 ; \mathrm{K}_{12}: 9$ & $\mathrm{~K}_{11}: 178 ; \mathrm{K}_{12}: 5$ \\
\hline & $\beta_{21}{ }^{[c]}$ & - & 372 & $2.2 \times 10^{3}$ & 890 \\
\hline & Covfit ${ }^{[b]}$ & - & $1.8 \times 10^{-4}$ & $2.0 \times 10^{-4}$ & $3.2 \times 10^{-4}$ \\
\hline \multirow{4}{*}{ 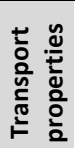 } & $\mathrm{Cl} / \mathrm{NO}_{3}\left(\mathrm{EC}_{50}, \mathrm{~mol} \%\right)^{[\mathrm{d}]}$ & $4.3 \times 10^{-1}$ & $7.0 \times 10^{-3}$ & $7.4 \times 10^{-3}$ & $1.5 \times 10^{-2}$ \\
\hline & $\mathrm{n}^{[\mathrm{e}]}$ & 1.2 & 1.2 & 1.2 & 0.93 \\
\hline & $\mathrm{KCl}\left(\mathrm{EC}_{50}, \mathrm{~mol} \%\right){ }^{[f]}$ & $3.8 \times 10^{-2}$ & $5.1 \times 10^{-4}$ & $6.3 \times 10^{-4}$ & $9.7 \times 10^{-4}$ \\
\hline & $\mathrm{n}^{[\mathrm{e}]}$ & 0.99 & 1.2 & 1.2 & 1.1 \\
\hline
\end{tabular}

[a] ${ }^{c} \log P$ values calculated using VCCLab. [b] The covariance of the fit (covfit) is calculated by dividing the covariance of the residual (experimental data - calculated data) with the covariance of the experimental data. [c] The association constant ( $\beta 21$ ) for the 2:1 and 1:2 host:guest complex calculated by multiplying $\mathrm{K}_{11}$ and $\mathrm{K}_{12}$ and $\mathrm{K}_{11}$ and $\mathrm{K}_{21}$, respectively. [d] $\mathrm{EC}_{50}$ from the $\mathrm{Cl} / \mathrm{NO}_{3}$ exchange assay. [e] Hill coefficient as an indicator of the stoichiometry the complex mediating transport. [f] $\mathrm{EC}_{50}$ from the $\mathrm{KCl}$ assay measuring $\mathrm{H}^{+} / \mathrm{Cl}^{-}$symport.

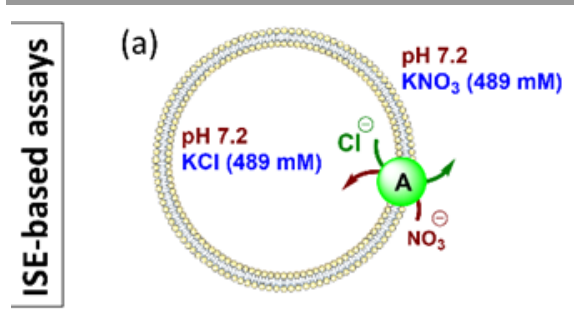

(b)

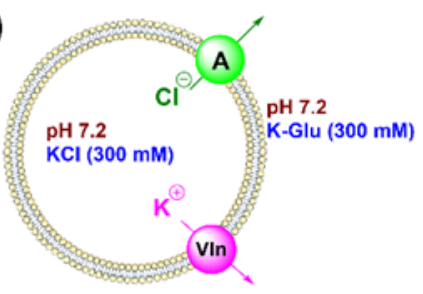

(c)

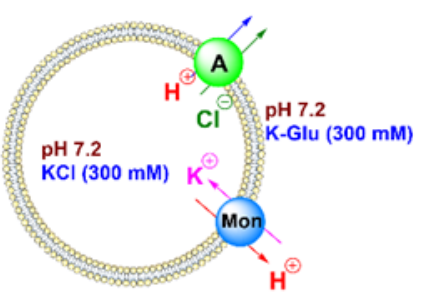

(d)

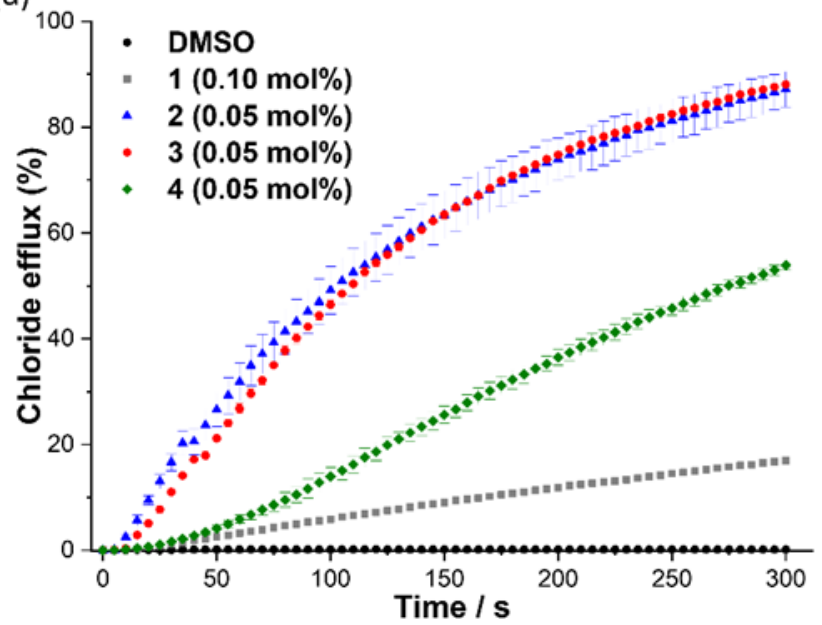

(e)

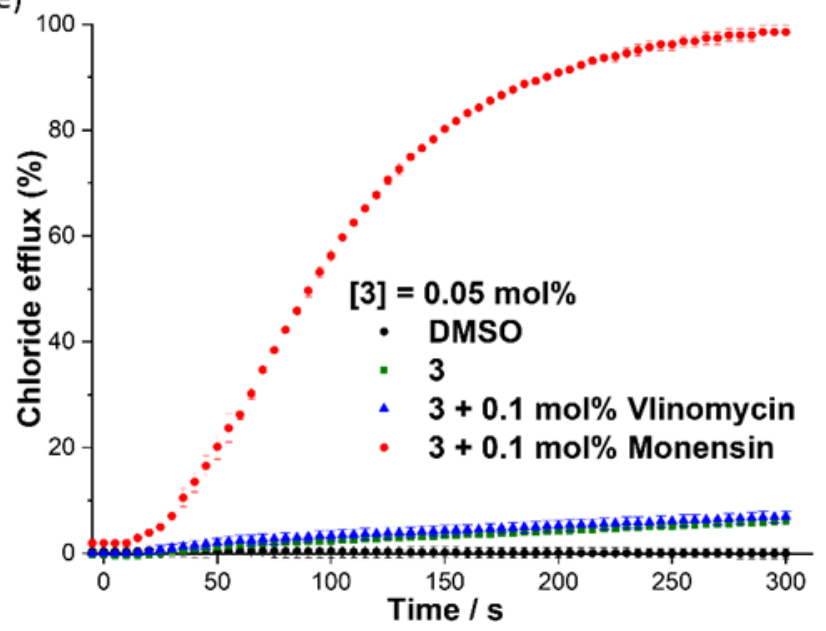

Fig. 3 (a-c) Schematic representation of ISE-based assays used to investigate the mechanism of anion transport of receptors 1-4 (a) $\mathrm{Cl}^{-} / \mathrm{NO}_{3}{ }^{-}$antiport, (b) and (c) cationophore coupled$\mathrm{KCl}$, valinomycin and monensin to measure the $\mathrm{Cl}^{-}$uniport and $\mathrm{M}^{+} / \mathrm{Cl}^{+}$transport, respectively. (d) Chloride efflux achieved by transporters 1-4 (0.10 mol\% for transporter 1 and 0.05 mol\% for transporters 2-4) from unilamellar POPC vesicles containing $489 \mathrm{mM} \mathrm{KCl}$ buffered to $\mathrm{pH} 7.2$ with $5 \mathrm{mM}$ potassium phosphate salts, suspended in $489 \mathrm{mM} \mathrm{KNO}{ }_{3}$ buffered to $\mathrm{pH} 7.2$ with $5 \mathrm{mM}$ phosphate salts. At the endpoint of each experiment ( $300 \mathrm{~s}$ ), the detergent (Triton X-100) was added to lyse the vesicles and calibrate the electrode to $100 \%$ chloride efflux. Each point represents the average of at least two trials. DMSO was used as a control experiment (e) Chloride efflux achieved by transporter 3 at 0.05 mol\% (rtl) in the absence or presence of cationophores (monensin or valinomycin) monitored over a period of 5 min (see SI for more description).

If the anionophore couples to both cationophores it is unselective and can facilitate either chloride uniport or $\mathrm{HCl}$ symport (Fig. 3). Compounds $\mathbf{1 - 4}$ were found to be highly efficient electroneutral $\mathrm{H}^{+} / \mathrm{Cl}^{-}$co-transporters (Fig. 3e, see $\mathrm{SI}$ ), while transporter $\mathbf{1}$ is less selective and can also function as a chloride uniporter. The selectivity for $\mathrm{HCl}$ co-transport may be the result of the high affinity of the bis-urea motif for phosphate resulting in strong phospholipid headgroup interactions (which is presumably lower for transporter $\mathbf{1}$ which lacks electron withdrawing substituents). ${ }^{[16]}$

The unsubstituted bisurea-based fluorescent receptor 1 was found to have the lowest activity in HPTS- $\mathrm{KCl}(\mathrm{HCl}$ symport, Fig. S23) with $\mathrm{EC}_{50}=3.8 \times 10^{-2} \mathrm{~mol} \%$. Appending electron withdrawing groups increased the ability to dissipate the $\mathrm{pH}$ gradient, with $\mathrm{EC}_{50}=5.1-9.7 \times 10^{-4} \mathrm{~mol} \%$ (Table 1$)$. The addition of the $\mathrm{K}^{+}$transporter valinomycin or proton transporter CCCP 
did not significantly affect the transport rates of 1-4 in the HPTS assay, consistent with the inability of these compounds to facilitate uniport processes.

The transport of fatty acid carboxylates across lipid bilayer membranes by anionophores can result in $\mathrm{pH}$ dissipation across the bilayer as the transported carboxylate protonates and then diffuses back across the bilayer and deprotonates. We used oleic acid ( $1 \mathrm{~mol} \%$ ) (as a source of fatty acid) and BSA (bovine serum albumin) to sequester fatty acids from liposomes in HPTS- $\mathrm{KCl}$ ( $\mathrm{HCl}$ symport) to investigate whether the fatty acids could play a role in the $\mathrm{pH}$ dissipation facilitated by receptors 1 4. The addition of fatty acid lowered the transport activity of tested compounds $\mathbf{1 - 4}$, which is presumably due to their ability to competitively bind to the carboxylate headgroups as reported $^{[5 d]}$ and thus lowering the chloride transport activity. BSA-treated liposomes were used to remove all fatty acids from the HPTS- $\mathrm{KCl}$ liposomes. Transport activity of the fluorescent receptors 1-3 was not affected by the fatty acid removal, suggesting that these transporters independently could transport $\mathrm{HCl}$ or protons. However, transporter 4 showed an increase in the $\mathrm{pH}$ dissipation which might indicate that the activity of this particular receptor is greatly compromised by the presence of fatty acids.

Cytotoxicity studies on human lung carcinoma cells (A549), human colon adenocarcinoma cells (SW620) and human breast adenocarcinoma cells (MCF-7) were investigated using the MTT assay. Surprisingly, only the most lipophilic compound 4 showed a significant cytotoxicity against all tested cell lines. Compound $\mathbf{4}$ showed the most cytotoxic effects against SW620 cells $\left(\mathrm{IC}_{50}=0.51 \pm 0.07\right)$ followed by $\mathrm{A} 549$ cells $\left(\mathrm{IC}_{50}=1.86 \pm\right.$ $0.39)$ and MCF-7 cells $\left(\mathrm{IC}_{50}=17.92 \pm 4.25\right)$. Further biological studies are currently underway to study the fluorescent behaviour of these anion transporters in cells using confocal fluorescent microscopy techniques.

In conclusion, we designed and synthesized a series of novel bisureas-anion transporters bearing the fluorescent 4-methyl coumarin. The fluorescent anion receptors were tested for their anion binding properties in solution and elicited a relatively strong chloride binding affinity in DMSO- $d_{6} / 0.5 \% \mathrm{H}_{2} \mathrm{O}$. These receptors showed a superior $\mathrm{Cl} / \mathrm{NO}_{3}{ }^{-}$exchange ability in ISEbased affinity and $\mathrm{H}^{+} / \mathrm{Cl}^{-}$cotransport activity than the previously reported fluorescent anion transporters.

$M F, X W, D A M, A M G, W L$ and PAG acknowledge and pay respect to the Gadigal people of the Eora Nation, the traditional owners of the land on which we research, teach and collaborate at the University of Sydney. PAG thanks the Australian Research Council (DP200100453) and the University of Sydney for funding. MF thanks UOW for the University Postgraduate Award and International Postgraduate Tuition Award scholarships and the University of Sydney for funding.

\section{Conflicts of interest}

There are no conflicts to declare.

\section{Notes and references}

[1] a) N. Mizushima, M. Komatsu, Cell, 2011, 147, 728-741; b) D. C. Gadsby, Nat. Rev. Mol. Cell Biol., 2009, 10, 344-352.

[2] a) A. S. Verkman, L. J. Galietta, Nat. Rev. Drug Discov., 2009, 8, 153; b) F. M. Ashcroft, Ion channels and disease, Academic Press, 1999; c) H. Li, H. Valkenier, L. W. Judd, P. R. Brotherhood, S. Hussain, J. A. Cooper, O. Jurcek, H. A. Sparkes, D. N. Sheppard, A. P. Davis, Nat. Chem., 2016, 8, 24-32.

[3] J. B. Kim, Korean J. Pediatr., 2014, 57, 1-18.

[4] J. M. Tomich, U. Bukovnik, J. Layman, B. D. Schultz, Channel replacement therapy for cystic fibrosis, IntechOpen, 2012.

[5] a) N. Busschaert, S. H. Park, K. H. Baek, Y. P. Choi, J. Park, E. N. W. Howe, J. R. Hiscock, L. E. Karagiannidis, I. Marques, V. Felix, W. Namkung, J. L. Sessler, P. A. Gale, I. Shin, Nat. Chem., 2017, 9, 667-675; b) W. Van Rossom, D. J. Asby, A. Tavassoli, P. A. Gale, Org. Biomol. Chem., 2016, 14, 26452650; c) A. I. Share, K. Patel, C. Nativi, E. J. Cho, O. Francesconi, N. Busschaert, P. A. Gale, S. Roelens, J. L. Sessler, Chem. Commun., 2016, 52, 7560-7563; d) S. J. Moore, C. J. Haynes, J. González, J. L. Sutton, S. J. Brooks, M. E. Light, J. Herniman, G. J. Langley, V. Soto-Cerrato, R. Pérez-Tomás, Chem. Sci., 2013, 4, 103-117; e) L. E. Karagiannidis, C. J. Haynes, K. J. Holder, I. L. Kirby, S. J. Moore, N. J. Wells, P. A. Gale, Chem. Commun., 2014, 50, 12050-12053.

[6] S. H. Park, S. H. Park, E. N. W. Howe, J. Y. Hyun, L. J. Chen, I. Hwang, G. Vargas-Zuniga, N. Busschaert, P. A. Gale, J. L. Sessler, I. Shin, Chem, 2019, 5, 2079-2098.

[7] V. Soto-Cerrato, P. Manuel-Manresa, E. Hernando, S. Calabuig-Farinas, A. Martinez-Romero, V. FernandezDuenas, K. Sahlholm, T. Knopfel, M. Garcia-Valverde, A. M. Rodilla, E. Jantus-Lewintre, R. Farras, F. Ciruela, R. PerezTomas, R. Quesada, J. Am. Chem. Soc., 2015, 137, 1589215898.

[8] S. N. Berry, V. Soto-Cerrato, E. N. Howe, H. J. Clarke, I. Mistry, A. Tavassoli, Y.-T. Chang, R. Pérez-Tomás, P. A. Gale, Chem. Sci., 2016, 7, 5069-5077.

[9] X. Wu, E. N. W. Howe, P. A. Gale, Acc. Chem. Res., 2018, 51, 1870-1879.

[10] X. Bao, X. Wu, S. N. Berry, E. N. W. Howe, Y. T. Chang, P. A. Gale, Chem. Commun., 2018, 54, 1363-1366.

[11] a) S. J. Brooks, P. R. Edwards, P. A. Gale, M. E. Light, New J. Chem., 2006, 30, 65-70; b) C. M. Dias, H. Y. Li, H. Valkenier, L. E. Karagiannidis, P. A. Gale, D. N. Sheppard, A. P. Davis, Org. Biomol. Chem., 2018, 16, 1083-1087.

[12] R. L. Atkins, D. E. Bliss, J. Org. Chem., 1978, 43, 1975-1980.

[13] T. S. Reddy, A. R. Reddy, Dyes Pigm., 2013, 96, 525-534.

[14] E. N. Howe, N. Busschaert, X. Wu, S. N. Berry, J. Ho, M. E. Light, D. D. Czech, H. A. Klein, J. A. Kitchen, P. A. Gale, J. Am. Chem. Soc., 2016, 138, 8301-8308.

[15] S. Bhosale, S. Matile, Chirality, 2006, 18, 849-856.

[16] X. Wu, J. R. Small, A. Cataldo, A. M. Withecombe, P. Turner, P. A. Gale, Angew. Chem. Int. Ed. Engl., 2019, 58, 1514215147. 


\section{Supporting Information}

for

\section{Coumarin-bisureas as potent fluorescent transmembrane anion transporters}

Mohamed Fares, ${ }^{a-c}$ Xin Wu, ${ }^{a}$ Daniel A. McNaughton, ${ }^{a}$ Alexander Gilchrist, ${ }^{a}$ William Lewis, ${ }^{a}$ Paul A. Keller, ${ }^{b}$ Alain Arias-Betancurd,e, Ricardo Pérez-Tomás ${ }^{d}$, Philip A. Gale, ${ }^{\star a, f}$

a. School of Chemistry, The University of Sydney, NSW 2006, Australia E-mail: philip.gale@sydney.edu.au

b. School of Chemistry \& Molecular Bioscience, Molecular Horizons, University of Wollongong, and Illawarra Health \& Medical Research Institute, Wollongong, NSW 2522, Australia.

C. Department of Pharmaceutical Chemistry, Faculty of Pharmacy, Egyptian Russian University, Cairo 11829, Egypt

d. Department of Pathology and Experimental Therapeutics, Faculty of Medicine and Health Sciences, Universitat de Barcelona, 08905 Barcelona, Spain

e. Department of Integral Adult Dentistry, Research Centre for Dental Sciences (CICO), Universidad de La Frontera, Temuco 4811230, Chile

f. The University of Sydney Nano Institute (SydneyNano), The University of Sydney, NSW 2006, Australia. 


\section{Table of Contents}

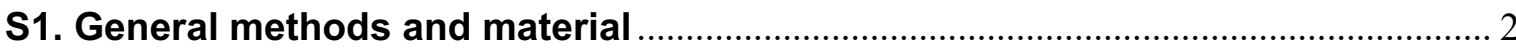

S2. Synthesis and charachterization:

S2.1. Overview of compounds:

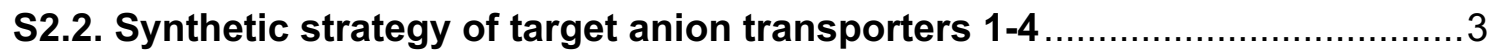

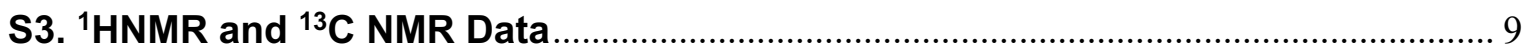

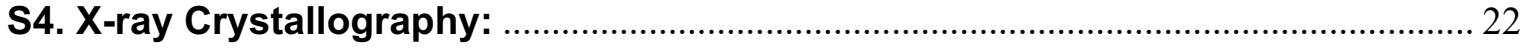

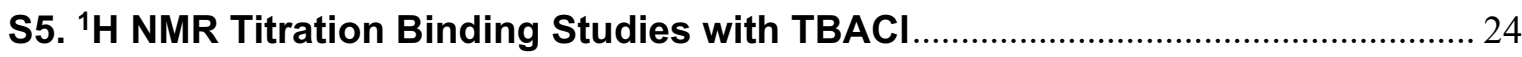

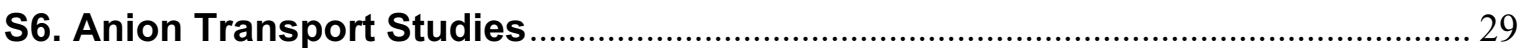

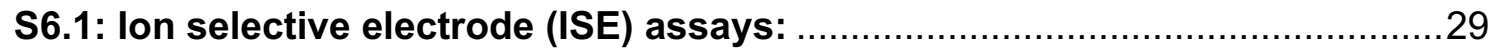

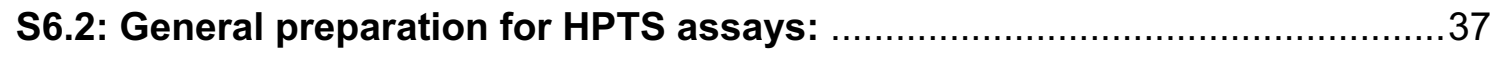

S7. Biological results:

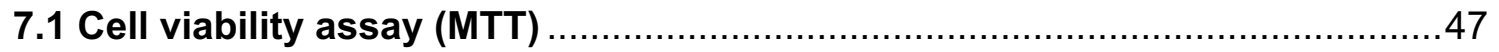

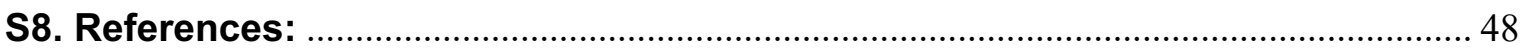




\section{S1. General methods and material}

All reagents and solvents were purified and dried by standard techniques. Reactions were monitored by TLC analysis using silica gel GF/UV 254. NMR spectra were recorded on Bruker $400 \mathrm{MHz}$ FT-NMR spectrometer and Varian Gemini-300BB 300 MHz FT-NMR spectrometers (Varian Inc., Palo Alto, CA). ${ }^{1} \mathrm{H}$ spectra were run at 300 and $400 \mathrm{MHz}$ and ${ }^{13} \mathrm{C}$ spectra were run at 75 and $101 \mathrm{MHz}$, in the stated solvent. Chemical shifts $\left(\delta_{\mathrm{H}}\right)$ are reported relative to TMS as internal standard and coupling constant $(J)$ values are reported in Hertz. The abbreviations used are as follows: s, singlet; $d$, doublet; $t$, triplet; $\mathrm{m}$, multiplet. Electrospray (ESI single quadrupole) mass spectra have their ion mass to charge values $(\mathrm{m} / \mathrm{z})$ stated with their relative abundances as a percentage in parentheses. Peaks assigned to the molecular ion are denoted as $[\mathrm{M}+\mathrm{H}]$ or $[\mathrm{M}+\mathrm{Na}]$. Column chromatography was performed using silica gel 60 (0.063-0.200 mm). Low resolution mass spectra (LRMS) and high resolution mass spectra (HRMS) were recorded using positive/negative ion electrospray ionization (ESI) on Bruker amaZon SL mass spectrometer. 


\section{S2. Synthesis and charachterization:}

S2.1. Overview of compounds:

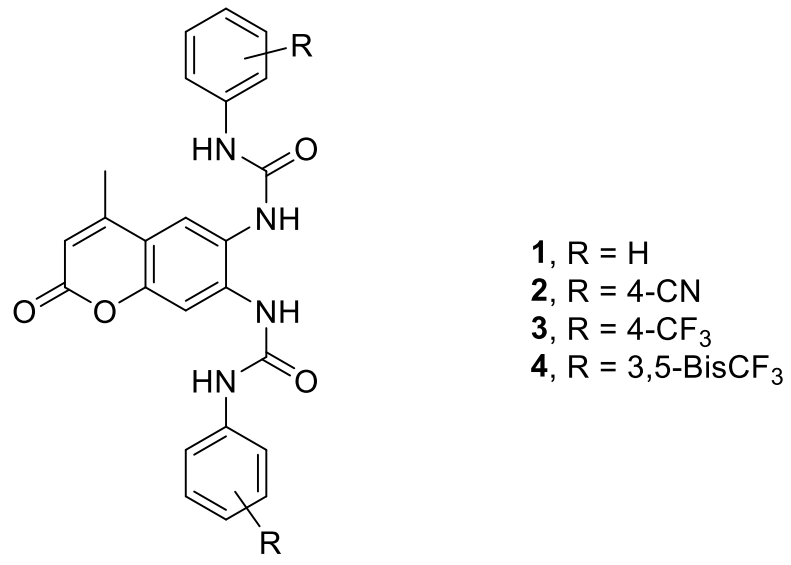

S2.2. Synthetic strategy of target anion transporters 1-4<smiles>Nc1cccc(O)c1</smiles><smiles>C1COC1</smiles><smiles>C/C=C(/C)CC</smiles><smiles>CCOC(=O)Nc1ccc2c(C)cc(=O)oc2c1</smiles>
yield $=36 \%$<smiles>Cc1cc(=O)oc2cc(N)c(N)cc12</smiles>

9

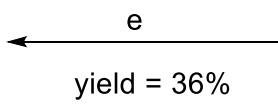

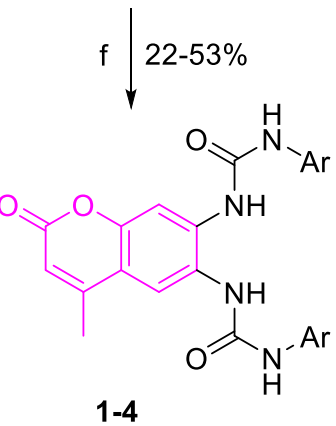

Scheme 1. a- Ethylchloroformate/DEE; b-Ethylacetoacetate, $70 \% \mathrm{H}_{2} \mathrm{SO}_{4}$; c- $\mathrm{Al}\left(\mathrm{NO}_{3}\right)_{3} .9 \mathrm{H}_{2} \mathrm{O}$, acetic anhydride.; dConc $\mathrm{H}_{2} \mathrm{SO}_{4}$, Glacial acetic acid, reflux.; e- $\mathrm{Sn} / \mathrm{HCl}$, reflux.; f- Suitable isocyanate, $\mathrm{DCM}, 45{ }^{\circ} \mathrm{C}$, or Suitable isocyanate, $45^{\circ} \mathrm{C}$. 
Synthesis of ethyl (3-hydroxyphenyl)carbamate $5:^{1}$ To a suspension of $m$-aminophenol<smiles>O=C(Nc1cccc(O)c1)OCCCCO</smiles>

5 $(10.0 \mathrm{~g}, 92.0 \mathrm{mmol})$ in diethyl ether $(400 \mathrm{~mL})$, ethyl chloroformate (10.0 g, $92.0 \mathrm{mmol})$ was added at once and a white precipitate appeared immediately. The reaction mixture was stirred for $2 \mathrm{~h}$ and the resulting salt was removed by filteration, while the solvent was removed under vacuum to give $8 \mathrm{~g}$ of white solid which was used in the next step without any further purification. ${ }^{1}$

Synthesis of ethyl(4-methyl-2-oxo-2H-chromen-7-yl)carbamate $6:^{1}$ To a mixture of ethyl $\underbrace{\mathrm{O}}_{6}$ (3-hydroxyphenyl)carbamate $5(8.0 \mathrm{~g}, 44.0 \mathrm{mmol})$ and ethylacetoacetate $(6.8 \mathrm{~mL}, 53.0 \mathrm{mmol}), 100 \mathrm{~mL}$ of $70 \%$ $\mathrm{H}_{2} \mathrm{SO}_{4}$ was added. The reaction mixture was stirred for $4 \mathrm{~h}$ at room temperature. The resutling solid was collected by filteration, washed with water $(2 \times 30 \mathrm{~mL})$ and recrystallized from ethanol to give $6(8.2 \mathrm{~g}$, 75\%) as a colorless needles. ${ }^{1} \mathbf{H}$ NMR (400 MHz, DMSO-d 6 ) $\delta: 1.40(\mathrm{t}, J=7.0 \mathrm{~Hz}, 3 \mathrm{H}$, $\mathrm{CH}_{2} \underline{\mathrm{CH}}_{3}$ ), 2.50 (s, 3H, $\mathrm{CH}_{3}$ ), 4.31 (q, J = 7.0 Hz, 2H, $\underline{\mathrm{CH}}_{2} \mathrm{CH}_{3}$ ), 6.32 (s, $1 \mathrm{H}, \mathrm{ArH}$ ), 7.51 (dd, $J=2.0,9.0 \mathrm{~Hz}, 1 \mathrm{H}, \mathrm{ArH}), 7.65(\mathrm{~d}, J=2.0 \mathrm{~Hz}, 1 \mathrm{H}, \mathrm{ArH}), 7.77$ (d, $J=9.0 \mathrm{~Hz}, 1 \mathrm{H}, \mathrm{ArH})$, 10.24 (s, 1H, NH); ${ }^{13} \mathrm{C}$ NMR (101 MHz, DMSO-d 6 ) $\delta: 14.9,18.4,61.1,104.8,112.3,114.6$, $114.7,126.3,143.3,153.6,153.8,154.3,160.5$.

Synthesis of ethyl (4-methyl-6-nitro-2-oxo-2H-chromen-7-yl)carbamate $7:^{2}$ To a

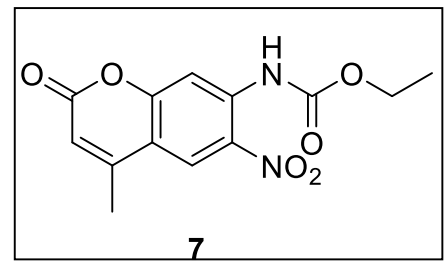
suspension of 7-carbethoxyamino-4-methylcoumarin $6(4.1 \mathrm{~g}$, $16.6 \mathrm{mmol})$ in acetic anhydride $(100 \mathrm{~mL})$, aluminium nitrate nonahydrate $(5.6 \mathrm{~g}, 6.5 \mathrm{mmol})$ was added portionwise and the reaction mixture was stirred for $16 \mathrm{~h}$. The mixture was slowly poured into ice cold water $(200 \mathrm{~mL})$ and the resulting yellow residue was purified via flash chromatography (hexane: ethyl acetate $=9: 1$ ) to give 7 (1.7 g, 36\%). ${ }^{1} \mathrm{H}$ NMR (500 MHz, DMSO-d $)$ ) $\delta: 1.27$ (t, $J=7.0 \mathrm{~Hz}, 3 \mathrm{H}, \mathrm{CH}_{2} \underline{\mathrm{CH}}_{3}$ ), 2.45 (s, 3H, CH $\mathrm{CH}_{3}, 4.18$ (q, J = 7.0 Hz, 2H, $\underline{\mathrm{CH}}_{2} \mathrm{CH}_{3}$ ), 6.46 (s, 1H, ArH), $7.72(\mathrm{~s}, 1 \mathrm{H}, \mathrm{ArH}), 8.35$ (s, 1H, ArH), 10.10 (s, 1H, NH); ${ }^{13}$ C NMR (126 MHz, DMSO-d 6 ) $\delta: 14.7,18.3,62.2,109.9$, 114.9, 115.7, 123.9, 136.1, 136.9, 152.8, 153.5, 156.3, 159.3; LRMS ESI' (m/z): 291 $(100 \%, M-H)$. 

carbethoxyamino-4-methylcoumarin $7(1.7 \mathrm{~g}, 5.8 \mathrm{mmol})$ was heated at reflux in a mixture of concentrated sulfuric acid $(6 \mathrm{~g})$ and glacial acetic acid $(6 \mathrm{~g})$ for $4 \mathrm{~h}$. After cooling the reaction mixture, was poured into ice water $(30 \mathrm{~mL})$ and let stand overnight. Ice was added, and neutralization of the acidic solution was accomplished using $\mathrm{NaOH}(50 \%)$. The formed yellow precipitate was filtered, washed thoroughly 3 times with ice water $(3 \mathrm{x}$ $10 \mathrm{~mL}$ ) and dried to give 8 as a yellow powder (1.0 g, 80\%). ${ }^{1} \mathbf{H}$ NMR (400 MHz, DMSOd $\boldsymbol{d}_{6} \boldsymbol{\delta}: 2.38\left(\mathrm{~s}, 3 \mathrm{H}, \mathrm{CH}_{3}\right), 6.18(\mathrm{~s}, 1 \mathrm{H}, \mathrm{ArH}), 6.81$ (s, $\left.1 \mathrm{H}, \mathrm{ArH}\right), 7.80$ (br. s, $2 \mathrm{H}, \mathrm{NH}_{2}$ ), 8.33 (s, $1 \mathrm{H}, \mathrm{ArH}) ;{ }^{13} \mathrm{C}$ NMR (101 MHz, DMSO-d 6 ) $\delta: 18.2,103.3,110.4,111.6,124.9,128.8$, 148.6, 153.4, 157.6, 159.7. LRMS ESI- (m/z): 219 (100\%, M-H)-.

Synthesis of 6,7-Diamino-4-methyl-2H-chromen-2-one 9:2 Conc. hydrochloric acid (15 $\underbrace{(}_{9}$ $\mathrm{mL}$ ) was added in three portions over 20 minutes to a mixture of tin powder (1.1 g, $9.2 \mathrm{mmol})$ and 6-nitro-7-amino-4-methyl-coumarin (1 $\mathrm{g}, 4.5 \mathrm{mmol}$ ) and the reaction mixture was heated at reflux for $3 \mathrm{~h}$. After cooling, the reaction mixture was poured into ice water $(50 \mathrm{~mL})$ and let stand overnight. Ice was added, and neutralization of the acidic solution was accomplished using $\mathrm{NaOH}(50 \%)$. The formed precipitate was extracted with ethyl acetate $(3 \times 200 \mathrm{~mL})$ and all the organic layers washed with water $(2 \times 10 \mathrm{~mL})$, brine $(1 \mathrm{x}$ $10 \mathrm{~mL}$ ) and dried over magnesium sulfate. Ethyl acetate was removed under vacuum to give 9 as a dark yellow powder (0.31 g, 36\%). ${ }^{1} \mathbf{H}$ NMR (300 MHz, DMSO-d 6 ) $\delta: 2.26$ (s, $3 \mathrm{H}, \mathrm{CH}_{3}$ ), 4.72 (br. s, 2H, NH${ }_{2}$ ), 5.63 (br. s, 2H, NH$)_{2}, 5.87$ (s, 1H, ArH), 6.44 (s, 1H, ArH), 6.76 (s, 1H, ArH); ${ }^{13} \mathrm{C}$ NMR (75 MHz, DMSO-d 6 ) $\delta: 18.1,99.0,107.1,107.6,109.2,131.9$, 141.3, 148.1, 153.1, 161.1. LRMS ESI- $(\mathbf{m} / \mathbf{z}): 191$ (100\%, M-H)-. HRMS (ESI ${ }^{+}$) calcd for $\mathrm{C}_{10} \mathrm{H}_{10} \mathrm{~N}_{2} \mathrm{NaO}_{2}\left(\mathrm{M}+\mathrm{Na}^{+}\right): 213.0635$, found: 213.06340 (0.22 ppm). 
Synthesis of target compounds 1-4:

\section{General procedure A:}

6,7-Diamino-4-methylcoumarin 9 (80 $\mathrm{mg}, 0.42 \mathrm{mmol}$ ) was suspended in $\mathrm{CH}_{2} \mathrm{Cl}_{2}$ and added dropwise to the corresponding isocyanate derivative solution with stirring. The suspension was stirred at $45^{\circ} \mathrm{C}$ overnight and after cooling the solvent removed under vacuum. The resulting residue was heated in ethanol $(25 \mathrm{~mL})$ and filtered while hot to give anion transporters 1, 2 and 4.

\section{Procedure B:}

Under inert atmosphere, 4-trifluoropmethylphenyl isocyanate $(0.79 \mathrm{~g}, 4.2 \mathrm{mmol})$ was added to 6,7-diamino-4-methylcoumarin $9(80 \mathrm{mg}, 0.42 \mathrm{mmol})$ with constant stirring. The reaction mixture was held at $45{ }^{\circ} \mathrm{C}$ overnight and after cooling the unreacted 4trifluorpmethylphenyl isocyanate was removed under vacuum and the remaining residue was heated in ethanol $(25 \mathrm{~mL})$ and filtered while hot to give $\mathbf{3}$ as white solid.

1,1'-(4-Methyl-2-oxo-2H-chromene-6,7-diyl)bis(3-phenylurea) 1: Using the general

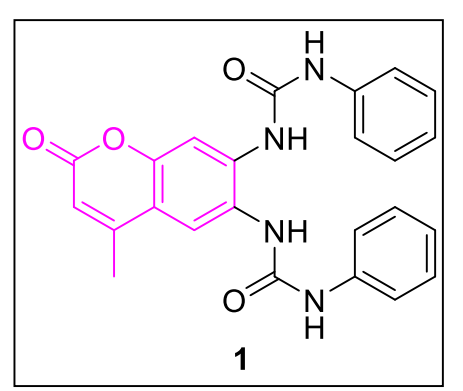
procedure $A$ and phenyl isocyanate $(200 \mathrm{mg}, 1.68 \mathrm{mmol})$, compound 1 (70 mg, 39\%) was isolated as a white solid. ${ }^{1} \mathbf{H}$ NMR (400 MHz, DMF- $\left.d_{7}\right) \delta: 2.40\left(\mathrm{~s}, 3 \mathrm{H}, \mathrm{CH}_{3}\right), 6.22(\mathrm{~s}, 1 \mathrm{H}$, $\operatorname{ArH}), 6.97$ (q, $J=7.0 \mathrm{~Hz}, 2 \mathrm{H}, \operatorname{ArH}), 7.27$ (t, $J=7.0 \mathrm{~Hz}, 4 \mathrm{H}$, ArH), $7.54(\mathrm{~m}, 4 \mathrm{H}, \mathrm{ArH}) 7.79(\mathrm{~s}, 1 \mathrm{H}, \mathrm{ArH}), 8.07(\mathrm{~s}, 1 \mathrm{H}, \mathrm{ArH})$, $8.18(\mathrm{~s}, 1 \mathrm{H}, \mathrm{NH}), 8.68(\mathrm{~s}, 1 \mathrm{H}, \mathrm{NH}), 9.06(\mathrm{~s}, 1 \mathrm{H}, \mathrm{NH}), 9.46(\mathrm{~s}$, $1 \mathrm{H}, \mathrm{NH}) ;{ }^{13} \mathrm{C}$ NMR (101 MHz, DMF- $\left.\boldsymbol{d}_{7}\right) \boldsymbol{\delta}$ : 17.8, 107.3, 112.6, 114.6, 118.5, 118.7, 122.1, $122.5,123.3,125.2,129.0,129.1,139.5,140.1,140.7,152.1,152.9,153.2,160.6$. LRMS $\operatorname{ESI}^{-}(\mathrm{m} / \mathrm{z}): 427(100 \%, \mathrm{M}-\mathrm{H})^{-}$. HRMS (ESI-) calcd for $\mathrm{C}_{24} \mathrm{H}_{19} \mathrm{~N}_{4} \mathrm{O}_{4}(\mathrm{M}-\mathrm{H})^{-}: 427.1412$, found: $427.1412(-0.06 \mathrm{ppm})$. 
1,1'-(4-Methyl-2-oxo-2H-chromene-6,7-diyl)bis(3-(4-cyanophenyl)urea) 2: Using the<smiles>Cc1ccc(NC(=O)Nc2ccc(C)cc2NC(=O)Nc2ccc(C)cc2)cc1</smiles>
general procedure $A$ and $p$-cyanophenyl isocyanate (242 mg, $1.68 \mathrm{mmol}$ ), compound 2 (106 mg, 53\%) was isolated as a buff solid. ${ }^{1} \mathrm{H}$ NMR $(500 \mathrm{MHz}$, DMSO-d 6 ) $\delta$ : 2.39 (s, 3H, $\left.\mathrm{CH}_{3}\right), 6.29(\mathrm{~s}, 1 \mathrm{H}, \mathrm{ArH}), 7.64-7.77(\mathrm{~m}, 9 \mathrm{H}$, $\mathrm{ArH}), 8.02(\mathrm{~s}, 1 \mathrm{H}, \mathrm{ArH}), 8.25(\mathrm{~s}, 1 \mathrm{H}, \mathrm{NH}), 8.65(\mathrm{~s}, 1 \mathrm{H}$, $\mathrm{NH}), 9.57$ (s, 1H, NH), 9.91 (s, 1H, NH); ${ }^{13} \mathrm{C}$ NMR (126 MHz, DMSO-d $\left.d_{6}\right) \delta: 18.5,103.8,104.2,107.7,113.1$, 114.9, 118.6, 118.7, 119.7, 119.8, 123.7, 124.7, 133.8, 133.9, 138.5, 144.1, 144.8, 151.7, 152.4, 153.4, 154.0, 160.0. LRMS ESI $(\mathbf{m} / \mathbf{z}): 513(100 \%, \mathrm{M}+\mathrm{Cl})^{-}$. HRMS (ESI ${ }^{+}$) calcd for $\mathrm{C}_{26} \mathrm{H}_{18} \mathrm{~N}_{6} \mathrm{O}_{4} \mathrm{Na}(\mathrm{M}+\mathrm{Na})^{+}: 501.1282$, found: 501.1287 (1.0 ppm).

1,1'-(4-Methyl-2-oxo-2H-chromene-6,7-diyl)bis(3-(4-(trifluoromethyl)phenyl)urea)

3:<smiles>Cc1cc2c(C)cc(=O)oc2cc1NC(=O)Nc1ccc(C(F)(F)F)cc1</smiles>

Using the procedure $\mathrm{B}$ and $p$-trifluormethylphenyl isocyanate $(0.79 \mathrm{~g}, 4.2 \mathrm{mmol})$, compound $3(53 \mathrm{mg}$, $22 \%)$ was isolated as a white solid. ${ }^{1} \mathrm{H}$ NMR $(400 \mathrm{MHz}$, DMF- $\left.d_{7}\right) \delta: 2.64\left(\mathrm{~s}, 3 \mathrm{H}, \mathrm{CH}_{3}\right), 6.48(\mathrm{~s}, 1 \mathrm{H}, \mathrm{ArH}), 7.87$ (d, $J=9.0 \mathrm{~Hz}, 4 \mathrm{H}, \mathrm{ArH}), 7.95-8.05(\mathrm{~m}, 4 \mathrm{H}, \mathrm{ArH}), 8.21(\mathrm{~s}$, $1 \mathrm{H}, \mathrm{ArH}), 8.40(\mathrm{~s}, 1 \mathrm{H}, \mathrm{ArH}), 8.51(\mathrm{~s}, 1 \mathrm{H}, \mathrm{NH}), 9.03$ (s, 1H, NH), 9.79 (s, 1H, NH), $10.06(\mathrm{~s}, 1 \mathrm{H}, \mathrm{NH}) ;{ }^{13} \mathrm{C}$ NMR

(101 MHz, DMF- $d_{7}$ ) $\delta: 17.8,107.6,112.9,115.0,118.4,118.5,122.6,122.9,123.0$ 123.3, $123.5,123.7,125.0,126.4,139.0,143.7,144.3,152.1,152.7,153.2,154.3,160.5 ;{ }^{19} \mathrm{~F}$ (376 MHz, DMF- $d_{7}$ ) $\delta:-60.03,-60.15$. LRMS ESI- (m/z): 563 (100\%, M-H)-. HRMS (ESI') calcd for $\mathrm{C}_{26} \mathrm{H}_{17} \mathrm{~F}_{6} \mathrm{~N}_{4} \mathrm{O}_{4}(\mathrm{M}-\mathrm{H}):$ : 563.1160, found: 563.1160 (-0.10 ppm). 
1,1'-(4-Methyl-2-oxo-2H-chromene-6,7-diyl)bis(3-(3,5-bis(trifluoromethyl)phenyl)urea) 4:

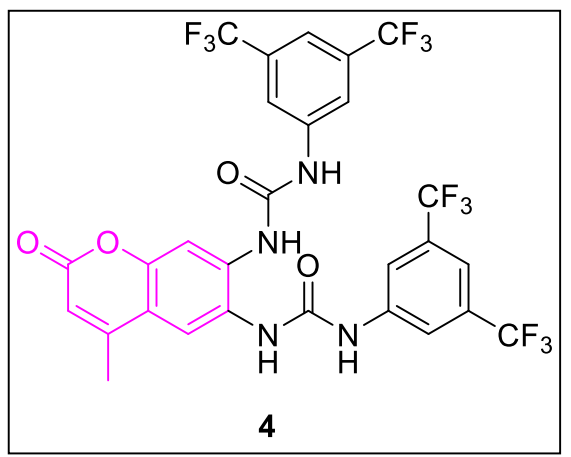

Using the general procedure $A$ and $p$-cyanophenyl isocyanate (428 mg, $1.68 \mathrm{mmol})$, compound 4 (78 $\mathrm{mg}, 27 \%$ ) was isolated as a buff solid. ${ }^{1} \mathrm{H}$ NMR (400 MHz, DMF-d $\left.d_{7}\right) \delta: 2.49\left(\mathrm{~s}, 3 \mathrm{H}, \mathrm{CH}_{3}\right), 6.31(\mathrm{~s}, 1 \mathrm{H}, \mathrm{ArH})$, $7.68(\mathrm{~s}, 1 \mathrm{H}, \mathrm{ArH}), 7.71$ (s, 1H, ArH), 8.05 (d, $J=7.0$ $\mathrm{Hz}, 4 \mathrm{H}, \mathrm{ArH}), 8.23-8.26(\mathrm{~m}, 4 \mathrm{H}, \mathrm{ArH}), 8.99(\mathrm{~s}, 1 \mathrm{H}$, $\mathrm{NH}), 9.41$ (s, 1H, NH), 10.54 (s, 1H, NH), 10.80 (s, 1H,

$\mathrm{NH}) ;{ }^{13} \mathrm{C}$ NMR (101 MHz, DMF- $\left.d_{7}\right) \delta: 17.7,107.1,112.8,114.7,117.8,119.7,121.6$, 122.4, 122.4, 124.5, 125.1, 127.8, 127.8, 131.4, 137.1, 142.1, 142.7, 151.4, 152.6, 153.1, 153.8, 160.3; ${ }^{19} \mathrm{~F}$ (376 MHz, DMF- $\left.\boldsymbol{d}_{7}\right)$ $\delta:-61.36,-61.44$. LRMS ESI ${ }^{+}(\mathrm{m} / \mathbf{z}): 723(100 \%$, $\mathrm{M}+\mathrm{Na})^{+}$. HRMS (ESI+) calcd for $\mathrm{C}_{28} \mathrm{H}_{16} \mathrm{~F}_{12} \mathrm{~N}_{4} \mathrm{O}_{4} \mathrm{Na}(\mathrm{M}+\mathrm{Na})^{+}:$723.0872, found: 723.0875 (0.4 ppm). 


\section{S3. ${ }^{1} \mathrm{HNMR}$ and ${ }^{13} \mathrm{C}$ NMR Data}

Figure S1: 7-Carbethoxyamino-4-methylcoumarin (6)
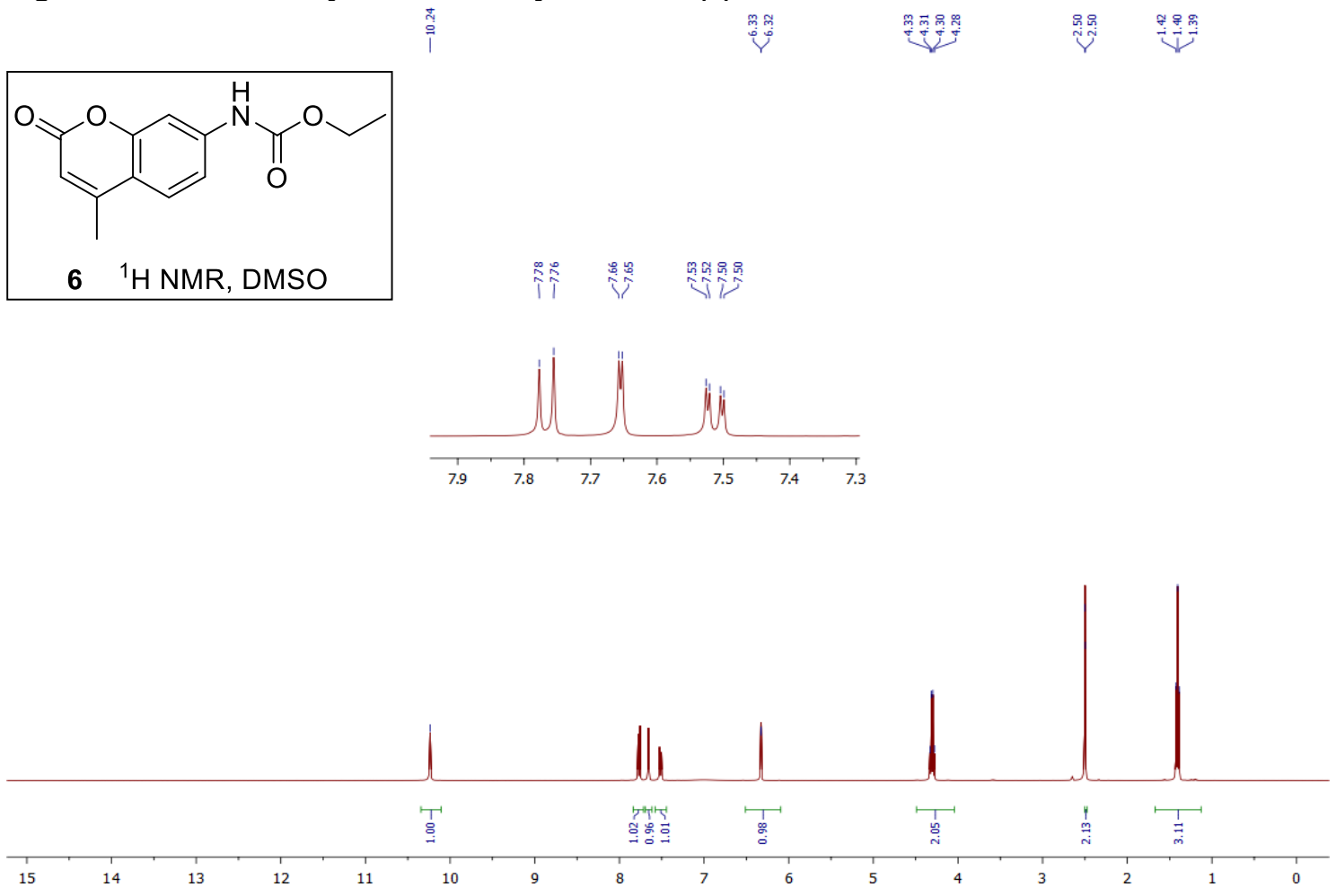


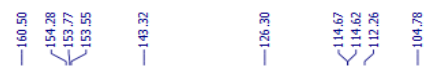
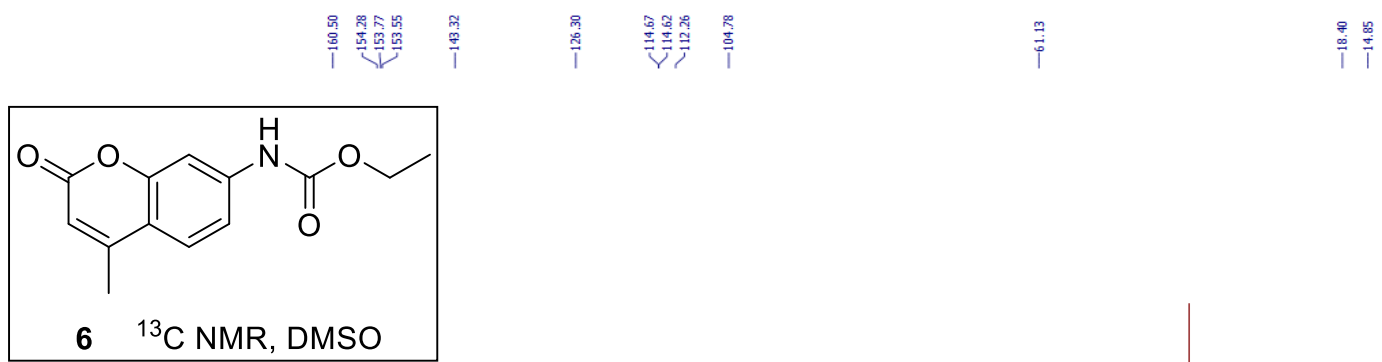

$6 \quad{ }^{13} \mathrm{C}$ NMR, DMSO

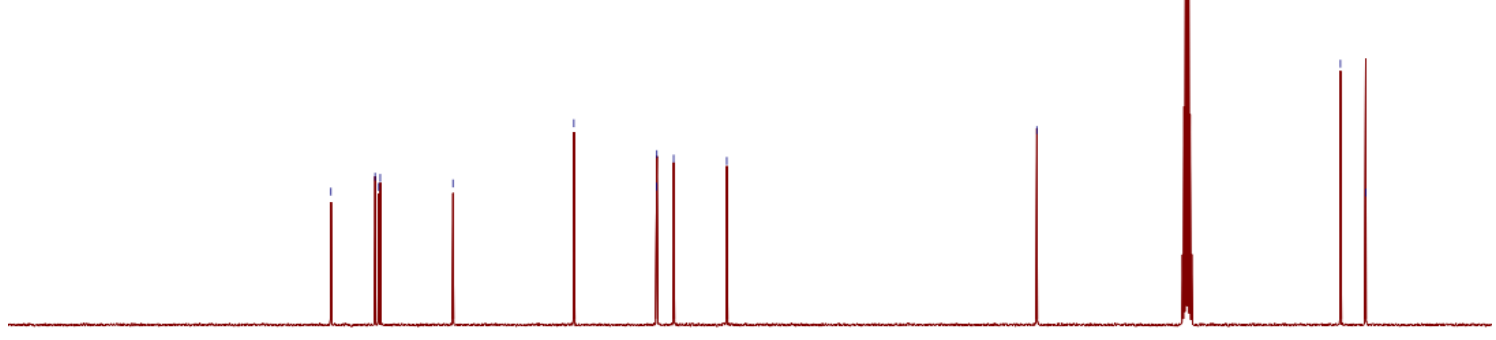

$\begin{array}{llllllllllllllllllll}1 & 100 & 190 & 180 & 170 & 160 & 150 & 140 & 130 & 120 & 110 & 100 & 1 & 1 & 1 & 1 & 1 & 1 & 1 & 1 \\ \mathrm{f}(\mathrm{ppm}) & 90 & 80 & 70 & 60 & 50 & 40 & 30 & 20 & 10 & 0\end{array}$

Figure S2: 6-Nitro-7- carbethoxyamino-4-methylcoumarin (7)
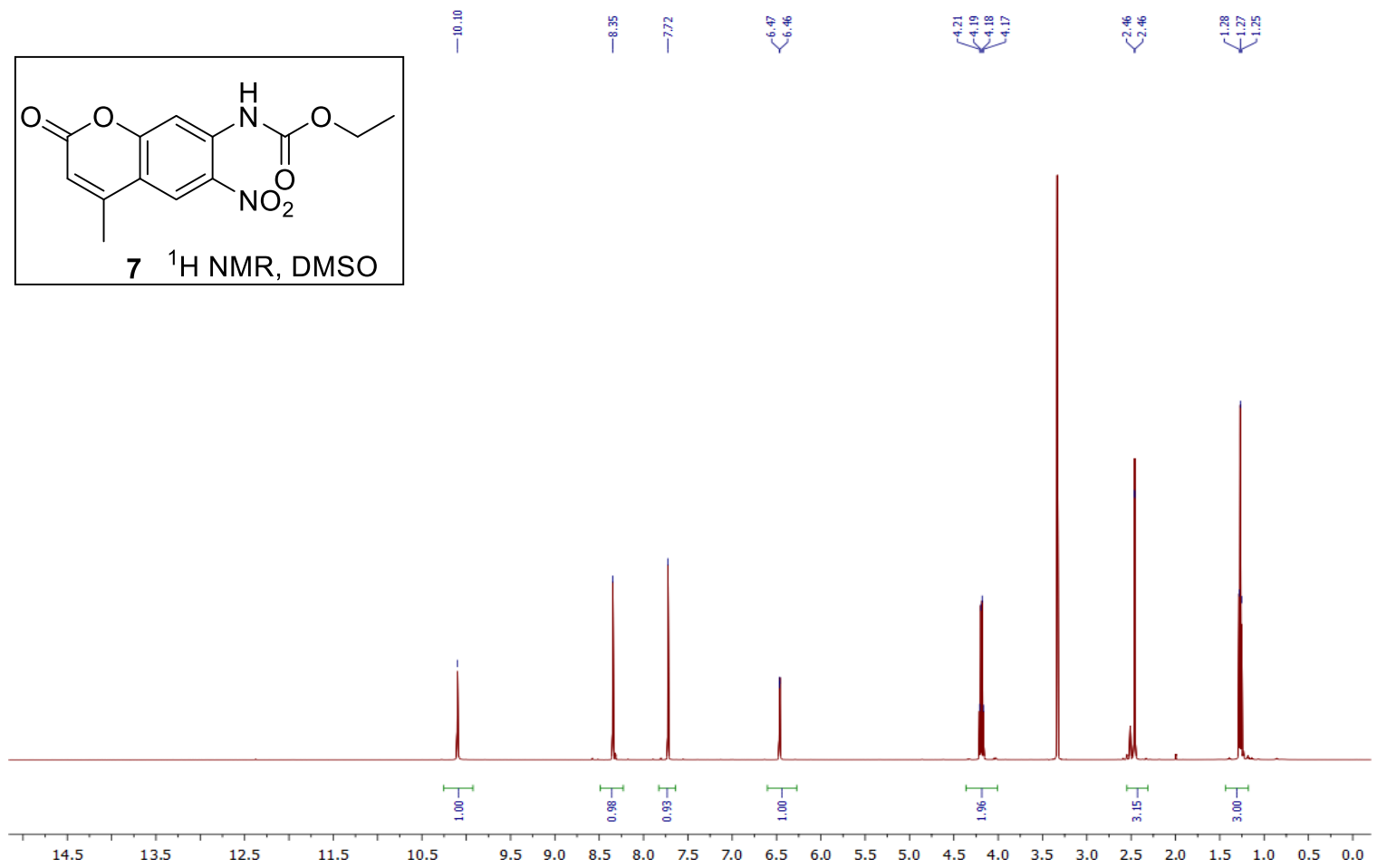

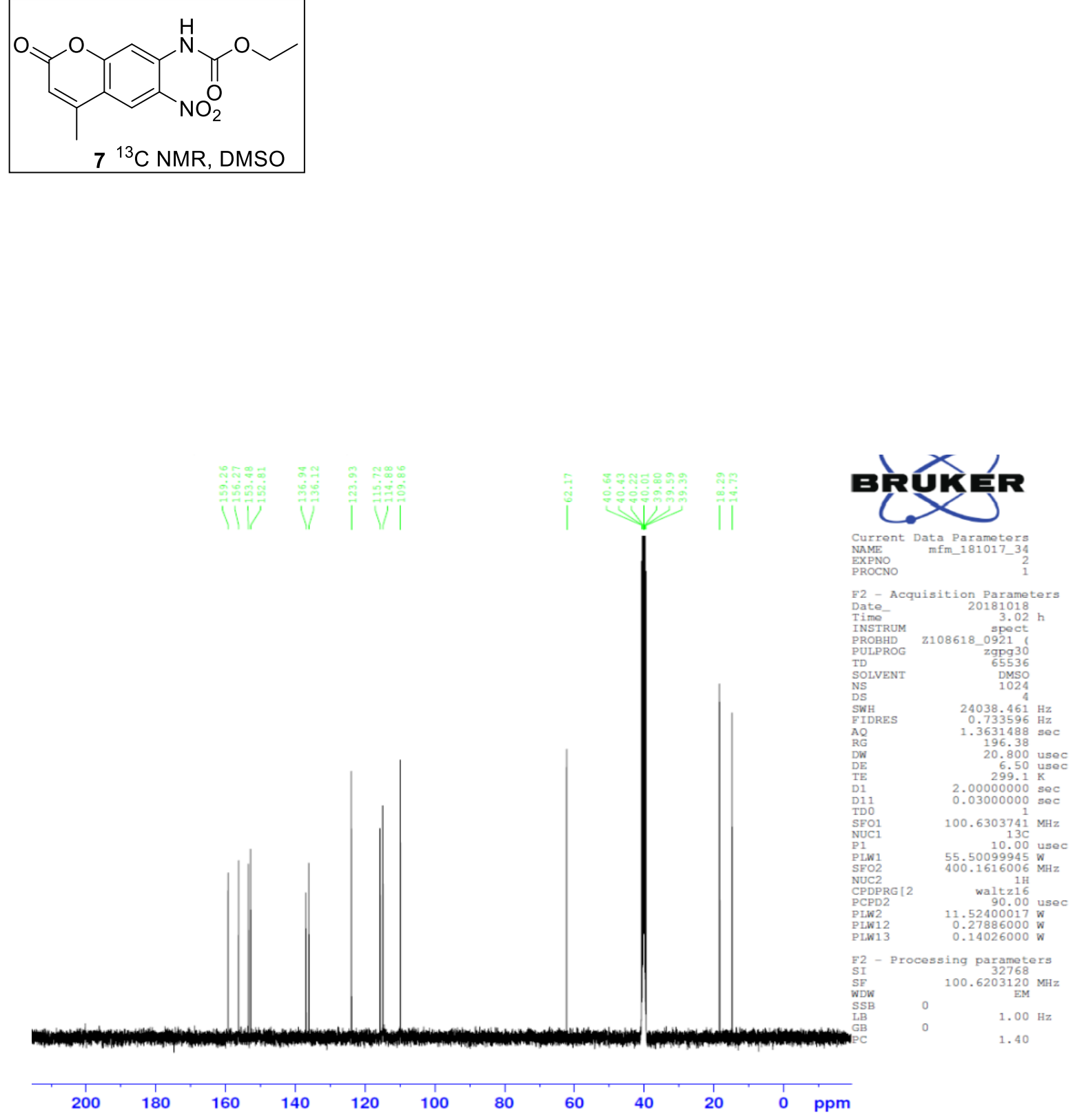
Figure S3: 6-Nitro-7-amino-4-methylcoumarin (8)
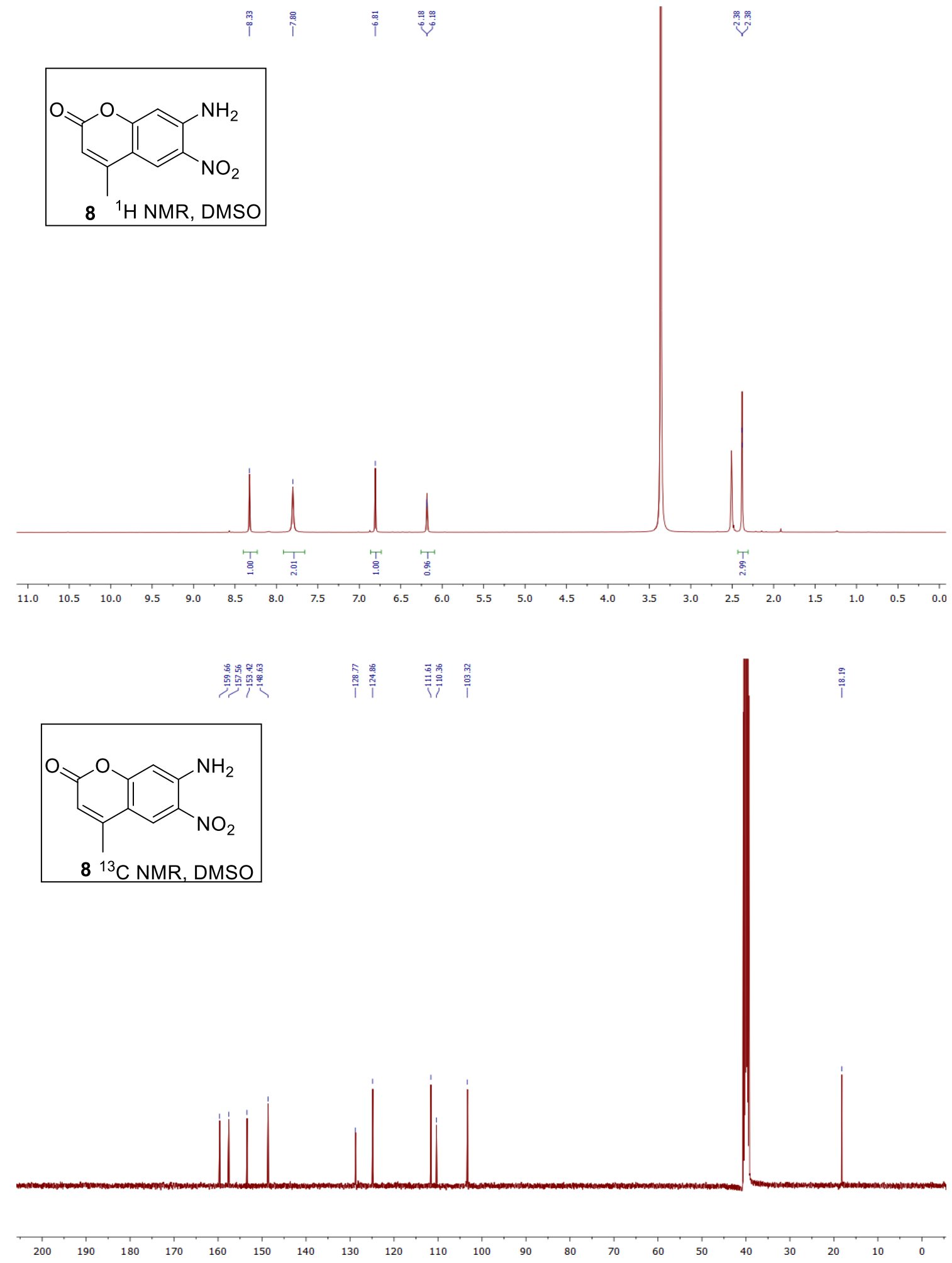
Figure S4: 6,7-Diamino-4-methylcoumarin (9)
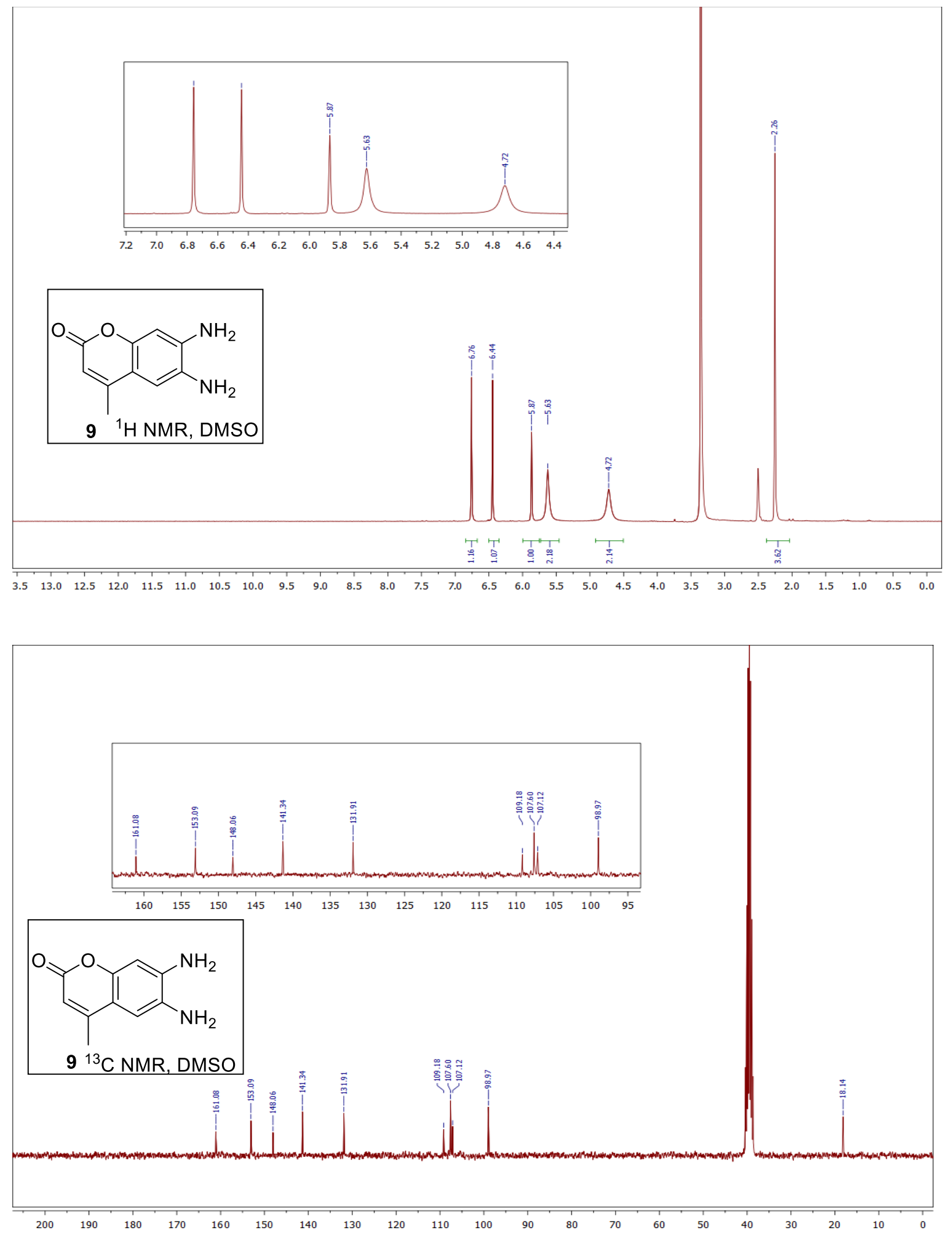
Figure S5: 1,1'-(4-methyl-2-oxo-2H-chromene-6,7-diyl)bis(3-phenylurea) (1)
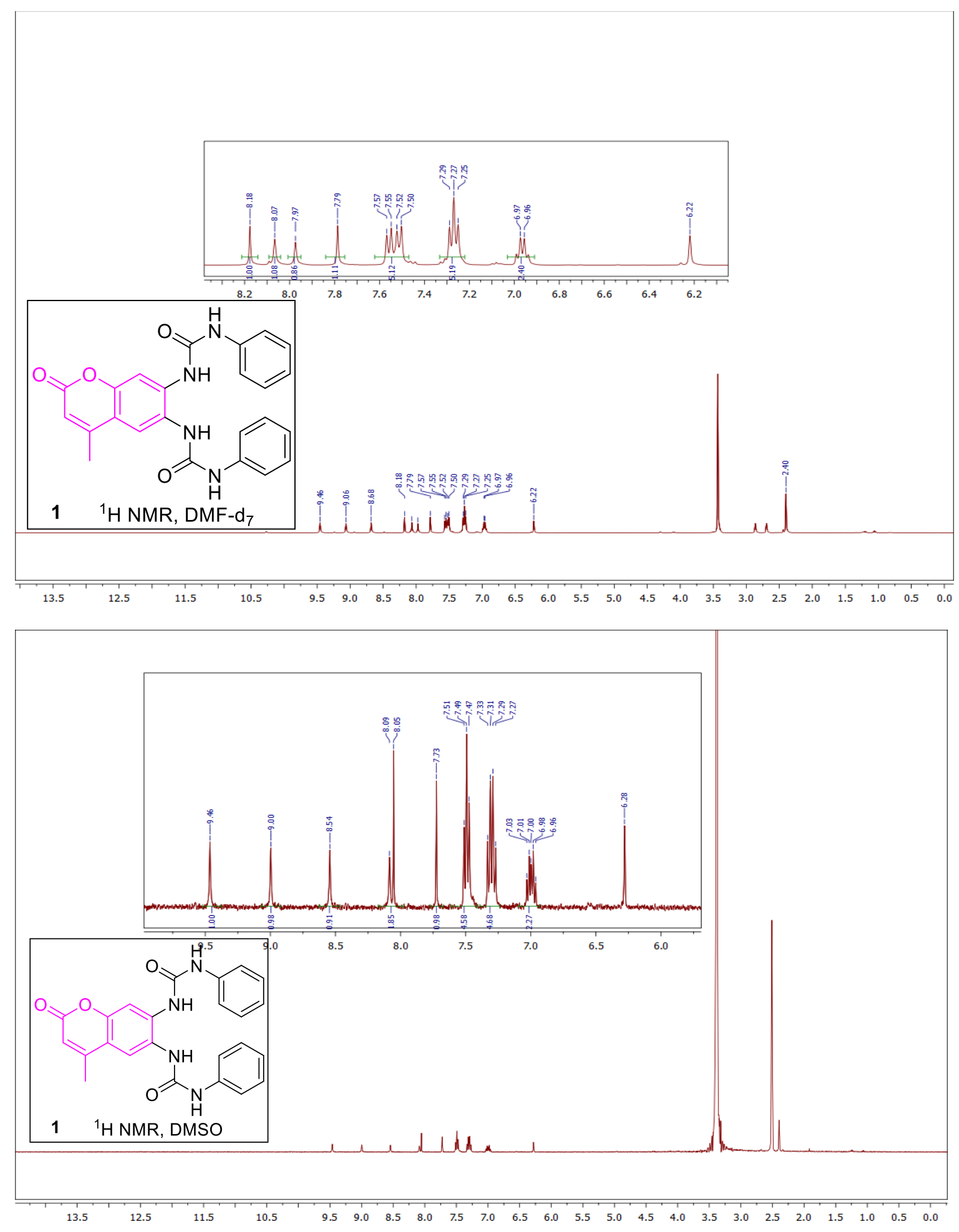


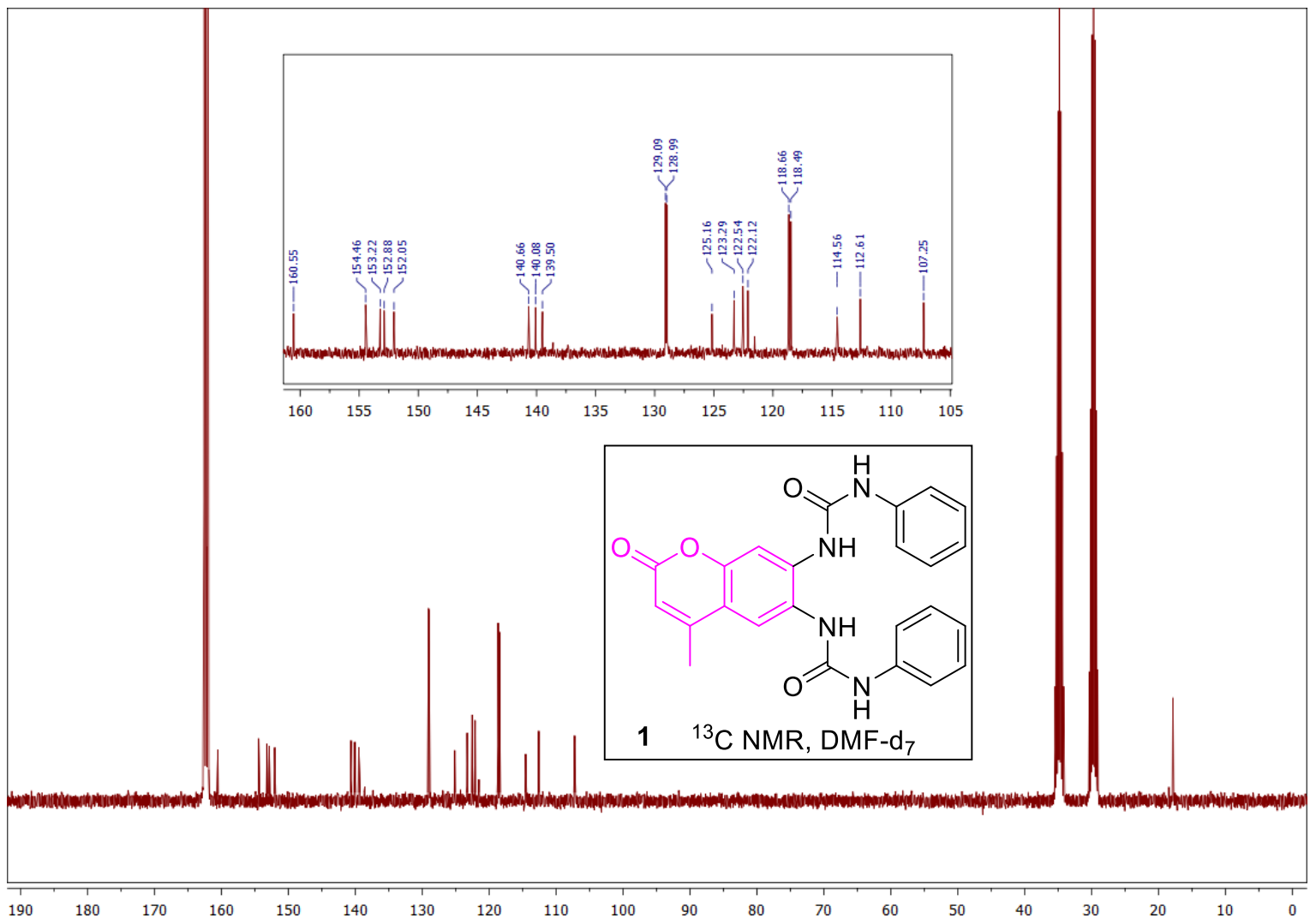


Figure S6: 1,1'-(4-methyl-2-oxo-2H-chromene-6,7-diyl)bis(3-(4-cyanophenyl)urea) (2)
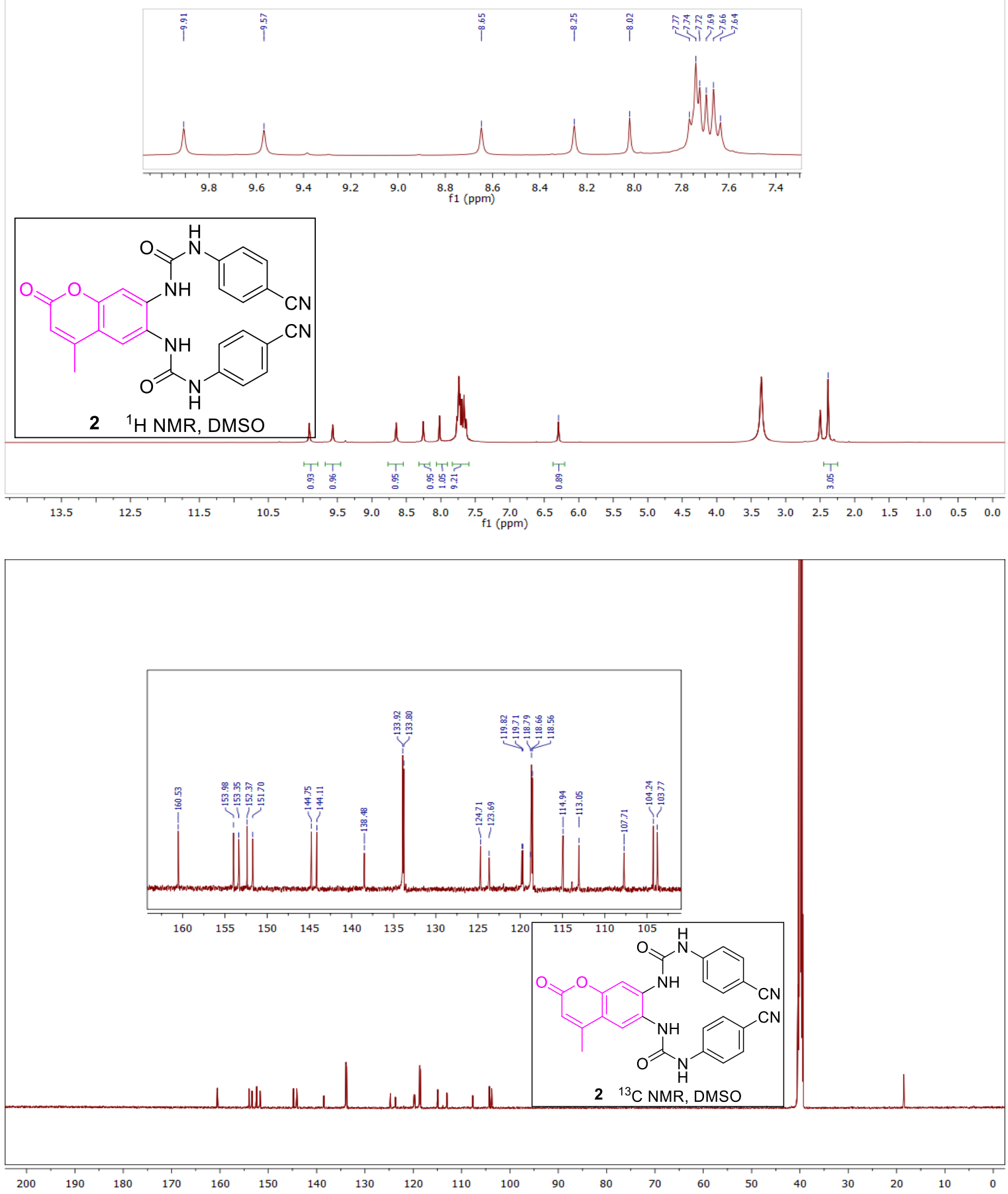

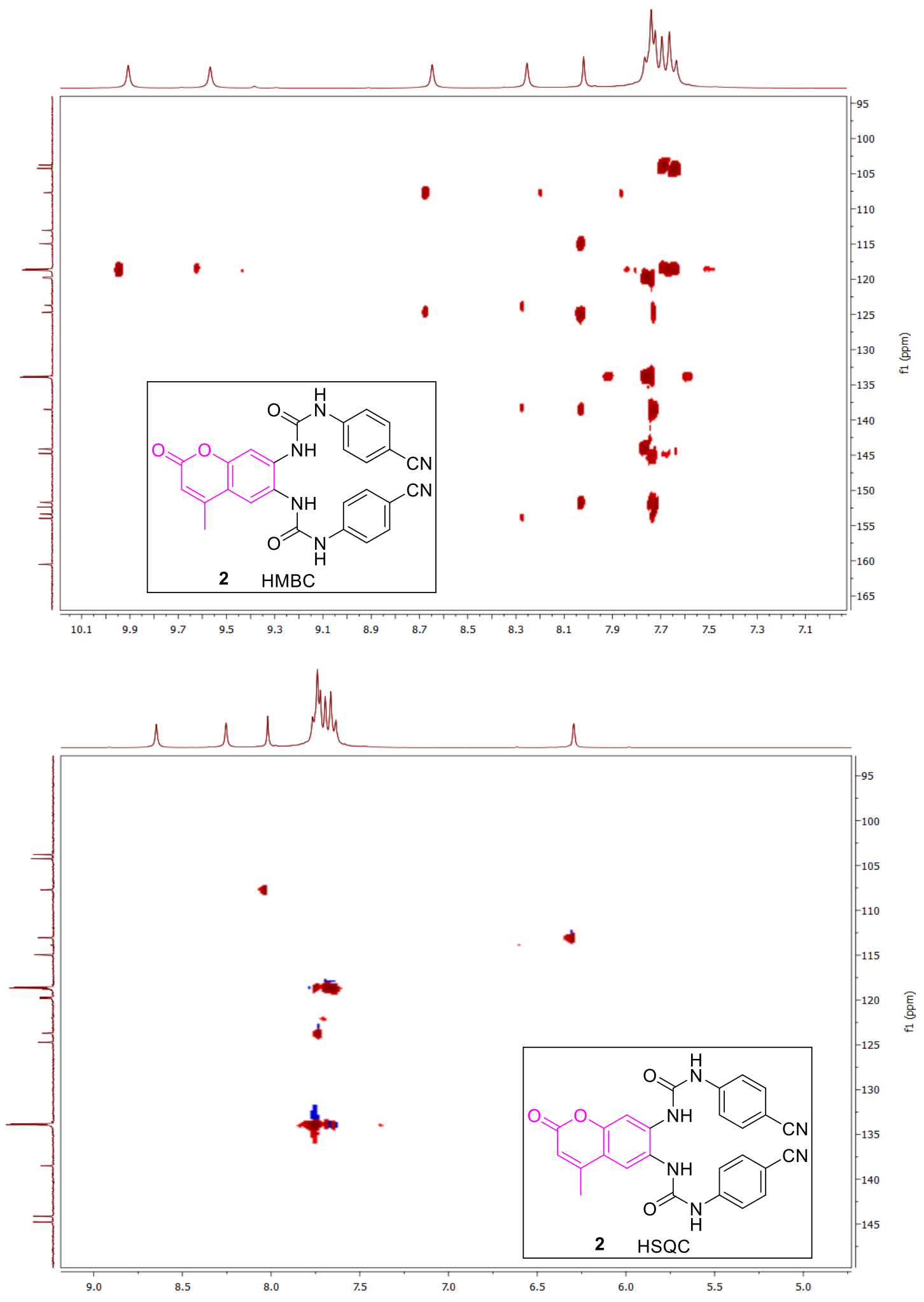
Figure S7: 1,1'-(4-methyl-2-oxo-2H-chromene-6,7-diyl)bis(3-(4-(trifluoromethyl)phenyl)urea) (3)
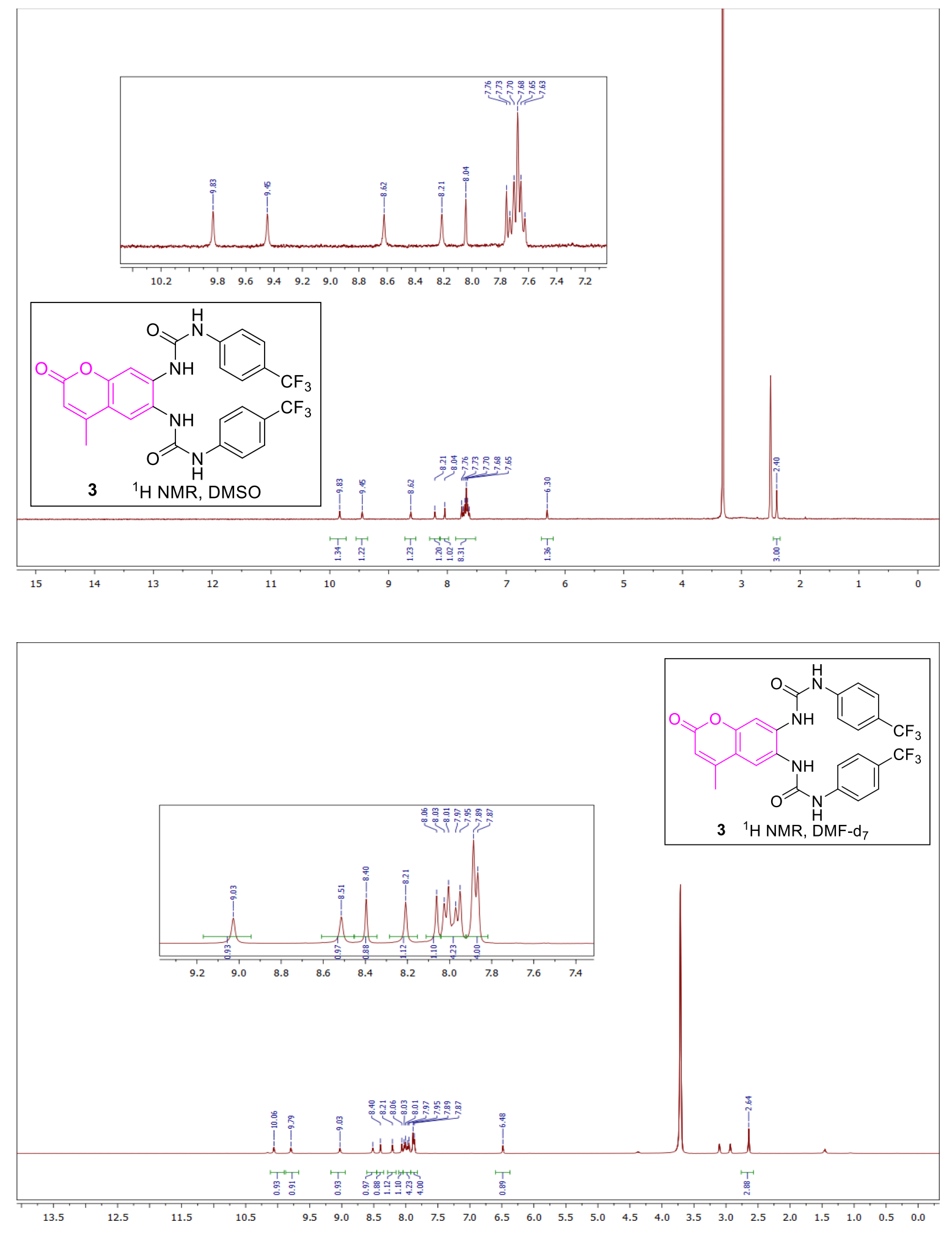

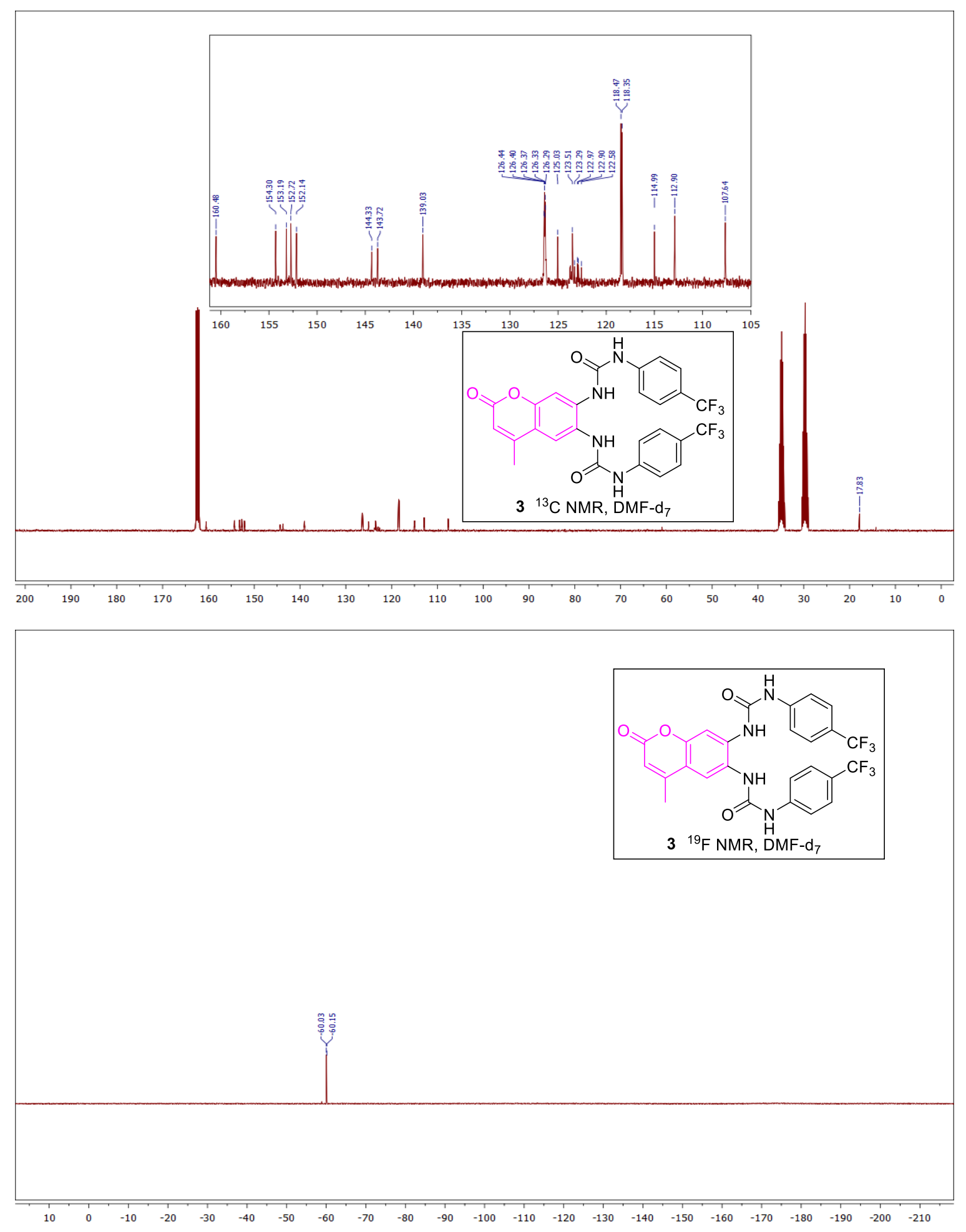
Figure S8: 1,1'-(4-methyl-2-oxo-2H-chromene-6,7-diyl)bis(3-(3,5-bis(trifluoromethyl)phenyl)urea) (4)
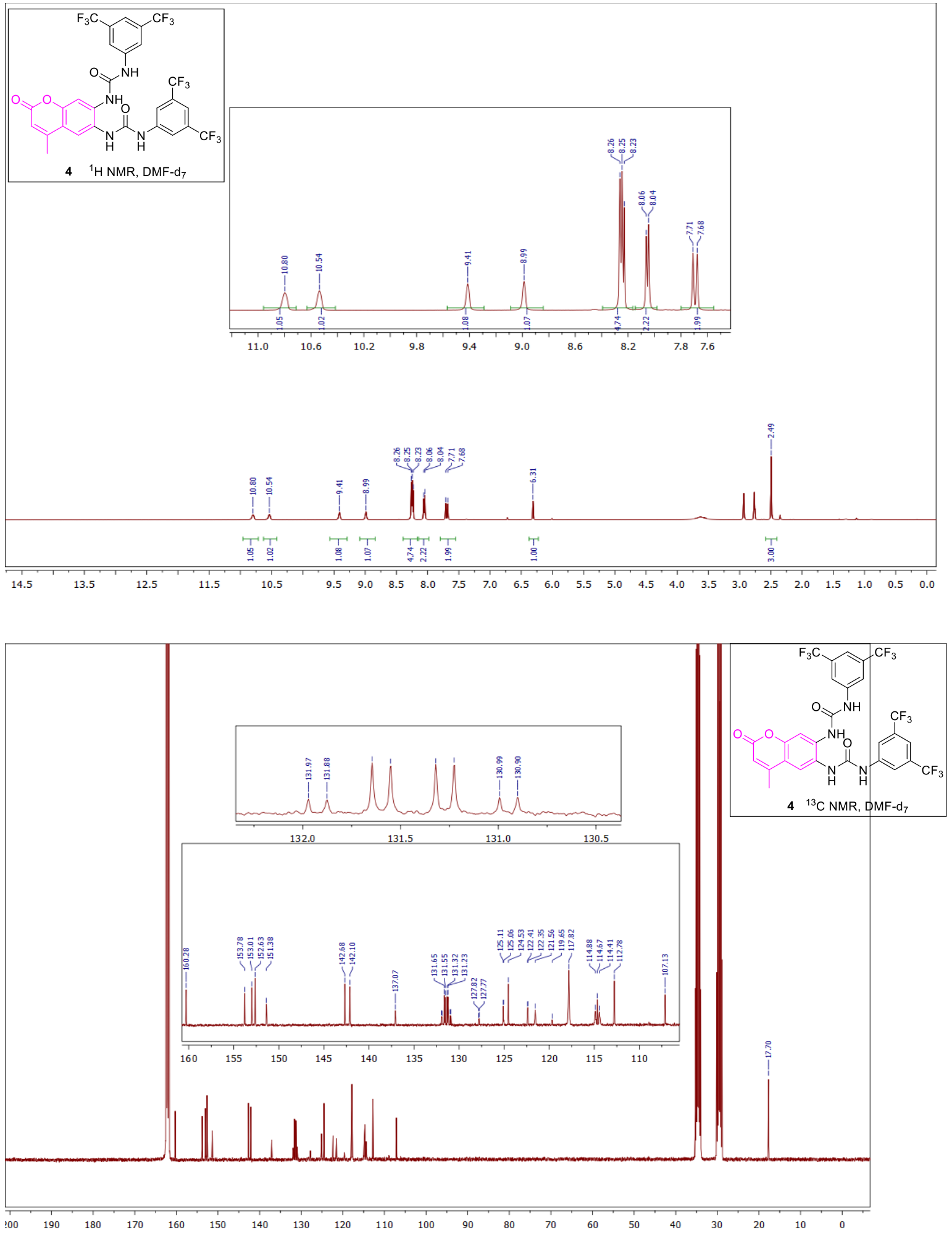


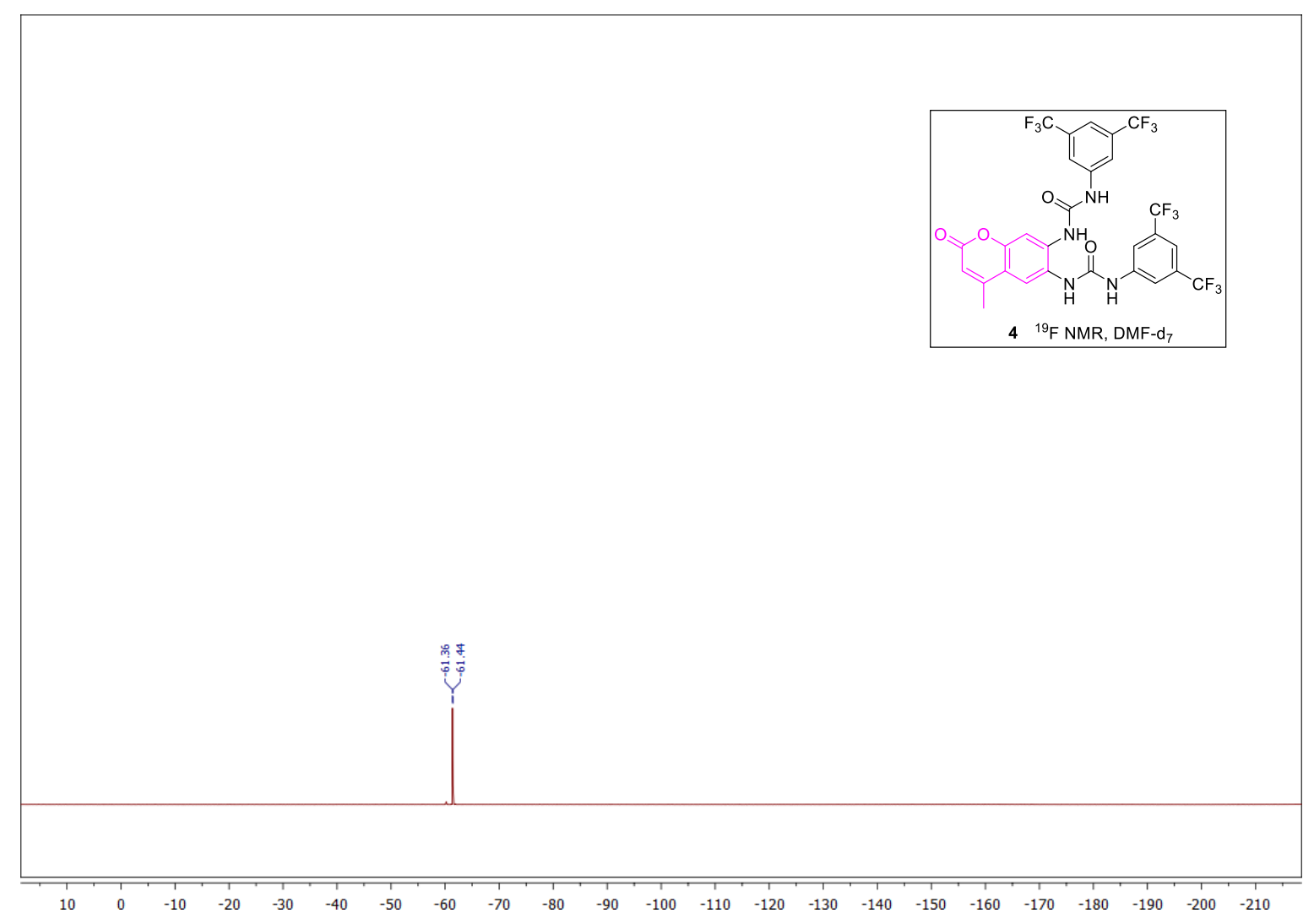




\section{S4. X-ray Crystallography:}

S5.1. X-ray of complex 1

Single crystals of transporter $1 \mathrm{C}_{26} \mathrm{H}_{26} \mathrm{~N}_{4} \mathrm{O}_{5}$ were crystallised from a mixture of dimethylformamide and ethanol. A suitable crystal was selected and in Paratone on a micromount on a SuperNova, Dual, $\mathrm{Cu}$ at home/near, Atlas diffractometer. The crystal was kept at $100 \mathrm{~K}$ during data collection. Using Olex2 ${ }^{3}$, the structure was solved with the ShelXS ${ }^{4}$ structure solution program using Direct Methods and refined with the ShelXL ${ }^{5}$ refinement package using Least Squares minimization.

Crystal Data for $\mathrm{C}_{26} \mathrm{H}_{26} \mathrm{~N}_{4} \mathrm{O}_{5} \quad(M=474.51 \mathrm{~g} / \mathrm{mol})$ : monoclinic, space group P2/c (no. 13), $a=$ 28.2772(10) $\AA, b=11.1135(9) \AA, c=7.9823(3) \AA, \beta=90.234(4)^{\circ}, V=2508.5(2) \AA^{3}, Z=4, T=$ $100(2) \mathrm{K}, \mu(\mathrm{Cu} \mathrm{K \alpha})=0.728 \mathrm{~mm}^{-1}$, Dcalc $=1.256 \mathrm{~g} / \mathrm{cm}^{3}, 19257$ reflections measured $\left(7.956^{\circ} \leq 2 \Theta\right.$ $\left.\leq 145.31^{\circ}\right), 4894$ unique $\left(R_{\text {int }}=0.0918, R_{\text {sigma }}=0.0957\right)$ which were used in all calculations. The final $R_{1}$ was $0.0661(\mathrm{I}>2 \sigma(\mathrm{I}))$ and $w R_{2}$ was 0.2088 (all data).

Figure S9: Packing diagram viewed down the $b$ axis showing intermolecular hydrogen-bonding interactions (green dots). All hydrogens in the packing diagram have been omitted for clarity, except those involved in hydrogen bonding interactions.

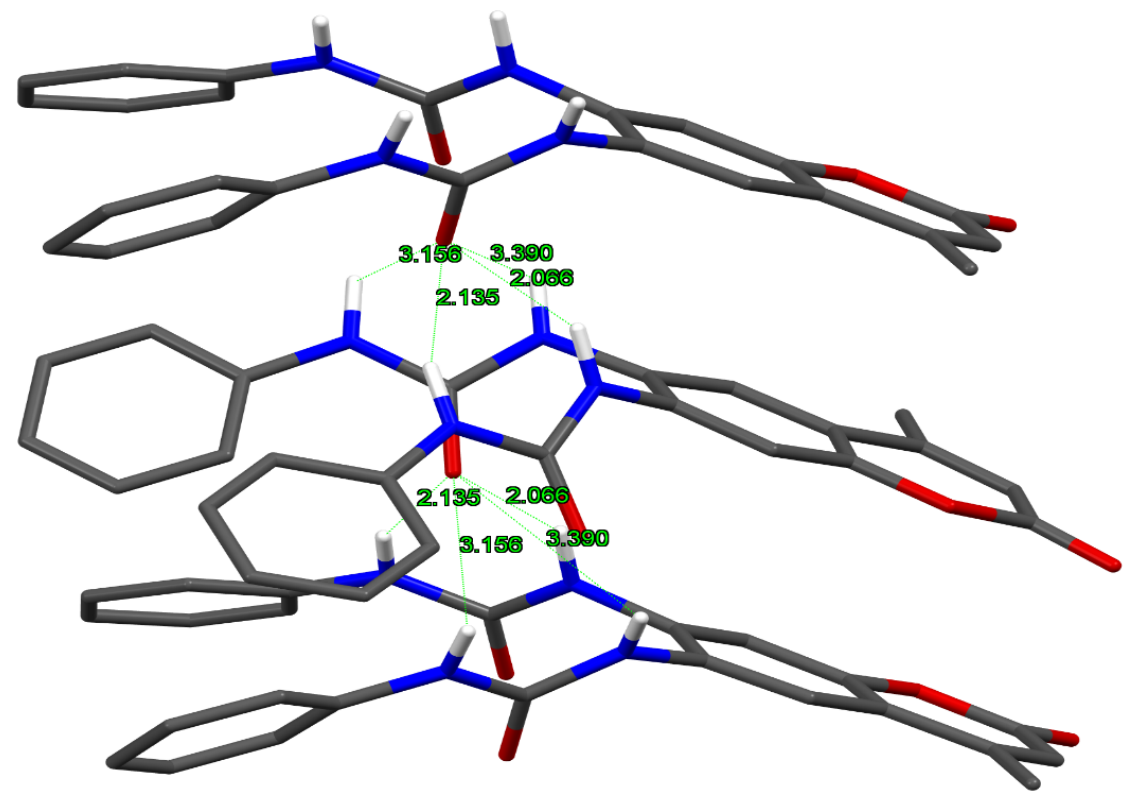


Figure S10: Packing diagram showing intermolecular electrostatic attraction (cyan dots) or receptor 1.
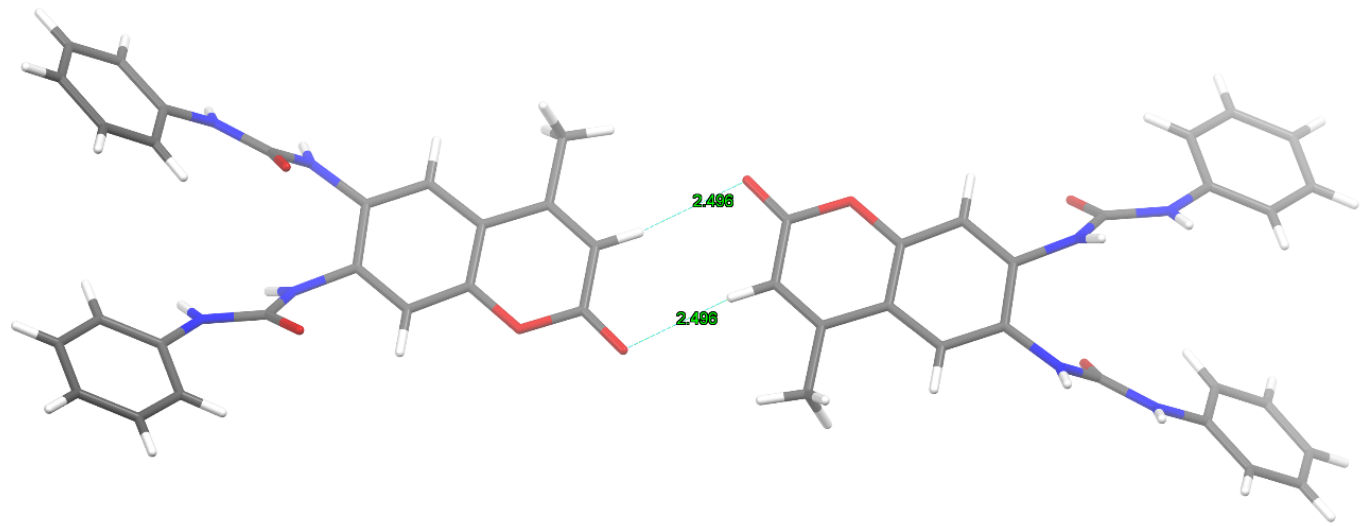


\section{S5. ${ }^{1} \mathrm{H}$ NMR Titration Binding Studies with TBACI}

Proton NMR titrations binding studies were performed on Bruker $400 \mathrm{MHz}$ FT-NMR spectrometer at $298 \mathrm{~K}$. Solution of receptors 1-4 in DMSO- $d_{6} / 0.5 \% \mathrm{H}_{2} \mathrm{O}$ were prepared in $2 \mathrm{mM}$ concentrations. The guest anion, tetra- $n$-butylammonium (TBA) chloride, was prepared with the same receptor solution, to ensure the overall receptor concentration stays constant whilst the guest anion concentration changes. Using small aliquots of the guest salt, the receptor solution was titrated, and after each addition, chemical shifts were reported in ppm in refence to residual solvent peaks. The isotherm based on the four $\mathrm{NH}$ chemical shifts were globally fitted using the online fitting program Bindfit. ${ }^{6}$ 

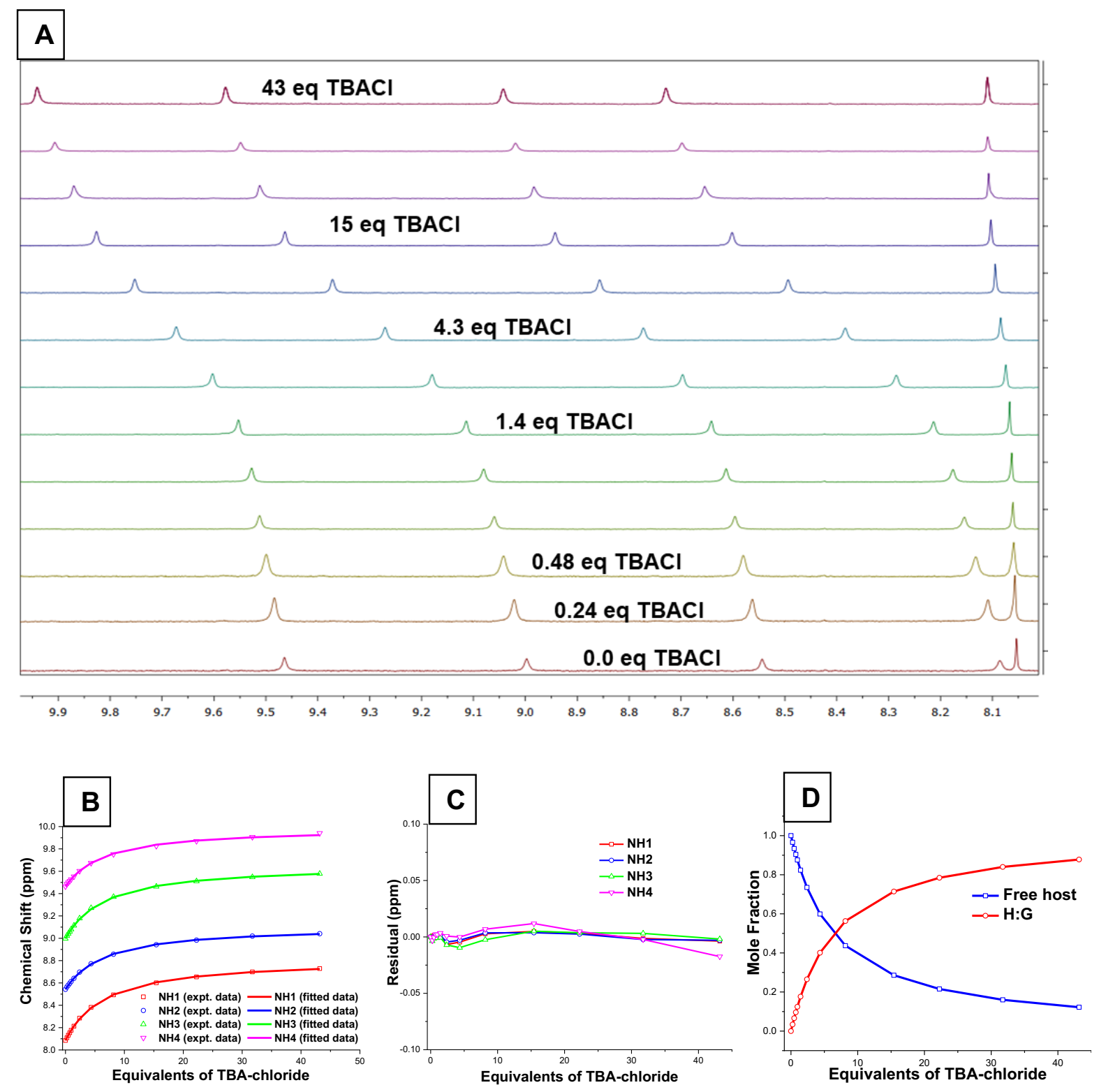

Figure S11: ${ }^{1} \mathrm{H}$ NMR spectroscopic titration of receptor $1(2 \mathrm{Mm})$ with TBACl in DMSO- $d_{6}$ with $0.5 \%$ water at $298 \mathrm{~K}$. (a) Stack plot. (b) Fitplot for $4 \mathrm{NH}$ protons at $\delta=8.09,8.54,9.00$ and $9.46 \mathrm{ppm}$ using global analysis with 1:1 $\left(\mathrm{K}_{\mathrm{a}}=81 \mathrm{M}^{-1}\right.$, error: $\left.1 \%\right)$. (c) Plot of the residuals for using global analysis. (d) Calculated mole fractions. 

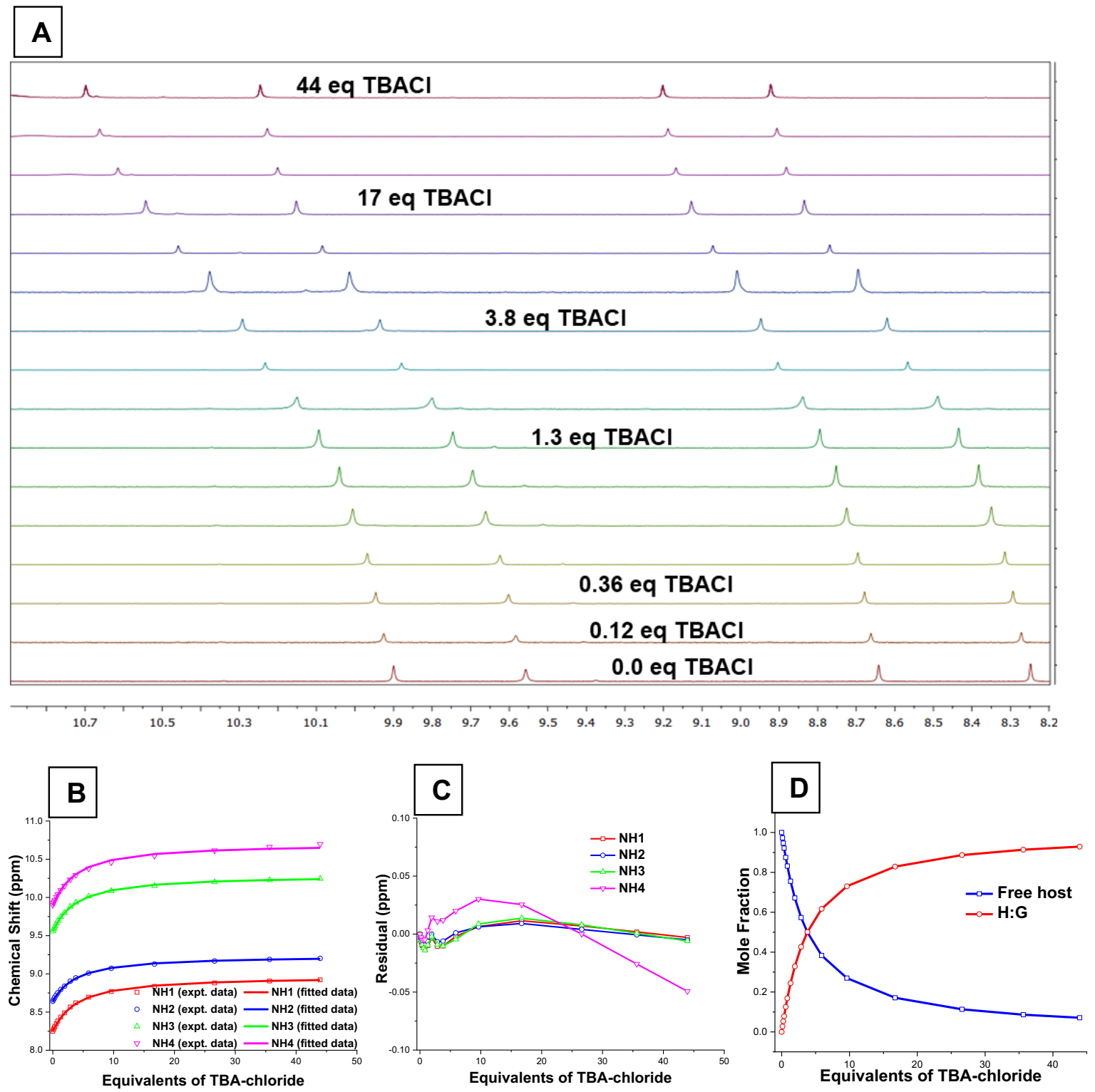

Figure S12: ${ }^{1} \mathrm{H}$ NMR spectroscopic titration of receptor $2(2 \mathrm{Mm})$ with TBACl in DMSO-d6 with $0.5 \%$ water at $298 \mathrm{~K}$. (a) Stack plot. (b) Fitplot for $4 \mathrm{NH}$ protons at $\delta=8.25,8.64,9.56$ and $9.90 \mathrm{ppm}$ using global analysis with 1:1 $\left(\mathrm{K}_{\mathrm{a}}=146 \mathrm{M}^{-1}\right.$, error: $\left.3 \%\right)$. (c) Plot of the residuals for using global analysis. (d) Calculated mole fractions. 

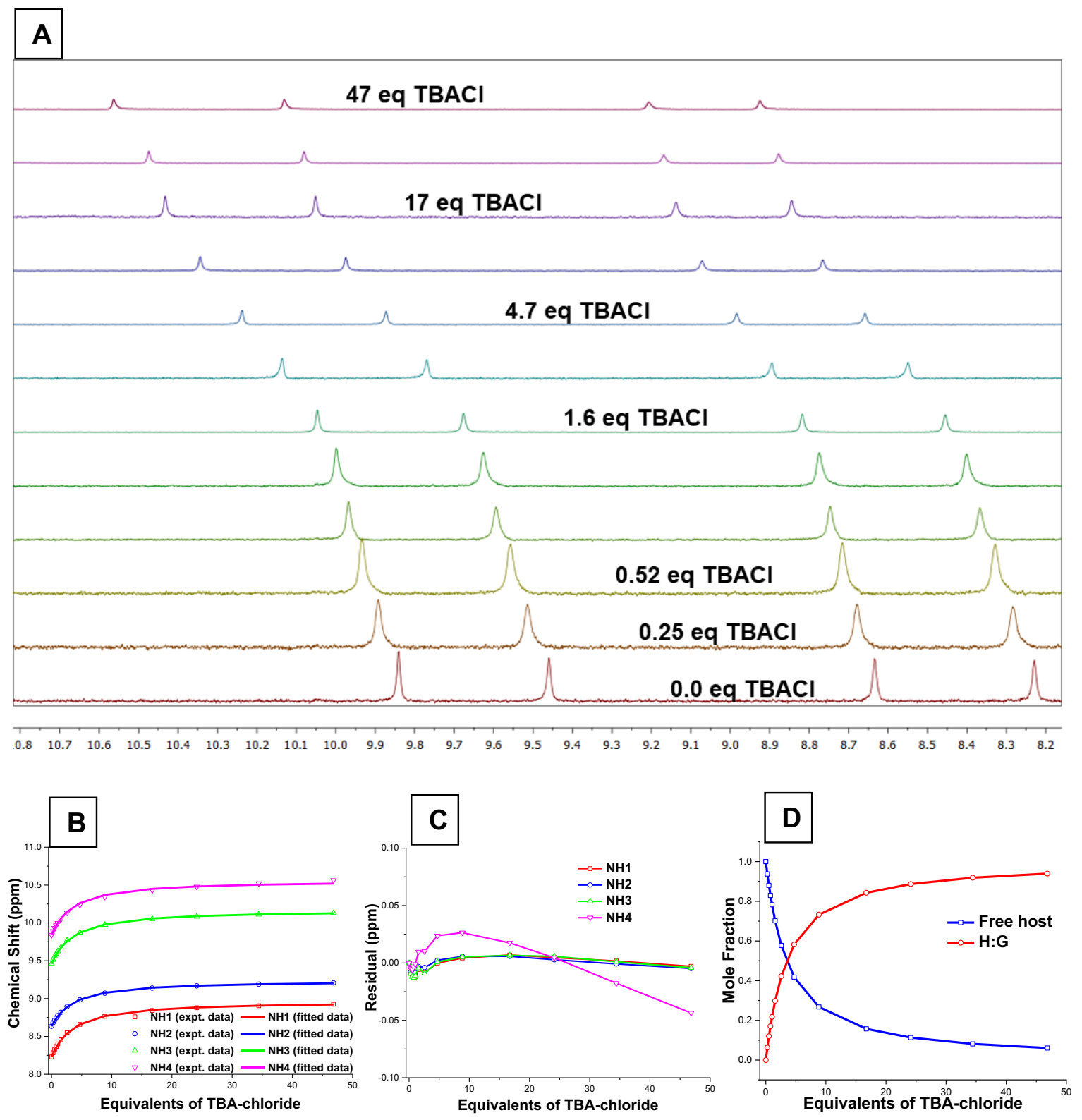

Figure S13: ${ }^{1} \mathrm{H}$ NMR spectroscopic titration of receptor $3(2 \mathrm{Mm})$ with TBACl in DMSO- $d_{6}$ with $0.5 \%$ water at $298 \mathrm{~K}$. (a) Stack plot. (b) Fitplot for $4 \mathrm{NH}$ protons at $\delta=8.23,8.63,9.46$ and $9.84 \mathrm{ppm}$ using global analysis with 1:1 ( $\mathrm{K}_{\mathrm{a}}=177 \mathrm{M}^{-1}$, error: $3 \%$ ). (c) Plot of the residuals for using global analysis. (d) Calculated mole fractions. 

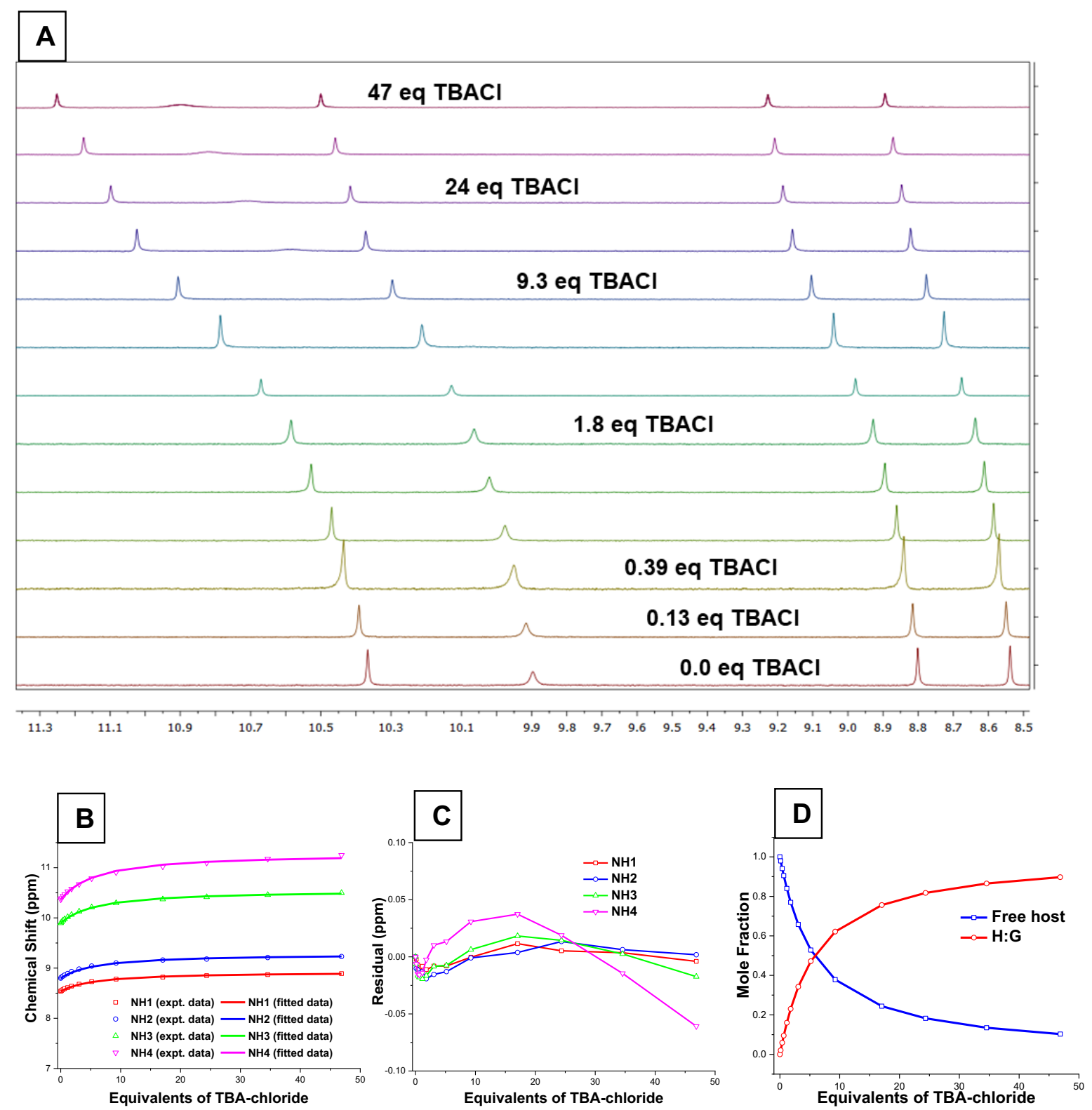

Figure S14: ${ }^{1} \mathrm{H}$ NMR spectroscopic titration of receptor $4(2 \mathrm{Mm})$ with TBACl in DMSO-d 6 with $0.5 \%$ water at $298 \mathrm{~K}$. (a) Stack plot. (b) Fitplot for $4 \mathrm{NH}$ protons at $\delta=8.54,8.80,9.90$ and 10.37 ppm using global analysis with $1: 1\left(\mathrm{~K}_{\mathrm{a}}=96 \mathrm{M}^{-1}\right.$, error: $\left.5 \%\right)$. (c) Plot of the residuals for using global analysis. (d) Calculated mole fractions. 


\section{S6. Anion Transport Studies}

S6.1: Ion selective electrode (ISE) assays:

a- $\mathrm{Cl} / \mathrm{NO}_{3}$ exchange assay:

Unilamellar vesicles were prepared as reported. ${ }^{7-9}$ Briefly, $\sim 30 \mathrm{mg}$ of POPC (1-palmitoyl2-oleoylphosphatidylcholine) was dissolved in $1 \mathrm{~mL}$ chloroform in a round-bottomed flask and the solvent was removed in vacuo to form a thin lipid layer. The thin film was dried under high vacuum for at least $6 \mathrm{~h}$ and was suspended on the internal solution $(4 \mathrm{~mL})$ and vortexed using a lab dancer to form large multilamellar vesicles, which was subjected to nine freeze-thaw cycles alternating between water (at room temperature) and liquid nitrogen. Further, the formed lipid was left to rest for 30 minutes and then subjected to extrusion through a $200 \mathrm{~nm}$ polycarbonate membranes 25 times to form the unilamellar vesicles. The formed vesicles were subjected to dialysis for $4 \mathrm{~h}$ in the desired external solution to remove any unencapsulated internal salts. Finally, using the required external solution, the lipid was diluted to $1.0 \mathrm{mM}$. The $\mathrm{pH}$ of the internal and external solutions was maintained at 7.2 using phosphate buffer with a $500 \mathrm{mM}$ total ionic strength. Test compound in DMSO $(10 \mu \mathrm{L})$ was added to start the experiment and chloride selective electrode was used to monitor the chloride efflux. Detergent $(50 \mu \mathrm{L})$ was added after 300 seconds to lyse the vesicles, while the $100 \%$ chloride efflux reading was taken at 420 seconds.

- Hill plots for $\mathrm{Cl} / \mathrm{NO}_{3}$ :

Hill plots were performed for $\mathrm{Cl} / \mathrm{NO}_{3}$ exchange assay by conducting transport assay at different concentrations of tested compounds. Receptor concentration vs chloride efflux at $270 \mathrm{~s}$ (the endpoint of transport assay) were plotted and fitted to the Hill equation using Origin 2019b:

$$
y=V_{\max } \frac{x^{n}}{k^{n}+x^{n}}=100 \% \frac{x^{n}}{\left(E C_{50}\right)^{n}+x^{n}}
$$

Where $y$ is the chloride efflux at $270 \mathrm{~s}(\%)$ and $\mathrm{x}$ is the tested compound concentration (mol\% relative to lipid concentration) 
$V_{\max }$ is the maximum efflux possible and considered as $100 \%$ as this is experimentally the maximum chloride efflux possible.

$k\left(\mathrm{EC}_{50}\right.$ value $)$ is the carrier concentration needed to reach $\mathrm{V}_{\max } / 2$.

Each data point on each Hill plot are an average of at least two repeated runs. Error bars represent standard deviation about the mean.

b- $\mathrm{KCl}$ efflux - cationohore coupling:

In this assay, $300 \mathrm{mM}$ total ionic strength of both $\mathrm{K}$ gluconate external solution and $\mathrm{KCl}$ internal solution were marinated. The vesicles were made in a similar way to $\mathrm{Cl} / \mathrm{NO}_{3}$ exchange assay except that gel filtration, using sephadex, replaced dialysis to allow exchange of any unencapsulated $\mathrm{KCl}$ for KGlu. External KGlu solution (10 mL) was used to dilute the lipid solution obtained after sephadex to obtain a lipid stock of known concentration. A cationohore, monensin or valinomycin, $(10 \mu \mathrm{L}, 0.5 \mathrm{mM})$ was added first to the lipid solution at concentration $0.1 \mathrm{~mol} \%$ with respect to lipid concentration. Then, receptor was added after 30 seconds of the cationohore addition to start the experiment. 

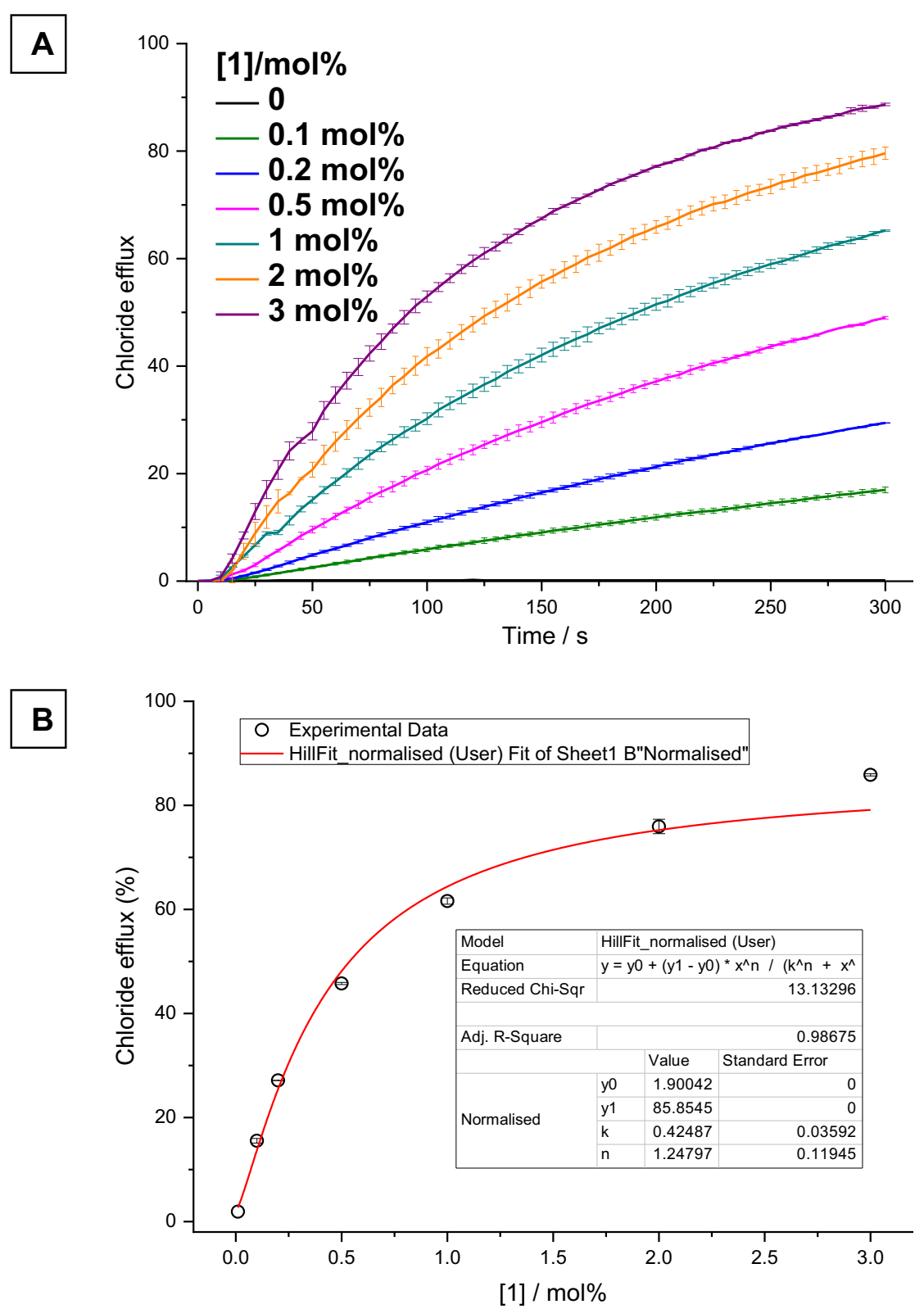

Figure S15: A-Dose response curve and B- Hill plot analysis of chloride efflux facilitated by compound 1 from unilamellar POPC vesicles that were loaded with a $489 \mathrm{mM} \mathrm{KCl}$ solution buffered to $\mathrm{pH} 7.2$ with $5 \mathrm{mM}$ phosphate, and were suspended in a $489 \mathrm{mM} \mathrm{KNO}_{3}$ solution buffered to $\mathrm{pH} 7.2$ with $5 \mathrm{mM}$ phosphate salts. DMSO was used as a control. Each point is the average of at least two repeats. 


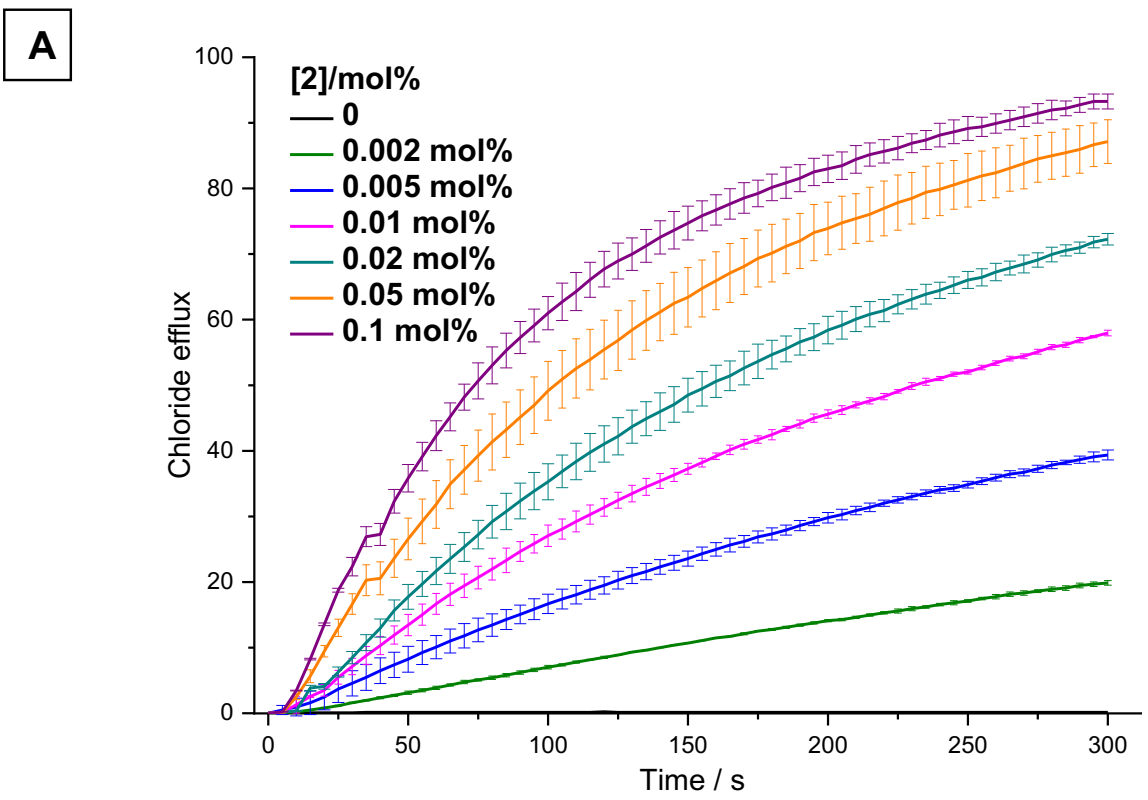

B

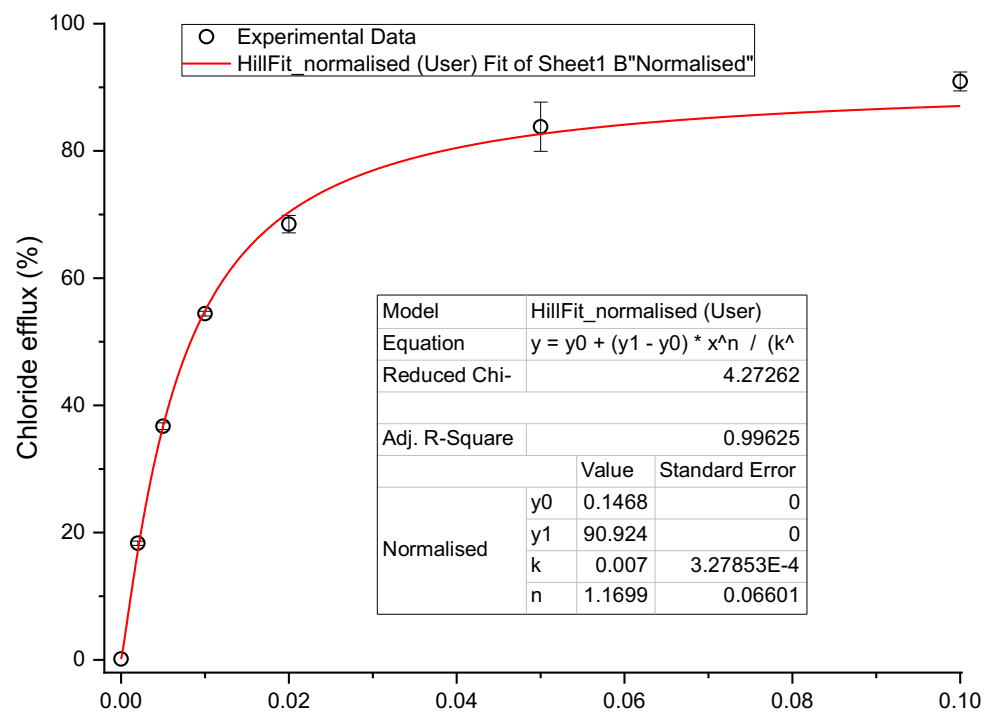

[2] / $\mathrm{mol} \%$

Figure S16: A-Dose response curve and B- Hill plot analysis of chloride efflux facilitated by compound 2 from unilamellar POPC vesicles that were loaded with a $489 \mathrm{mM} \mathrm{KCl}$ solution buffered to $\mathrm{pH} 7.2$ with $5 \mathrm{mM}$ phosphate, and were suspended in a $489 \mathrm{mM} \mathrm{KNO}_{3}$ solution buffered to $\mathrm{pH} 7.2$ with $5 \mathrm{mM}$ phosphate salts. DMSO was used as a control. Each point is the average of at least two repeats. 


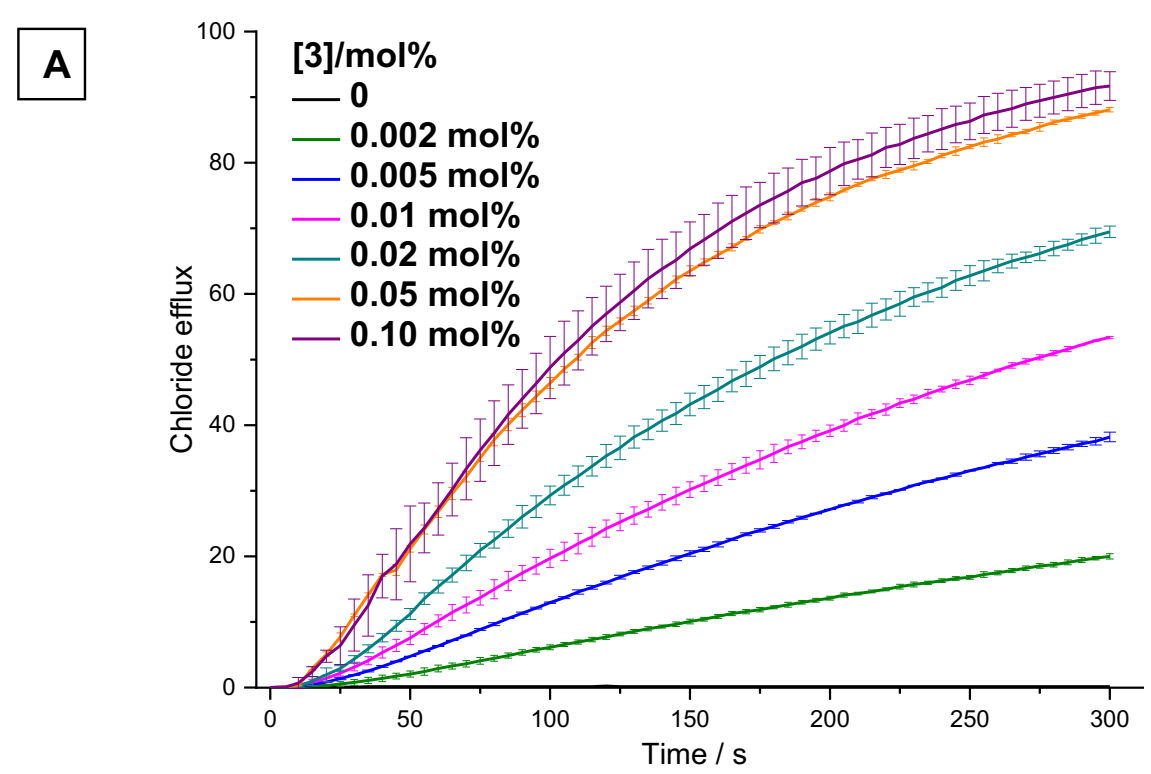

B

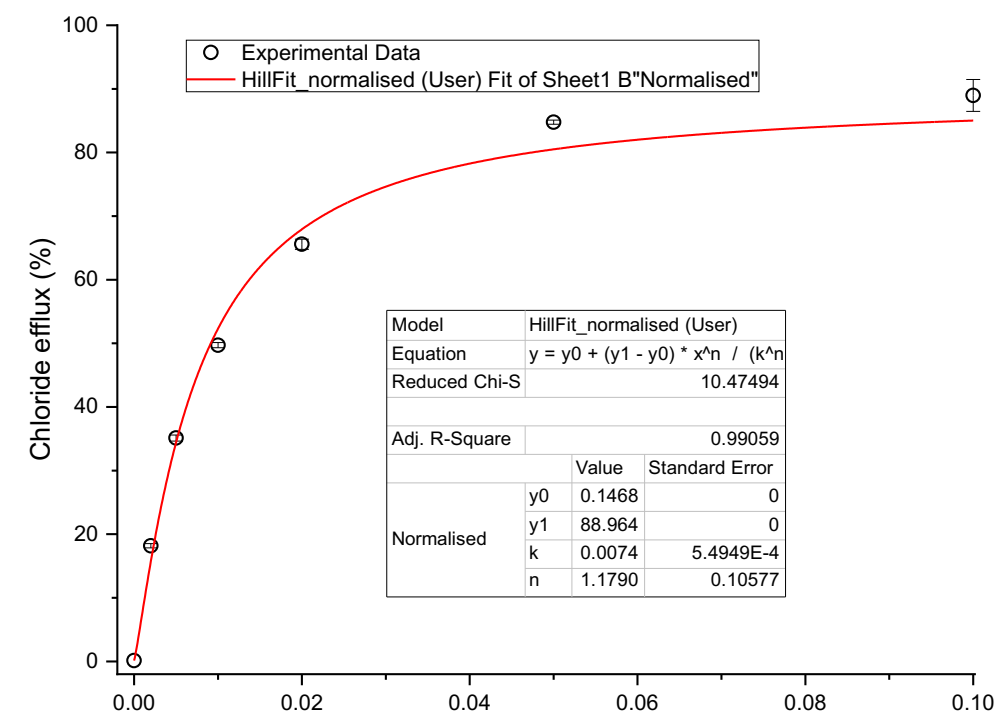

[3] / $\mathrm{mol} \%$

Figure S17: A-Dose response curve and B- Hill plot analysis of chloride efflux facilitated by compound 3 from unilamellar POPC vesicles that were loaded with a $489 \mathrm{mM} \mathrm{KCl}$ solution buffered to $\mathrm{pH} 7.2$ with $5 \mathrm{mM}$ phosphate, and were suspended in a $489 \mathrm{mM} \mathrm{KNO}_{3}$ solution buffered to $\mathrm{pH} 7.2$ with $5 \mathrm{mM}$ phosphate salts. DMSO was used as a control. Each point is the average of at least two repeats. 


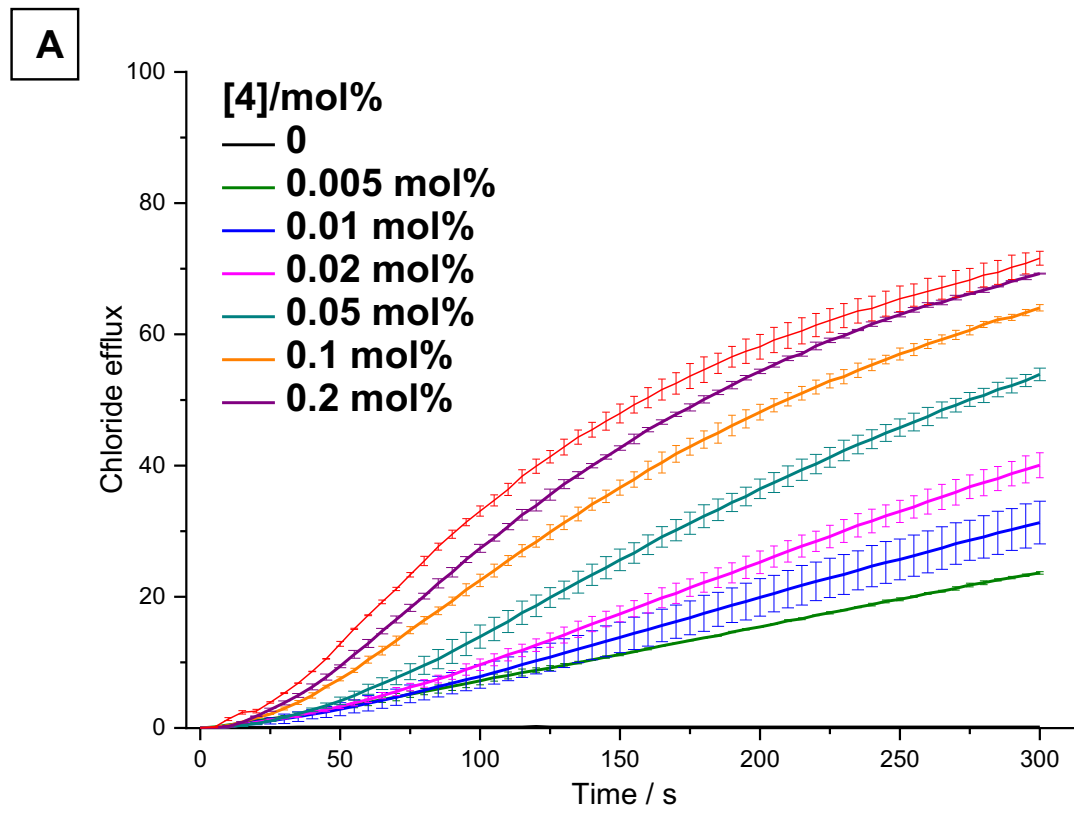

B

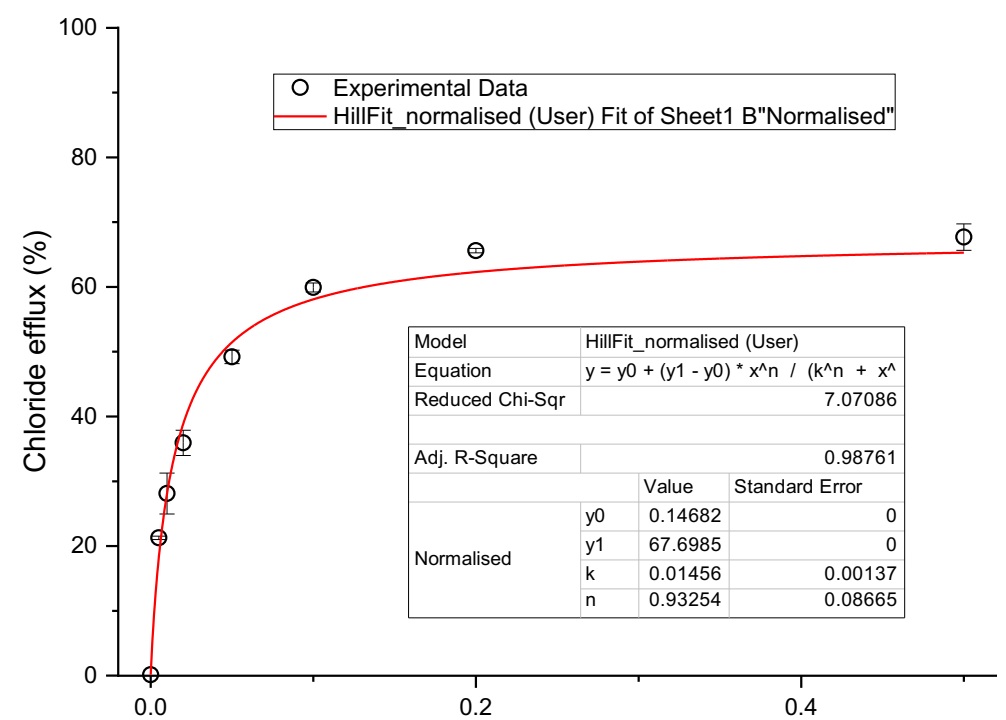

$[4] / \mathrm{mol} \%$

Figure S18: A-Dose response curve and B- Hill plot analysis of chloride efflux facilitated by compound 4 from unilamellar POPC vesicles that were loaded with a $489 \mathrm{mM} \mathrm{KCl}$ solution buffered to $\mathrm{pH} 7.2$ with $5 \mathrm{mM}$ phosphate, and were suspended in a $489 \mathrm{mM} \mathrm{KNO}_{3}$ solution buffered to $\mathrm{pH} 7.2$ with $5 \mathrm{mM}$ phosphate salts. DMSO was used as a control. Each point is the average of at least two repeats. 


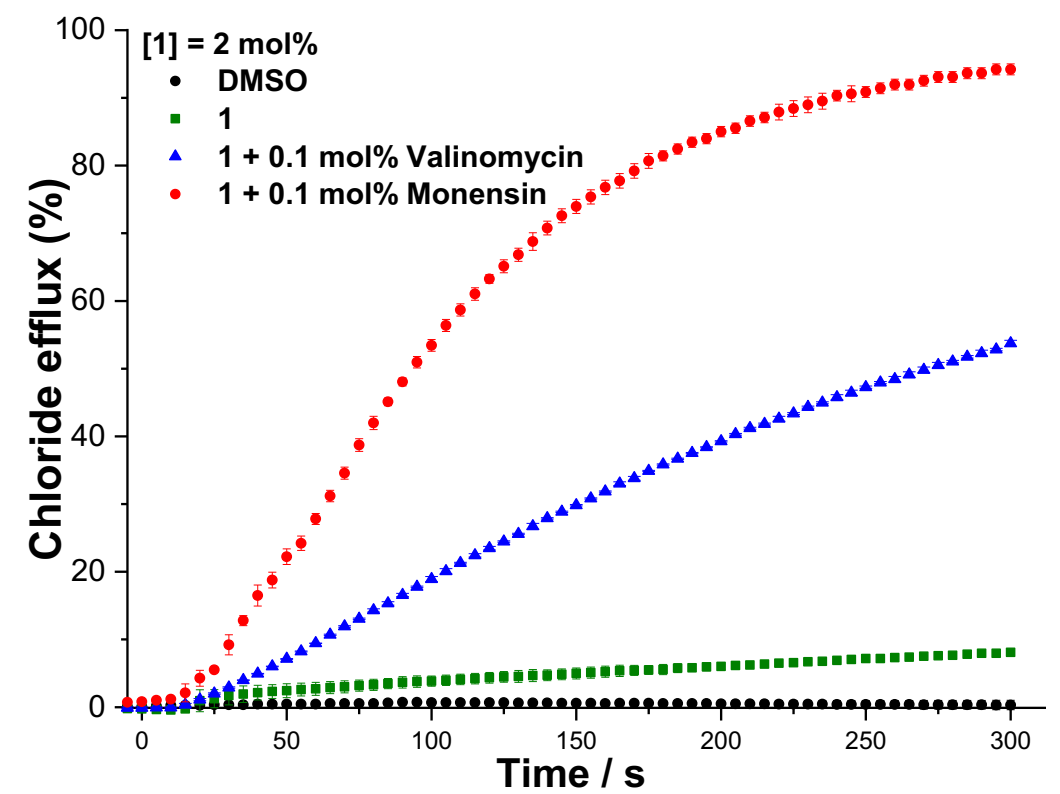

Figure S19: Electrogenic or electroneutral transport mediated by compound 1 ( $2 \mathrm{~mol} \%$ with respect to lipid) in the presence of monensin or valinomycin $(0.1 \mathrm{~mol} \%$ with respect to lipid). Unilamellar POPC vesicles were loaded with a $300 \mathrm{mM} \mathrm{KCl}$ solution buffered to $\mathrm{pH} 7.2$ with $5 \mathrm{mM}$ phosphate and were suspended in a $300 \mathrm{mM} \mathrm{KGlu}$ solution buffered to $\mathrm{pH} 7.2$ with $5 \mathrm{mM}$ phosphate salts. DMSO was used as a control. Each point is the average of at least two repeats.

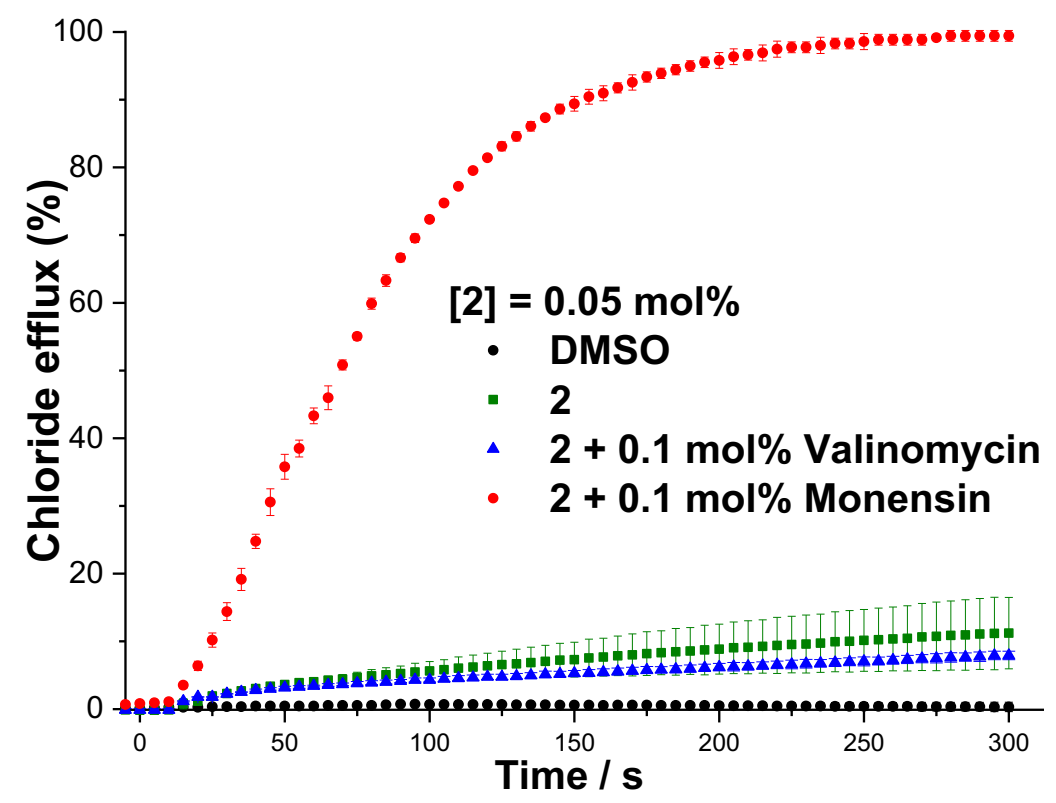

Figure S20: Electrogenic or electroneutral transport mediated by compound $2(0.05 \mathrm{~mol} \%$ with respect to lipid) in the presence of monensin or valinomycin $(0.1 \mathrm{~mol} \%$ with respect to lipid). Unilamellar POPC vesicles were loaded with a $300 \mathrm{mM} \mathrm{KCl}$ solution buffered to $\mathrm{pH} 7.2$ with $5 \mathrm{mM}$ phosphate and were suspended in a $300 \mathrm{mM} \mathrm{KGlu}$ solution buffered to $\mathrm{pH} 7.2$ with $5 \mathrm{mM}$ phosphate salts. DMSO was used as a control. Each point is the average of at least two repeats. 


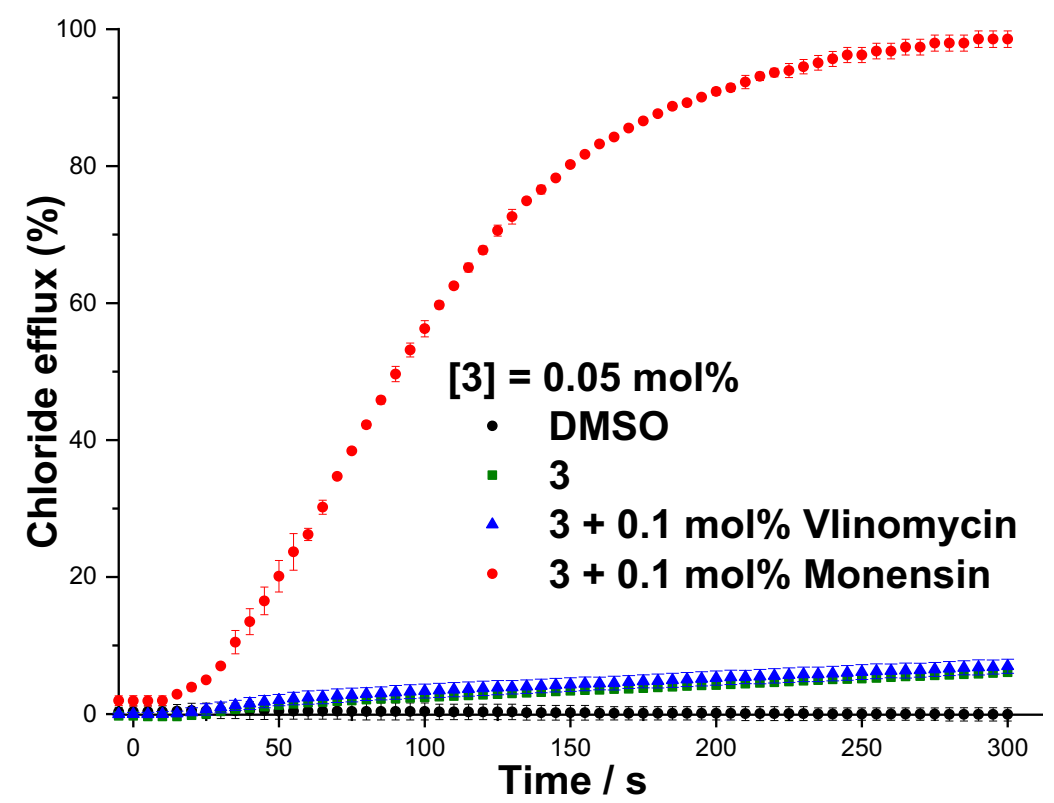

Figure S21: Electrogenic or electroneutral transport mediated by compound $\mathbf{3}(0.05 \mathrm{~mol} \%$ with respect to lipid) in the presence of monensin or valinomycin $(0.1 \mathrm{~mol} \%$ with respect to lipid). Unilamellar POPC vesicles were loaded with a $300 \mathrm{mM} \mathrm{KCl}$ solution buffered to $\mathrm{pH} 7.2$ with $5 \mathrm{mM}$ phosphate and were suspended in a $300 \mathrm{mM} \mathrm{KGlu}$ solution buffered to $\mathrm{pH} 7.2$ with $5 \mathrm{mM}$ phosphate salts. DMSO was used as a control. Each point is the average of at least two repeats.

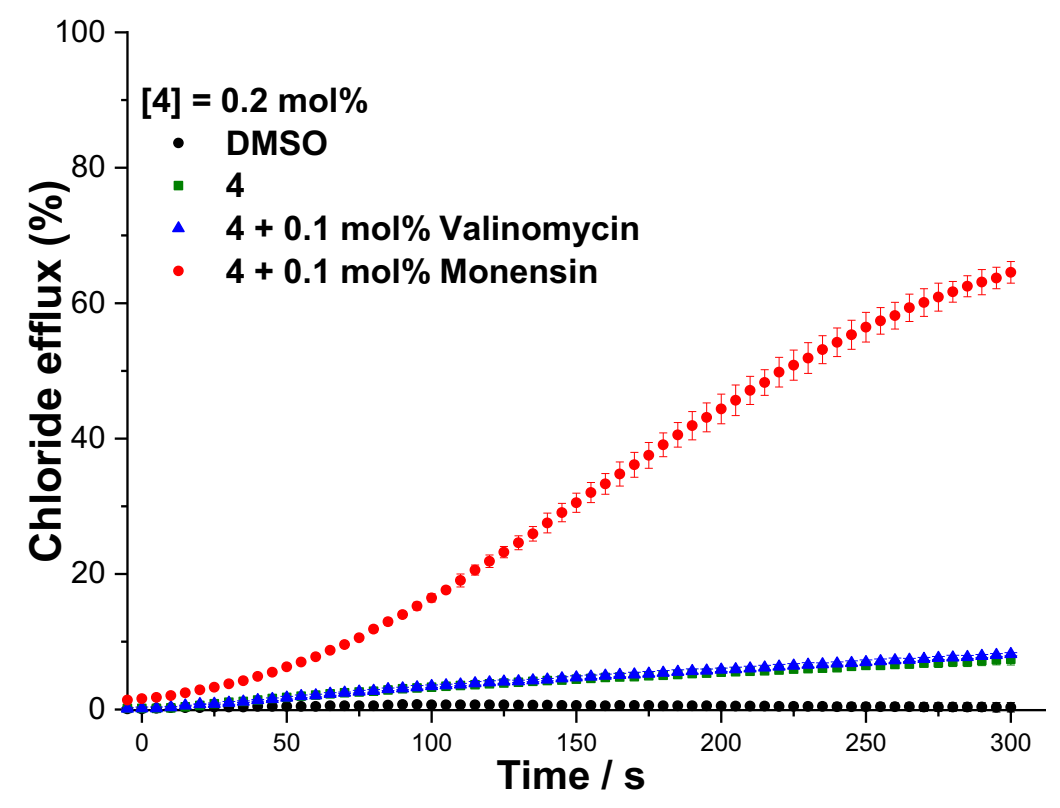

Figure S22: Electrogenic or electroneutral transport mediated by compound $4(0.2 \mathrm{~mol} \%$ with respect to lipid) in the presence of monensin or valinomycin $(0.1 \mathrm{~mol} \%$ with respect to lipid). Unilamellar POPC vesicles were loaded with a $300 \mathrm{mM} \mathrm{KCl}$ solution buffered to $\mathrm{pH} 7.2$ with $5 \mathrm{mM}$ phosphate and were suspended in a $300 \mathrm{mM} \mathrm{KGlu}$ solution buffered to $\mathrm{pH} 7.2$ with $5 \mathrm{mM}$ phosphate salts. DMSO was used as a control. Each point is the average of at least two repeats. 


\section{S6.2: General preparation for HPTS assays:}

Base-pulse 8-hydroxypyrene-1,3,6-trisulfonic acid trisodium salt (HPTS) assays were conducted using unilamellar 1-palmitoyl-2-oleoylphosphatidylcholine vesicles (POPC) with a mean diameter of $200 \mathrm{~nm}$ loaded with the $\mathrm{pH}$ sensitive fluorescence dye HPTS (1 $\mathrm{mM}){ }^{7-9}$ A chloroform solution of POPC ( $30 \mathrm{mg} / \mathrm{mL}$ ) was evaoprated under vacuum and dried for at least $6 \mathrm{~h}$. The thin film was hydrated by the internal solution containing HPTS ( $1 \mathrm{mM}$ ) and was was subjected to nine freeze-thaw cycles followed by extrusion 25 times through a $200 \mathrm{~nm}$ polycarbonate membrane. Size exclusion chromatography using sephadex G-25 column and HPTS-free external solution as an eluent was conducted to remove unentrapped HPTS from the vesicles' solution. The internal and external solutions used were identical salt solution potassium chloride $\mathrm{KCl}(100 \mathrm{mM})$ buffered with $10 \mathrm{mM}$ HEPES at $\mathrm{pH}$ 7.0. Finally, for each measurement, external solution $(\mathrm{KCl})$ was used to dilute the lipid tock to obtain $2.5 \mathrm{~mL}$ lipid suspension containing $0.1 \mathrm{mM}$ lipid. A base pulse of $\mathrm{KOH}(25 \mu \mathrm{L}, 0.5 \mathrm{M})$ at final concentration $5 \mathrm{mM}$ was added to generate a transmembrane $\mathrm{pH}$ gradient. After the tested receptors were added, HPTS fluorescence ratio $\left(\lambda_{\mathrm{ex}}=460 \mathrm{~nm}, \lambda_{\mathrm{em}}=510 \mathrm{~nm}\right.$ divided by $\left.\lambda_{\mathrm{ex}}=403 \mathrm{~nm}, \lambda_{\mathrm{em}}=510 \mathrm{~nm}\right)$ was recorded. Assisting ionophore (carbonyl cyanide phenylhydrazone (CCCP) or valinomycin) was used as a $5 \mu \mathrm{L}$ DMSO. Bovine serum albumins (BSA) was added to vesicles at $1 \mathrm{~mol} \%$ (with respect to lipid) and allowed to stir for 30 minutes to test if the transport is fatty acid independent, while, oleic acid ( $1 \mathrm{~mol} \%$ ) was used as a source of fatty acid to test if the transport is fatty acid dependent. Detergent $(25 \mu \mathrm{L})$ was added at 200 seconds to destroy the $\mathrm{pH}$ gradient to calibrate the assay.

Results are the average of at least three repeats and the fractional fluorescence intensity $\left(I_{f}\right)$ was determined using the following formula:

$$
I_{f}=\frac{R_{t}-R_{0}}{R_{d}-R_{0}}
$$

Where

- $R_{\mathrm{t}}$ is the fluorescence ratio at time $\mathrm{t}$. 
- $R_{0}$ is the fluorescence ratio at time 0

- $R_{\mathrm{d}}$ is the fluorescence ratio after detergent addition.

Hill plots were determined for $\mathrm{KCl}$ transport assay by conducting transport assays at different tested receptors concentrations. Receptor concentration vs fractional fluorescence intensity $I_{f}$ at $200 \mathrm{~s}$ (the endpoint of transport assay) were plotted and fitted to the Hill equation using Origin 2019b:

The following formula was used to calculate hill coefficients $(n)$ and $\mathrm{EC}_{50}(200 \mathrm{~s})$ values by fitting the curves to the following equation:

$$
y=y_{0}+\left(y_{\max }-y_{0}\right) \frac{x^{n}}{k^{n}+x^{n}}
$$

Where:

- $\quad y$ is $I_{f}(200 s)$ value of the ionophore at concentration $x$ (receptors concentration is expressed as ionophore to lipid molar ratio).

- $\quad y_{0}$ is $I_{f}$ value at $200 \mathrm{~s}$, without addition of the ionophore.

- $y_{\max }$ is the maximum If value.

- $\quad n$ is the Hill coefficient, and $K$ is the $\mathrm{EC}_{50}(200 \mathrm{~s})$ value. 
(a)
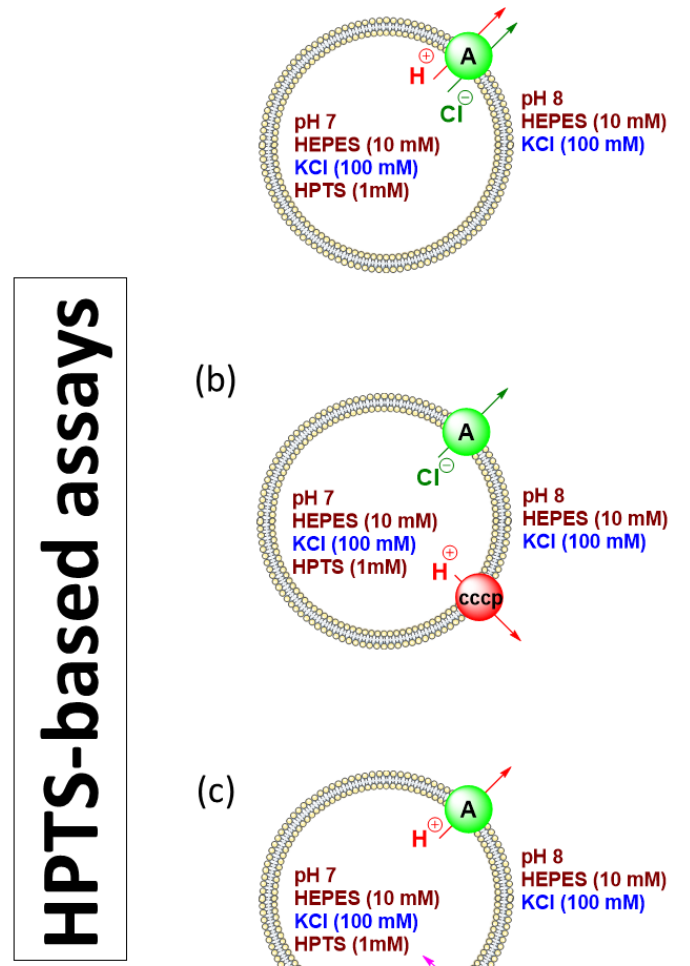

(b)

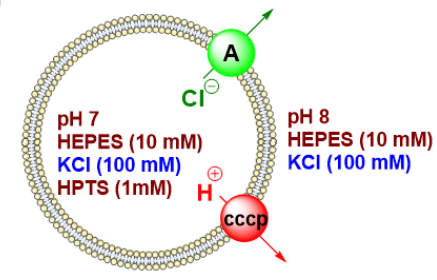

(c)

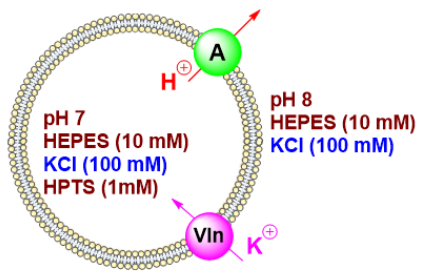

(d)

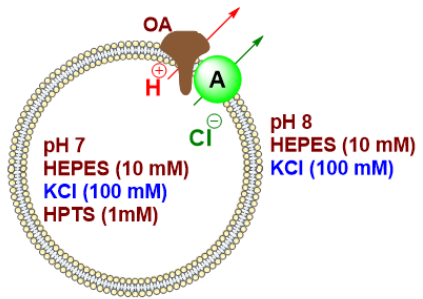

Figure S23: Schematic representation of the HPTS-based assays used in the current study (a) $\mathrm{H}^{+} / \mathrm{Cl}^{-}$symport or $\mathrm{OH}^{-} / \mathrm{Cl}^{-}$antiport (b) the presence of cccp (protonophore) to asses $\mathrm{Cl}^{-}$ uniport (c) the presence of valinomycin to measure the proton flux (d) the effect of fatty acid presence as a fuel on the transport. 

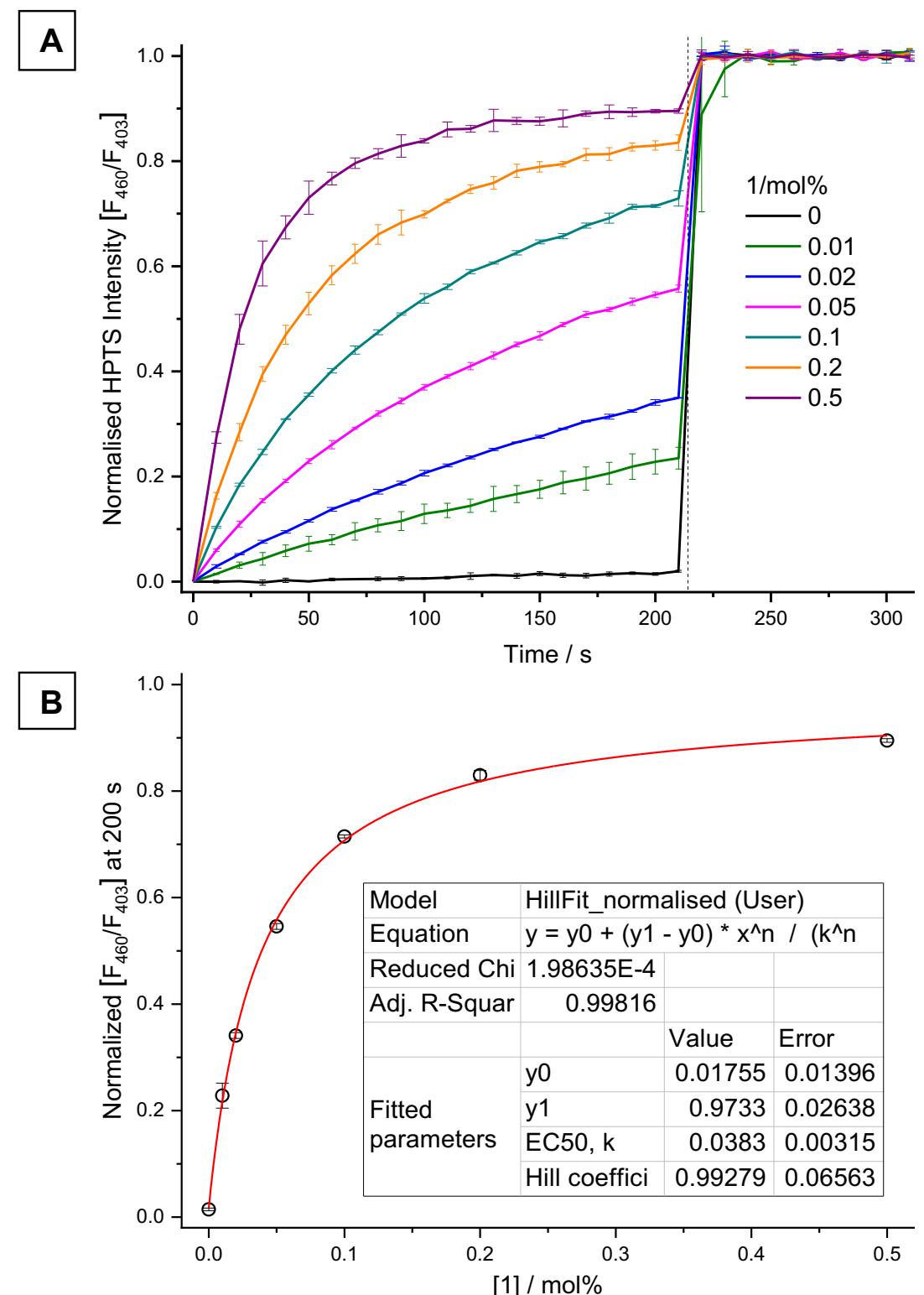

Figure S24: A-Dose response curve, B-Hill plot analysis of $\mathrm{H}^{+} / \mathrm{Cl}^{-}$symport or $\mathrm{Cl}^{-} / \mathrm{OH}^{-}$antiport facilitated by compound 1 using $\mathrm{KCl}-\mathrm{KOH}$ assay from POPC vesicles loaded with $\mathrm{KCl}(100 \mathrm{mM})$, buffered to $\mathrm{pH} 7.0$ with HEPES $(10 \mathrm{mM})$. The test compound was added at $0 \mathrm{~s}$ and detergent was added at $200 \mathrm{~s}$. lonophore concentrations are shown as ionophore to lipid molar ratios. Error bars represent SD from at least three repeats. 


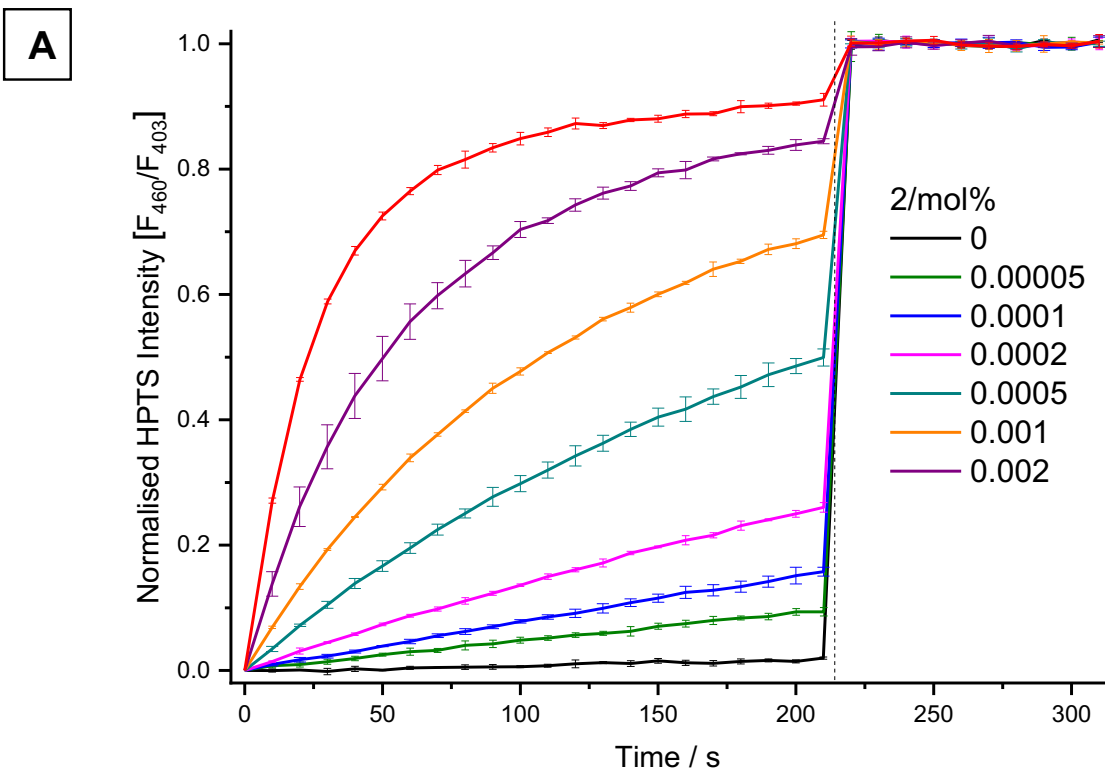

B

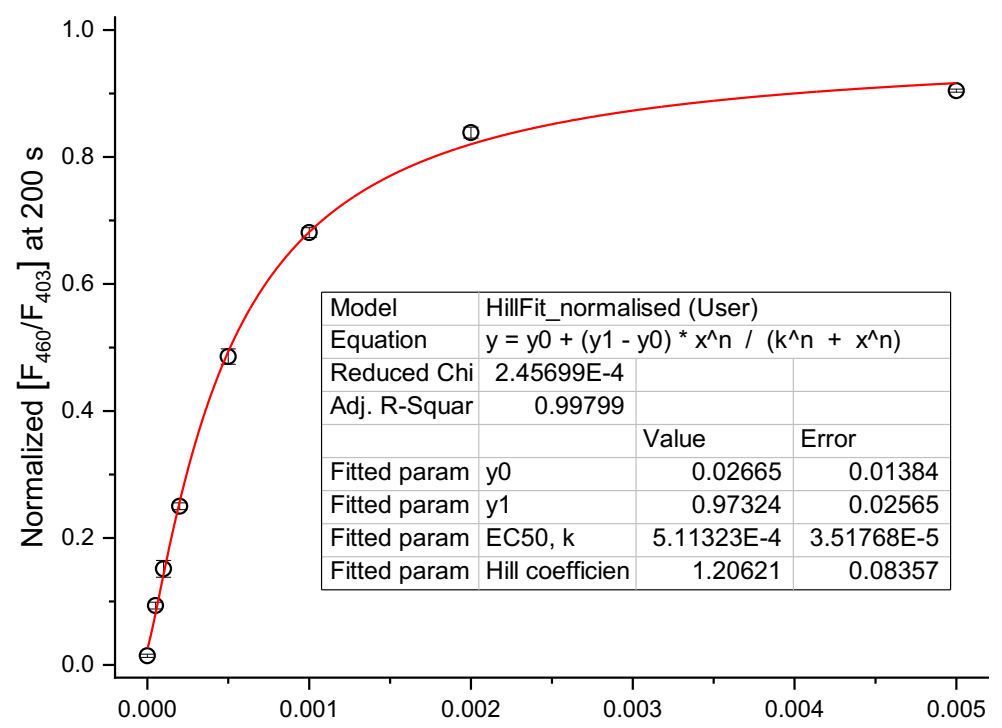

[2] $/ \mathrm{mol} \%$

Figure S25: A-Dose response curve, B-Hill plot analysis of $\mathrm{H}^{+} / \mathrm{Cl}^{-}$symport or $\mathrm{Cl} / \mathrm{OH}^{-}$antiport facilitated by compound 2 using $\mathrm{KCl}-\mathrm{KOH}$ assay from POPC vesicles loaded with $\mathrm{KCl}(100 \mathrm{mM})$, buffered to $\mathrm{pH} 7.0$ with HEPES $(10 \mathrm{mM})$. The test compound was added at $0 \mathrm{~s}$ and detergent was added at $200 \mathrm{~s}$. lonophore concentrations are shown as ionophore to lipid molar ratios. Error bars represent SD from at least three repeats. 

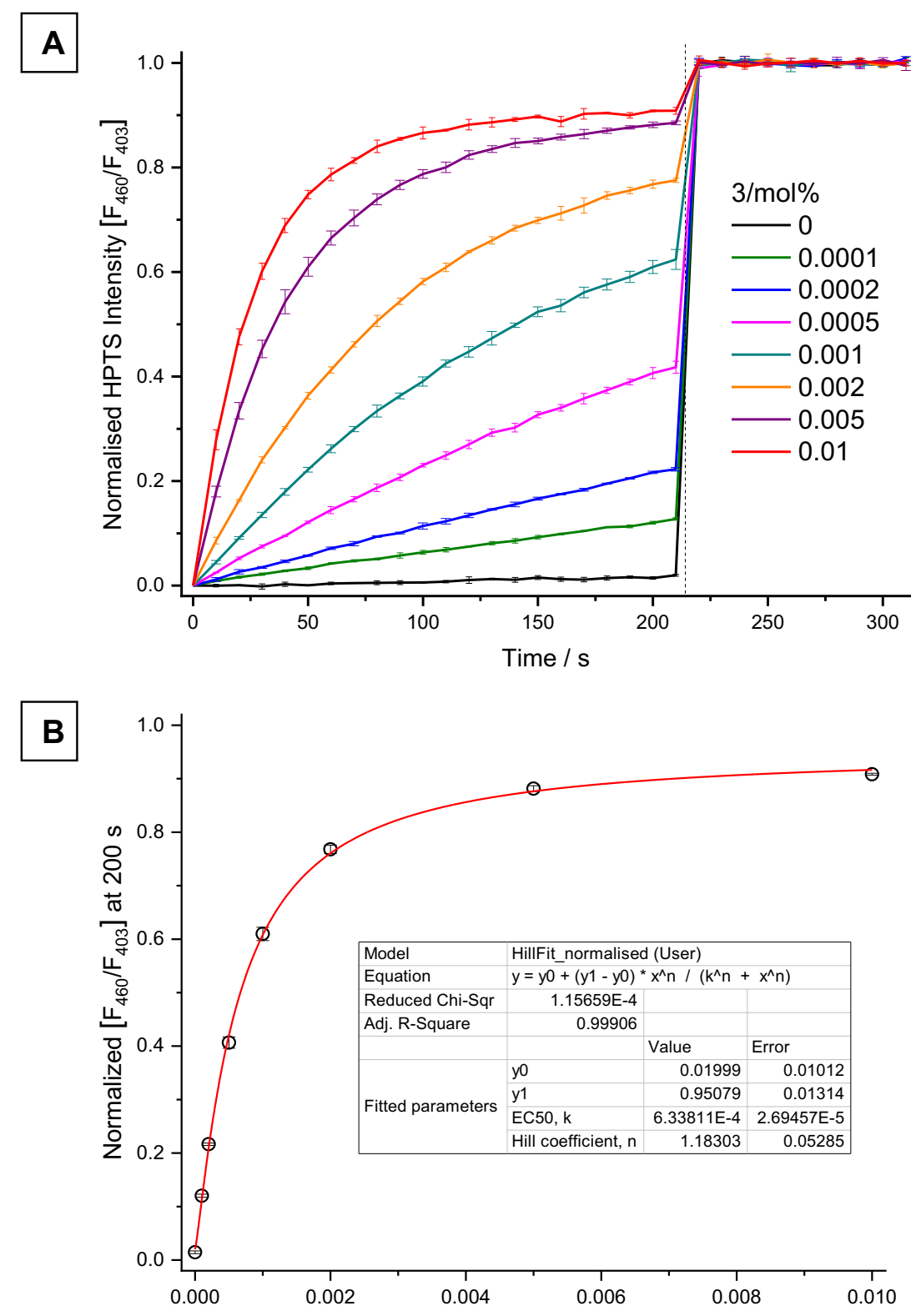

[3] / $\mathrm{mol} \%$

Figure S26: A-Dose response curve, B-Hill plot analysis of $\mathrm{H}^{+} / \mathrm{Cl}^{-}$symport or $\mathrm{Cl}^{-} / \mathrm{OH}^{-}$antiport facilitated by compound 3 using $\mathrm{KCl}-\mathrm{KOH}$ assay from POPC vesicles loaded with $\mathrm{KCl}(100 \mathrm{mM})$, buffered to $\mathrm{pH} 7.0$ with HEPES $(10 \mathrm{mM})$. The test compound was added at $0 \mathrm{~s}$ and detergent was added at $200 \mathrm{~s}$. lonophore concentrations are shown as ionophore to lipid molar ratios. Error bars represent SD from at least three repeats. 

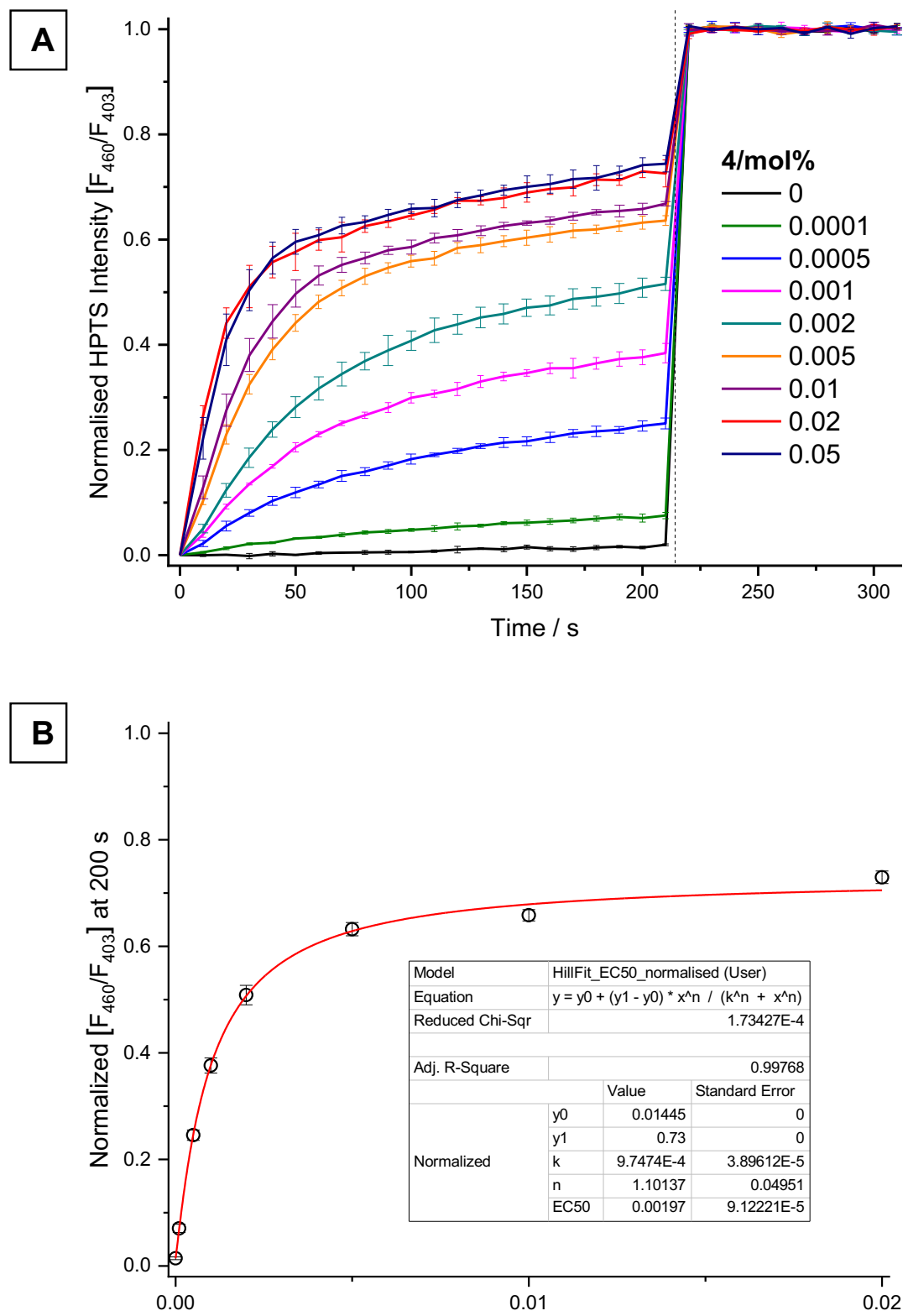

[4] / mol\%

Figure S27: A-Dose response curve, B-Hill plot analysis of $\mathrm{H}^{+} / \mathrm{Cl}^{-}$symport or $\mathrm{Cl}^{-} / \mathrm{OH}^{-}$antiport facilitated by compound 4 using $\mathrm{KCl}-\mathrm{KOH}$ assay from POPC vesicles loaded with $\mathrm{KCl}(100 \mathrm{mM})$, buffered to $\mathrm{pH} 7.0$ with HEPES $(10 \mathrm{mM})$. The test compound was added at $0 \mathrm{~s}$ and detergent was added at $200 \mathrm{~s}$. lonophore concentrations are shown as ionophore to lipid molar ratios. Error bars represent SD from at least three repeats. 


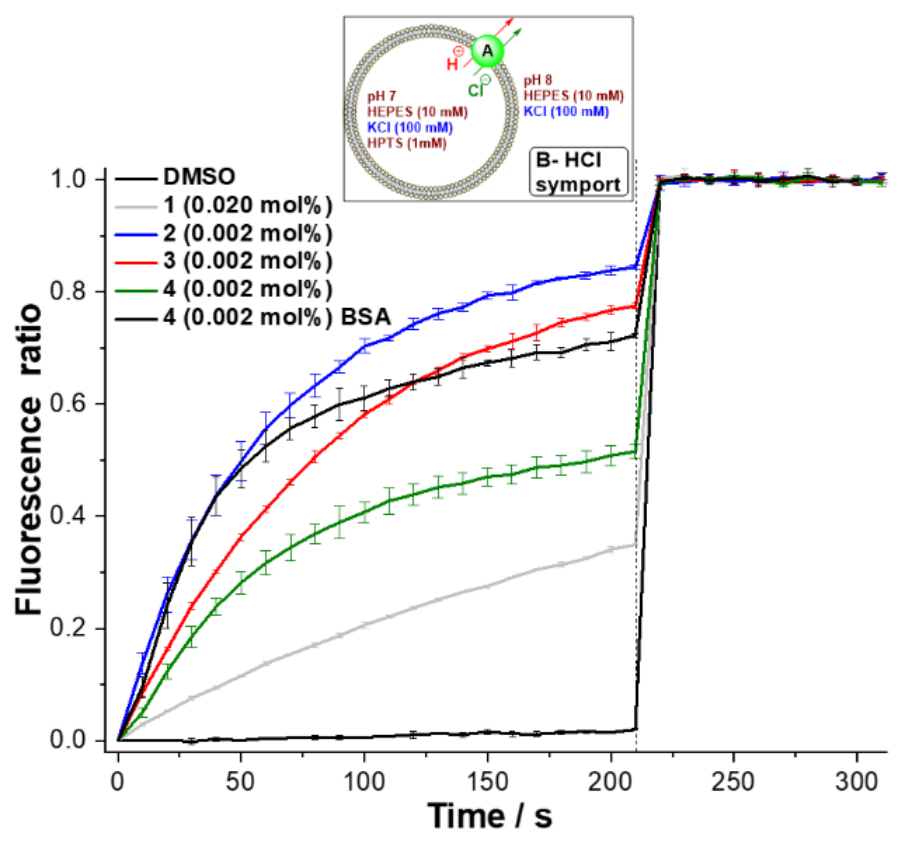

Figure S28; $\mathrm{H}^{+} / \mathrm{Cl}^{-}$symport or $\mathrm{OH}^{-} / \mathrm{Cl}^{-}$antiport facilitated by compounds 1-4 $(0.02 \mathrm{~mol} \%$ (rtl) for transporter 1 and $0.002 \mathrm{~mol} \%$ (rtl) for transporters 2-4) from unilamellar POPC vesicles loaded with $100 \mathrm{mM} \mathrm{KCl}$ buffered to $\mathrm{pH} 7.0$ with $10 \mathrm{mM}$ HEPES buffer and $1 \mathrm{mM} \mathrm{HPTS}$ internal sensor. and suspended in an external solution of $100 \mathrm{mM} \mathrm{KCl}$ buffered to $\mathrm{pH} 7.0$ with $10 \mathrm{mM}$ HEPES buffer. At $200 \mathrm{~s}$, the detergent was added to lyse the vesicles and collapse the $\mathrm{pH}$ gradient for calibration of HPTS fluorescence. Transporter 4 was tested in the presence of BSA-treated lipids. DMSO was used as a control experiment. 


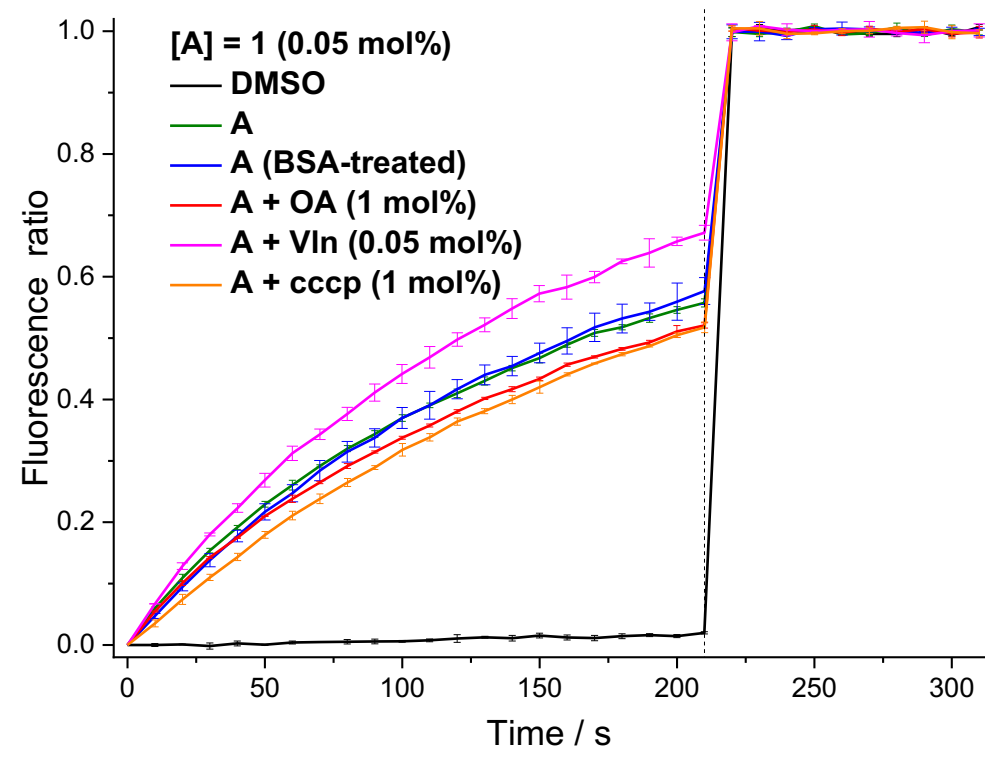

Figure S29: Using $\mathrm{KCl}-\mathrm{KOH}$ assay from POPC vesicles loaded with $\mathrm{KCl}(100 \mathrm{mM})$, buffered to $\mathrm{pH} 7.0$ with HEPES (10 mM), different conditions were applied including using BSA-treated lipid (to test if the transport is fatty acid dependent) addition of oleic acid at $1 \mathrm{~mol} \%$ (as a source of fatty acid), addition of the protonphore cccp at $1 \mathrm{~mol} \%$ (to measure of chloride uniport solely), or addition of valinomycin at $0.05 \mathrm{~mol} \%$ (as a measure of $\mathrm{H}^{+}$flux), on the rate of chloride transport of receptor $1(0.05 \mathrm{~mol} \%)$.

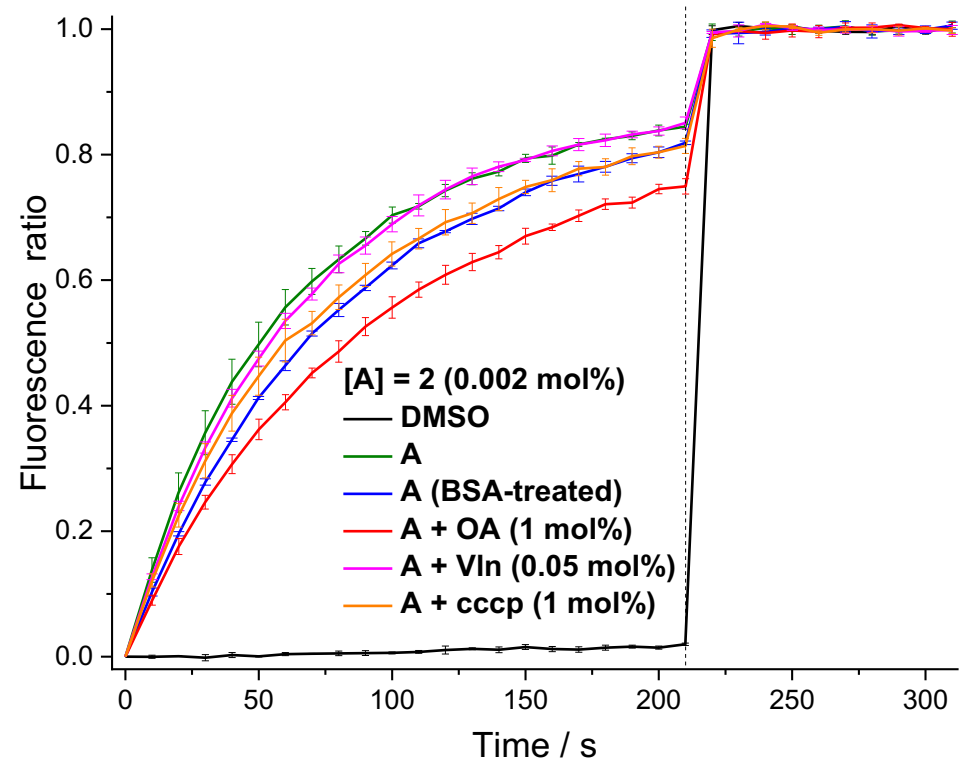

Figure S30: Using $\mathrm{KCl}-\mathrm{KOH}$ assay from POPC vesicles loaded with $\mathrm{KCl}(100 \mathrm{mM})$, buffered to $\mathrm{pH} 7.0$ with HEPES (10 mM), different conditions were applied including using BSA-treated lipid (to test if the transport is fatty acid dependent) addition of oleic acid at $1 \mathrm{~mol} \%$ (as a source of fatty acid), addition of the protonphore cccp at $1 \mathrm{~mol} \%$ (to measure of chloride uniport solely), or addition of valinomycin at $0.05 \mathrm{~mol} \%$ (as a measure of $\mathrm{H}^{+}$flux), on the rate of chloride transport of receptor $2(0.002 \mathrm{~mol} \%)$. 


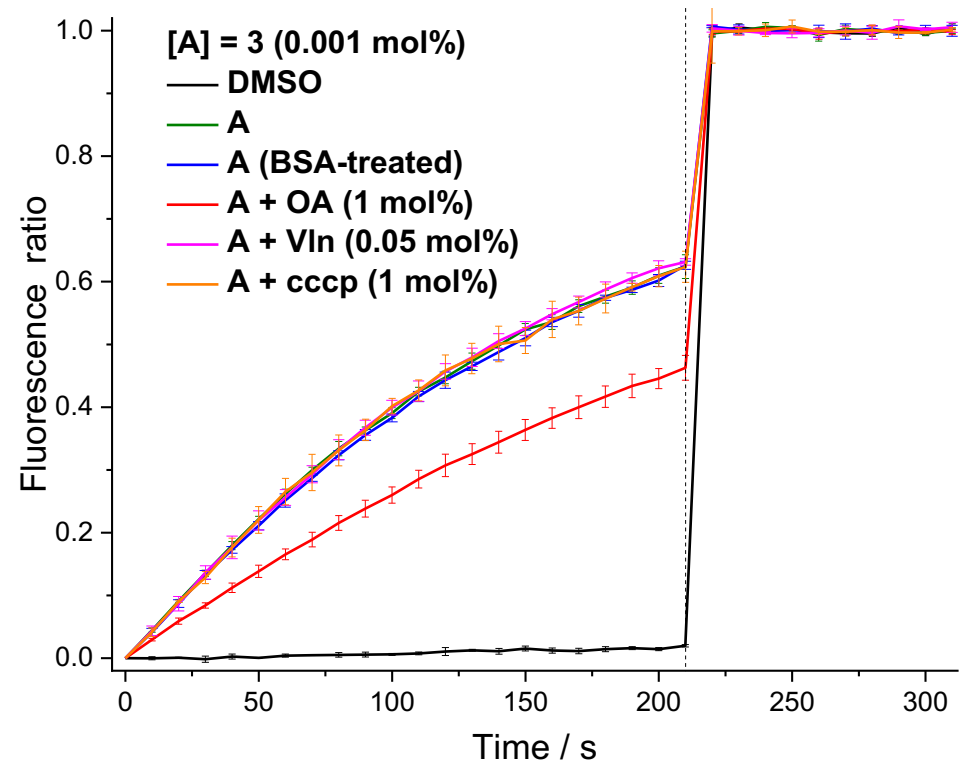

Figure S31: Using $\mathrm{KCl}-\mathrm{KOH}$ assay from $\mathrm{POPC}$ vesicles loaded with $\mathrm{KCl}(100 \mathrm{mM})$, buffered to $\mathrm{pH} 7.0$ with HEPES $(10 \mathrm{mM}$ ), different conditions were applied including using BSA-treated lipid (to test if the transport is fatty acid dependent) addition of oleic acid at $1 \mathrm{~mol} \%$ (as a source of fatty acid), addition of the protonphore cccp at $1 \mathrm{~mol} \%$ (to measure of chloride uniport solely), or addition of valinomycin at $0.05 \mathrm{~mol} \%$ (as a measure of $\mathrm{H}^{+}$flux), on the rate of chloride transport of receptor $3(0.001 \mathrm{~mol} \%)$.

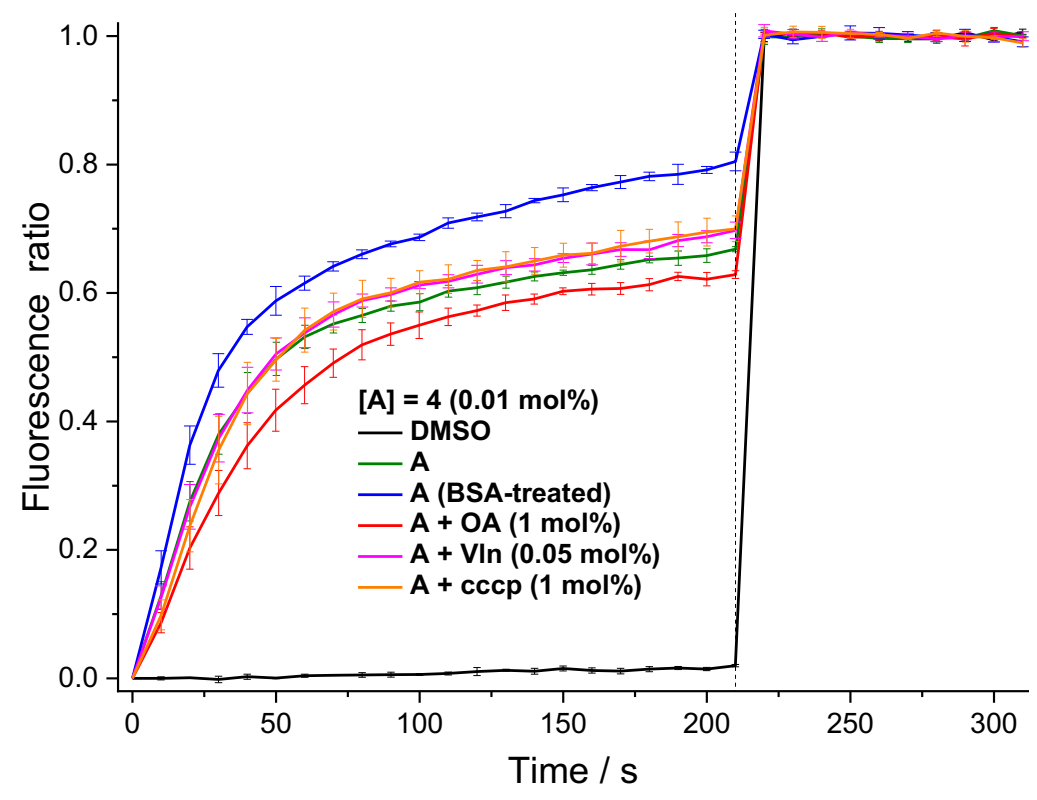

Figure S32: Using $\mathrm{KCl}-\mathrm{KOH}$ assay from POPC vesicles loaded with $\mathrm{KCl}(100 \mathrm{mM})$, buffered to $\mathrm{pH} 7.0$ with HEPES (10 mM), different conditions were applied including using BSA-treated lipid (to test if the transport is fatty acid dependent) addition of oleic acid at $1 \mathrm{~mol} \%$ (as a source of fatty acid), addition of the protonphore cccp at $1 \mathrm{~mol} \%$ (to measure of chloride uniport solely), or addition of valinomycin at $0.05 \mathrm{~mol} \%$ (as a measure of $\mathrm{H}^{+}$flux), on the rate of chloride transport of receptor $4(0.01 \mathrm{~mol} \%)$. 


\section{S7. Biological results:}

\section{General cell culture information:}

Human cell lines A549 (lung carcinoma), human colon adenocarcinoma cells (SW620) and MCF-7 (breast adenocarcinoma) were obtained from the American Type Culture Collection (ATCC, Manassas VA) and maintained in DMEM media (Biological Industries, Beit Haemek, Israel) supplemented with $100 \mathrm{U} / \mathrm{mL}$ penicillin, $100 \mu \mathrm{g} / \mathrm{mL}$ streptomycin, and $2 \mathrm{mM}$ L-glutamine, all from Biological Industries and 10\% fetal bovine serum (FBS; Invitrogen- Life Technologies, Carlsbad, CA). Cells were grown at $37^{\circ} \mathrm{C}$ under a $5 \% \mathrm{CO} 2$ atmosphere.

\subsection{Cell viability assay (MTT)}

Cell viability was determined by the MTT assay. Cells $(1 \times 105$ cells $/ \mathrm{mL})$ were seeded in 96-well microtiter plates and incubated for $24 \mathrm{~h}$ to allow cells to attach. Afterwards, they were treated for $24 \mathrm{~h}$ with different compound concentrations to obtain the dose-response curves (range 0.78 to $100 \mu \mathrm{M}$ ) and inhibitory concentration of $50 \%$ of cell population (IC50 values) were calculated. Compound diluent (maximum 1\% DMSO) was added to control cells. Then, $10 \mu \mathrm{M}$ of 3-(4,5-dimethylthiazol-2-yl)-2,5-diphenyltetrazolium bromide diluted in PBS (MTT, Sigma-Aldrich, St Louis, MO) was added to each well for an additional $2 \mathrm{~h}$. The medium was removed and the MTT formazan precipitate was dissolved in $100 \mu$ of DMSO. Absorbance was read on a Multiskan multiwell plate reader (Thermo Scientific Inc., Waltham, MA) at $570 \mathrm{~nm}$. For each condition, at least three independent experiments were performed in triplicates. Cell viability was expressed as a percentage of control cells, and data are shown as the mean value \pm S.D. Dose-response curves and $\mathrm{IC}_{50}$ values were calculated with GraphPad Prism 8 software. 
Table 1: $I C_{25}, I C_{50}$ and $I C_{75}$ values of compounds 1-4 on human lung carcinoma (A549), human colon adenocarcinoma (SW620) and human breast adenocarcinoma (MCF-7) cell lines: $(\mathrm{ND}=$ non determined $)$

\begin{tabular}{|c|c|c|c|c|}
\hline & & A549 & SW620 & MCF7 \\
\hline \multirow{4}{*}{1} & $\mathrm{IC}_{75}$ & $\mathrm{ND}$ & $\mathrm{ND}$ & $\mathrm{ND}$ \\
\cline { 2 - 5 } & $\mathrm{IC}_{50}$ & $\mathrm{ND}$ & $\mathrm{ND}$ & $\mathrm{ND}$ \\
\cline { 2 - 5 } & $\mathrm{IC}_{25}$ & $\mathrm{ND}$ & $\mathrm{ND}$ & $\mathrm{ND}$ \\
\hline \multirow{4}{*}{2} & $\mathrm{IC}_{75}$ & $\mathrm{ND}$ & $\mathrm{ND}$ & $\mathrm{ND}$ \\
\cline { 2 - 6 } & $\mathrm{IC}_{50}$ & $\mathrm{ND}$ & $\mathrm{ND}$ & $\mathrm{ND}$ \\
\cline { 2 - 6 } & $\mathrm{IC}_{25}$ & $\mathrm{ND}$ & $\mathrm{ND}$ & $\mathrm{ND}$ \\
\hline \multirow{3}{*}{3} & $\mathrm{IC}_{75}$ & $\mathrm{ND}$ & $\mathrm{ND}$ & $\mathrm{ND}$ \\
\cline { 2 - 6 } & $\mathrm{IC}_{50}$ & $\mathrm{ND}$ & $\mathrm{ND}$ & $\mathrm{ND}$ \\
\cline { 2 - 6 } & $\mathrm{IC}_{25}$ & $\mathrm{ND}$ & $\mathrm{ND}$ & $\mathrm{ND}$ \\
\hline \multirow{3}{*}{4} & $\mathrm{IC}_{75}$ & $6.06 \pm 1.44$ & $0.83 \pm 0.09$ & $35.71 \pm 11.93$ \\
\cline { 2 - 6 } & $\mathrm{IC}_{50}$ & $1.86 \pm 0.39$ & $0.51 \pm 0.07$ & $17.92 \pm 4.25$ \\
\cline { 2 - 6 } & $\mathrm{IC}_{25}$ & $0.61 \pm 0.23$ & $0.32 \pm 0.08$ & $9.29 \pm 2.41$ \\
\hline
\end{tabular}

\section{S8. References:}

1. $\quad$ R. L. Atkins and D. E. Bliss, J. Org. Chem., 1978, 43, 1975-1980.

2. T. S. Reddy and A. R. Reddy, Dyes Pigm., 2013, 96, 525-534.

3. L. J. Bourhis, O. V. Dolomanov, R. J. Gildea, J. A. Howard and H. Puschmann, Acta Crystallogr. Sect. A: Found. Adv., 2015, 71, 59-75.

4. O. V. Dolomanov, L. J. Bourhis, R. J. Gildea, J. A. Howard and H. Puschmann, J. Appl. Crystallogr., 2009, 42, 339-341.

5. G. M. Sheldrick, Acta Crystallogr. Sect. A: Found. Crystallogr., 2008, 64, 112-122.

6. X. Wu, P. Wang, P. Turner, W. Lewis, O. Catal, D. S. Thomas and P. A. Gale, Chem, $2019, \mathbf{5}, 1210-1222$. 
7. S. N. Berry, V. Soto-Cerrato, E. N. Howe, H. J. Clarke, I. Mistry, A. Tavassoli, Y.-T. Chang, R. Pérez-Tomás and P. A. Gale, Chem. Sci., 2016, 7, 5069-5077.

8. X. Wu, L. W. Judd, E. N. Howe, A. M. Withecombe, V. Soto-Cerrato, H. Li, N. Busschaert, H. Valkenier, R. Pérez-Tomás and D. N. Sheppard, Chem, 2016, 1, 127-146.

9. L. A. Jowett, E. N. Howe, X. Wu, N. Busschaert and P. A. Gale, Chem. Eur. J., 2018, 24, 10475-10487. 